\title{
Analysis of the Chemical Composition of the Essential Oils Extracted from Lippia lacunosa Mart. \& Schauer and Lippia rotundifolia Cham. (Verbenaceae) by Gas Chromatography and Gas Chromatography-Mass Spectrometry
}

\section{Suzana G. Leitão, ${ }^{*, a}$ Danilo R. de Oliveira, ${ }^{b}$ Valeria Sülsen, ${ }^{c}$ Virginia Martino, ${ }^{c}$ Ymira Galico Barbosa, ${ }^{a}$ Humberto R. Bizzo, ${ }^{d}$ Daíse Lopes, ${ }^{d}$ Lyderson F. Viccini, ${ }^{e}$ Fatima R. G. Salimena, ${ }^{e}$ Paulo H. P. Peixoto ${ }^{e}$ and Gilda G. Leitão ${ }^{b}$}

\author{
${ }^{a}$ Faculdade de Farmácia, Universidade Federal do Rio de Janeiro, Bloco A, Ilha do Fundão, \\ 21941-590 Rio de Janeiro-RJ, Brazil
}

${ }^{b}$ Núcleo de Pesquisas de Produtos Naturais, Universidade Federal do Rio de Janeiro, Bloco H, Rio de Janeiro-RJ, Brazil

${ }^{c}$ Facultad de Farmacia y Bioquímica, Universidad de Buenos Aires, Junín 956 (1113) Buenos Aires, Argentina

${ }^{d}$ Embrapa Agroindústria de Alimentos, Avenida das Américas 29501, 23020-470 Rio de Janeiro-RJ, Brazil

${ }^{e}$ Instituto de Ciências Biológicas, Universidade Federal de Juiz de Fora, Juiz de Fora-MG, Brazil

\begin{abstract}
Lippia lacunosa e L. rotundifolia são duas espécies brasileiras que formam um complexo de difícil delimitação taxonômica. A composição química do óleo essencial das folhas e flores dessas plantas foi investigada por cromatografia com fase gasosa (CG) e por cromatografia com fase gasosa acoplada à espectrometria de massas (CG-EM). Principais constituintes dos óleos essenciais de $L$. lacunosa (flores e folhas): mirceno (14,7\% e $11,9 \%)$, mircenona $(45,2 \%$ e $64,2 \%)$, Z-ocimenona (5,7\% e 5,2\%), e $E$-ocimenona ( $14,7 \%$ e $4,1 \%)$, respectivamente; $L$. rotundifolia (flores e folhas): $\alpha$-pineno $(8,7 \%$ e $1,8 \%)$, mirceno $(5,1 \%$ e $3,6 \%)$, limoneno $(26,0 \%$ e $7,9 \%)$, cis-pinocanfona (4,5\% e 3,1\%) e mirtenal (22,3\% e 16,7\%), respectivamente. Os óleos essenciais de L. lacunosa apresentaram um forte e agradável aroma de manga, que foi relacionado à presença de mirceno e mircenona. Diferenças fundamentais na composição química de seus óleos essenciais podem representar uma poderosa ferramenta na classificação botânica das espécies.
\end{abstract}

Lippia lacunosa and L. rotundifolia (Verbenaceae) are two Brazilian species of complex taxonomic delimitation. The composition of the essential oils from leaves and flowers of these plants was investigated by gas chromatography (GC) and gas chromatography coupled with mass spectrometry (GC-MS) analysis. The major components of the essential oils of flowers and leaves of L. lacunosa were: myrcene ( $14.7 \%$ and $11.9 \%)$, myrcenone ( $45.2 \%$ and $64.2 \%), Z$-ocimenone (5.7\% and 5.2\%), and E-ocimenone (14.7\% and 4.1\%), respectively; whereas in L. rotundifolia (flowers and leaves) were $\alpha$-pinene ( $8.7 \%$ and $1.8 \%$ ), myrcene $(5.1 \%$ and $3.6 \%)$, limonene $(26.0 \%$ and $7.9 \%)$, cis-pinocamphone ( $4.5 \%$ and $3.1 \%$ ) and myrtenal $(22.3 \%$ and $16.7 \%)$, respectively. The essential oils from L. lacunosa exhibited a strong and pleasant mango aroma, which was related to the presence of myrcene and myrcenone. The marked differences in the chemical composition of their essential oils may represent a powerful tool for the botanical classification.

Keywords: Lippia lacunosa, Lippia rotundifolia, myrcene, myrcenone, (E)-ocimenone, limonene, myrtenal, GC, GC-MS

\section{Introduction}

The genus Lippia (Verbenaceae) comprises about 200 species occurring mainly in Central and South America, as also

*e-mail: sgleitao@pharma.ufrj.br in some areas of Tropical Africa. ${ }^{1}$ One of the main diversity centers of the genus Lippia is located at the "Cadeia do Espinhaço" Mountains, in the State of Minas Gerais, Brazil. ${ }^{2}$ There are some taxonomical controversies on the number of Lippia species. Moldenke ${ }^{3}$ compared the descriptions given by various authors to this genus, and presumably all the authors 
included Acantholippia, Aloysia and Phyla in their concept of Lippia. ${ }^{3,4}$ Some species, like L. alba and L. graveolens are largely used in folk medicine and culinary. ${ }^{1}$ As part of our continuing study on Lippia species occurring in Brazil, L. lacunosa Mart. \& Schauer and L. rotundifolia Cham. were selected for investigation. Included in the Section Corymbosae, they form a complex of very difficult taxonomic delimitation, and were considered as synonyms in many herbarium samples. ${ }^{5}$ They both possess a developed underground system, coriaceous leaves, and corymb inflorescences with pink flowers. They are strongly aromatic due to a dense layer of glandular hairs. Distinction between them is very difficult and is only accomplished by analyses of the leaf (foliar limbus) base morphology and of the floral bracts. ${ }^{5}$ However, pollen analysis showed relevant differences ${ }^{6}$ and further taxonomic studies led to the classification of these plants as two different species. In this way, chemical studies might contribute as an extra tool to reinforce this delimitation.

The aim of this work was to investigate the chemical composition of the essential oils obtained from flowers and leaves of L. lacunosa and L. rotundifolia. To the best of our knowledge, no previous studies concerning their chemistry have been published.

\section{Experimental}

\section{Plant material}

Fresh leaves and flowers of L. lacunosa and L. rotundifolia, cultivated, from original clones ${ }^{4}$ originary from Diamantina (MG-Brazil), were collected at the campus of the Federal University of Juiz de Fora, Juiz de Fora, Brazil, (2246'48.6”'S, 4322'24.5'W) in August, 2005. The plants were authenticated by Dr. Fatima Regina Gonçalves Salimena, and voucher specimens were deposited at the Herbarium of the Departamento de Botânica, Universidade Federal de Juiz de Fora (CESJ 41.691 and CESJ 31.376, for L. lacunosa, and L. rotundifolia, respectively).

\section{Essential oil extraction}

The essential oils from fresh leaves and flowers of L. lacunosa and L. rotundifolia were obtained separately by hydrodistillation in a Clevenger-type apparatus for $2 \mathrm{~h}$. The oils were dried over anhydrous sodium sulphate and stored in sealed vials at low temperature.

\section{GC and GC-MS analyses}

Gas chromatographic analyses were performed using a HP 5890 series II gas chromatograph (Palo Alto, CA, USA) equipped with a flame ionization detector (FID) detector and a HP-5 (5\% phenyl/95\% dimethylpolysiloxane) fused silica capillary column $(30 \mathrm{~m} \times 0.25 \mathrm{~mm}$; film thickness $0.25 \mu \mathrm{m})$. Hydrogen was the carrier gas $\left(1.0 \mathrm{~mL} \mathrm{~min}^{-1}\right)$. The injector temperature was kept at $250{ }^{\circ} \mathrm{C}$ and the oven temperature program was from $60^{\circ}$ to $240^{\circ} \mathrm{C}$ at a rate of $3{ }^{\circ} \mathrm{C} \mathrm{min}^{-1}$. Detector (FID) was operated at $280{ }^{\circ} \mathrm{C}$. Pure oils $(0.03 \mu \mathrm{L})$ were injected in split mode (100:1).

The GC-MS analyses were performed in an Agilent $5973 \mathrm{~N}$ mass selective detector coupled to an Agilent 6890 gas chromatograph (Palo Alto, CA), equipped with a HP5MS capillary column $(30 \mathrm{~m} \times 0.25 \mathrm{~mm} \times 0.25 \mu \mathrm{m})$, operating in electronic ionization mode at $70 \mathrm{eV}$, with transfer line maintained at $260{ }^{\circ} \mathrm{C}$, while quadrupole and ion source temperature were held at $150{ }^{\circ} \mathrm{C}$ and $230^{\circ} \mathrm{C}$, respectively. Helium (1.0 mL min ${ }^{-1}$ ) was used as carrier gas. Oven temperature program, injector temperature and split rate were the same as stated for $\mathrm{GC}$ analyses.

A standard solution of $n$-alkanes $\left(\mathrm{C}_{7}-\mathrm{C}_{26}\right)$ was used to obtain the retention indices. ${ }^{7}$ Individual volatile components were identified by comparison of their mass spectra (MS) and retention indices (RI) with those reported in literature ${ }^{8}$ and also to the Wiley Registry of Mass Spectral Data, $6^{\text {th }}$ Edition (Wiley Interscience, New York).

\section{Isolation of myrcenone from L. lacunosa essential oil}

Approximately $0.7 \mathrm{~mL}$ of L. lacunosa essential oil was submitted to silica gel column chromatography eluted with a mixture of hexane-ethyl acetate (98:2). Seventy five fractions of $1 \mathrm{~mL}$ were obtained. Fractions 11-21 afforded 2 $\mathrm{mg}$ of pure myrcene as green fluorescent oil. Fractions 59-61 were pooled together to afford $30 \mathrm{mg}$ of pure myrcenone (99\% purity by GC). The identity of the myrcenone was confirmed by ${ }^{1} \mathrm{H}$ and ${ }^{13} \mathrm{C}$ NMR data measurement on a Bruker Avance DRX400 (Karlsruhe, Germany) at $25{ }^{\circ} \mathrm{C}$, operating at $400.13 \mathrm{MHz}$ for ${ }^{1} \mathrm{H}$ and $100.61 \mathrm{MHz}$ for ${ }^{13} \mathrm{C}$ NMR spectra were recorded in $\mathrm{CDCl}_{3}$ using TMS as internal standard. Data were in accordance with those in the literature. ${ }^{9}{ }^{1} \mathrm{H} \mathrm{NMR}\left(\mathrm{CDCl}_{3}\right): 1.96\left(\mathrm{~s}, \mathrm{CH}_{3}\right), 2.22\left(\mathrm{~s}, \mathrm{CH}_{3}\right)$, $3.37\left(\mathrm{~s}, \mathrm{CH}_{2}\right), 5.18$ (d, 11, $\left.1 \mathrm{H}, \mathrm{CH}=\mathrm{CH}_{2}\right), 5.19(\mathrm{sl}, 1 \mathrm{H}$, $\left.\mathrm{C}=\mathrm{CH}_{2}\right), 5.25\left(\mathrm{~d}, 17.5,1 \mathrm{H}, \mathrm{CH}=\mathrm{C}_{2}\right), 5.32\left(\mathrm{sl}, 1 \mathrm{H}, \mathrm{C}=\mathrm{C}_{2}\right)$, $6.24(\mathrm{sl}, \mathrm{C}=\mathrm{C} \underline{\mathrm{H}}), 6.53\left(\mathrm{dd}, 17.5,11, \mathrm{C} \underline{\mathrm{H}}=\mathrm{CH}_{2}\right) ;{ }^{13} \mathrm{C}-\mathrm{NMR}$ $\left(\mathrm{CDCl}_{3}\right): 198.41(\mathrm{C}=\mathrm{O}), 156.84\left(\mathrm{CH}_{2}=\underline{\mathrm{C}}\right), 141.03\left(\mathrm{CH}_{2}=\underline{\mathrm{C}}\right)$, $138.58(\mathrm{C}=\underline{\mathrm{CH}}), 122.81(\mathrm{C}=\underline{\mathrm{CH}}), 120.24\left(\underline{\mathrm{CH}}_{2}=\mathrm{C}\right), 115.31$ $\left(\underline{\mathrm{CH}}_{2}=\mathrm{C}\right), 48.38(\mathrm{CH} 2), 28.10\left(\mathrm{CH}_{3}\right), 21.16\left(\mathrm{CH}_{3}\right)$.

\section{Direct olfactive analysis of L. lacunosa essential oil (leaves)}

Direct olfactive analysis was carried out on May 2007 with a new sample of the essential oil obtained from leaves 
of Lippia lacunosa collected on May $14^{\text {th }}, 2007$, from the same specimen at the Campus of the Federal University of Juiz de Fora. Flowers were not available by this time of the year. GC-MS analysis of this oil, in the same conditions described above, revealed the same chemical composition reported here for that one collected in August 2005. Direct olfactive analyses were performed by a panel composed of three trained analysts from the perfumery company "MANE do Brasil", located at Estrada do Guerenguê, 1.421, CEP 22.713-000, Jacarepaguá, Rio de Janeiro, RJ, Brazil.

\section{Results and Discussion}

The flowers (fluorescent greenish-yellow oil) and leaves (fluorescent light green oil) of L. lacunosa yielded $0.38 \%$ and $0.44 \%$ of oil, respectively, while the distillation of L. rotundifolia yielded $0.33 \%$ and $0.01 \%$ of oil, respectively for flowers (light yellow oil) and leaves (light yellow oil). The main compounds (with relative \% peak area above 0.1 ) identified in the essential oils of L. lacunosa and $L$. rotundifolia are listed in Table 1 . The essential oils from leaves and flowers of L. lacunosa and from the flowers of $L$. rotundifolia showed a high content of monoterpenes (over $80 \%$ ) and very low contents of sesquiterpenes.

In the oils of L. lacunosa flowers and leaves, 67 and 57 compounds were detected, respectively. Twenty six compounds were identified in the essential oils from both flowers and leaves of L. lacunosa, of which the major components were myrcene (flowers: 14.7, leaves: 11.9\%), myrcenone (flowers: $45.2 \%$, leaves: $64.2 \%$ ), (Z)-ocimenone (flowers: $5.7 \%$, leaves: $5.2 \%$ ), and $(E)$-ocimenone (flowers: $14.7 \%$, leaves: $4.1 \%$ ), respectively. In the oils of L. rotundifolia 54 (flowers) and 108 (leaves) compounds were detected, while 58 different compounds were identified in both oils. Among them, the most abundant were limonene (flowers: 26.0, leaves: $7.9 \%$ ) and myrtenal (flowers: $22.3 \%$, leaves: $16.7 \%$ ), respectively.

The oils from $L$. rotundifolia contain a variety of monoand sesquiterpenes in amounts below $1 \%$. In the oil from the leaves 51 identified compounds accounted for $88 \%$ of the oil, whereas in that obtained from the flowers 41 identified compounds accounted for $97.8 \%$ of the oil. A difference between the essential oils from the two plants concerns their yields: L. rotundiflolia leaves essential oil yield $(0.01 \%)$ is much lower than that of the flowers $(0.33 \%)$.

The major component of $L$. lacunosa essential oils, myrcenone, has been described as an important constituent of other Lippia species: L. adoensis ${ }^{10}(0.8$ to $14.9 \%$ in wild plants; 0.06 to $0.8 \%$ from cultivated plants), L. alba ${ }^{11}$ (38 to $50 \%)$, L. multiflora ${ }^{12}(54.6 \%)$, L. juneliana ${ }^{13}(17.2 \%$, in plants growing wild), L. javanica ${ }^{14}$ (myrcenone, and
(E)- and (Z)-ocimenone were the major constituents) and L. asperifolia ${ }^{15}$ (ocimene $(80 \%)$, and a mixture of ketones: myrcenone, ocimenone, etc, referred by the author as "tagetenones"); and Aloysia"16 (A. triphylla, 36.5\%, cultivated) essential oils, as well as in Hyptis mutabilis ${ }^{17}$ $(14.8 \%$,) oil, a genus belonging to the Lamiaceae, which is a family taxonomically very close to the Verbenaceae. In this way, the oil from the leaves of L. lacunosa was submitted to column chromatography, to afford pure myrcenone ( $99 \%$ purity by GC), as a yellow fluorescent oil. Its identity was confirmed by comparison of its NMR data with those in literature. ${ }^{9}$ By this procedure, myrcene was also separated in its pure form as a green fluorescent oil.

The essential oils of L. lacunosa flowers and leaves exhibited a strong and pleasant mango aroma, the former one being sweeter than the latter, which resembled more the aroma of unripe mangos. That difference may, in part, be due to the myrcene/myrcenone ratio, since both single substances, separated by column chromatography, exhibited mango aroma. In view of these findings we decided to have the essential oil from the leaves evaluated by a panel, involving three analysts from the perfumery company "MANE do Brasil". As a result, the identified notes described in the panel were: tea/fruity (mango) as head notes; fruity/green as heart notes; and vegetal-like as base note. This result corroborates our initial findings, and it is interesting to note that the heart and base notes (green and "vegetal-like") described in the panel are in agreement with our perception of unripe mango aroma (green). A survey on the literature about volatile substances related to the aroma of mango fruits revealed that, in some mango varieties, myrcene plays an important role. Andrade et al. ${ }^{18}$ studied the volatiles of 15 Brazilian mango fruit varieties, extracted by simultaneous distillation-extraction followed by GC-MS analysis. They could distinguish between three aroma groups, one of which was rich in myrcene (30.3-57.1\%). Also, in another work by MacLeod and Pieris, ${ }^{19}$ myrcene and $(Z)-\beta$ ocimene were demonstrated to be characteristic of the aroma of two varieties from India and Sri Lanka. Lopes et al., ${ }^{20}$ analysing the aroma of commercial Brazilian mangos by High Resolution Gas Chromatography-Olfatometry-Aroma Extract Dilution Analysis-Mass Spectrometry (HRGC-OAEDA-MS) reported that myrcene is the main constituent of the varieties Carlota and Coração de Boi, and that it contributes to the "unripe" (green) flavour of the fruit.

The presence of dihydrotagetone, tagetone, as well as $(Z)$-and $(E)$-ocimenone in the essential oils of flowers and leaves of L. lacunosa are also noteworthy, as they are the main constituents of Tagetes oil, ${ }^{21}$ a yellow to dark orange liquid with a strong aromatic fruity odor, obtained by stem distillation of Tagetes minuta L. 
Table 1. Chemical composition (relative \% peak area) of the essential oils from Lippia lacunosa and L. rotundifolia (flowers and leaves) obtained by GC and GC-MS on a HP-5 column

\begin{tabular}{|c|c|c|c|c|c|c|c|}
\hline \multirow{2}{*}{ Constituents } & \multirow{2}{*}{$\mathrm{RI}^{\mathrm{a}}$} & \multicolumn{3}{|c|}{ Lippia lacunosa } & \multicolumn{2}{|c|}{ Lippia rotundifolia } & \multirow{2}{*}{ Identification Method } \\
\hline & & Flowers & Leaves $^{\mathrm{d}}$ & Leaves $^{\mathrm{e}}$ & Flowers & Leaves & \\
\hline tricyclene & 926 & --- & --- & --- & 0.1 & --- & 1,2 \\
\hline A-thujene & 930 & --- & --- & --- & 1.4 & 0.6 & 1,2 \\
\hline$\alpha$-pinene & 938 & --- & --- & --- & 8.7 & 1.8 & 1,2 \\
\hline camphene & 953 & --- & --- & --- & 0.8 & 0.3 & 1,2 \\
\hline thuja-2,4(10)-diene & 958 & --- & --- & --- & 0.1 & --- & 1,2 \\
\hline sabinene & 977 & --- & 0.1 & --- & 2.2 & 0.9 & 1,2 \\
\hline$\beta$-pinene & 980 & --- & --- & --- & 9.5 & 3.0 & 1,2 \\
\hline 1-octen-3-ol & 981 & 0.3 & --- & --- & -- & -- & 1,2 \\
\hline myrcene & 992 & 14.7 & 11.9 & 15.2 & 5.1 & 3.6 & 1,2 \\
\hline N.I. ${ }^{c}$ & 999 & --- & --- & 0.7 & --- & --- & \\
\hline$\alpha$-phellandrene & 1007 & --- & --- & --- & 0.1 & 0.1 & 1,2 \\
\hline$\alpha$-terpinene & 1019 & --- & --- & --- & 0.3 & 0.2 & 1,2 \\
\hline para-cymene & 1028 & -- & --- & --- & 0.7 & 1.3 & 1,2 \\
\hline limonene & 1032 & 1.8 & 0.8 & 1.3 & 26.0 & 7.9 & 1,2 \\
\hline 1,8-cineole & 1035 & --- & --- & --- & 1.4 & 0.4 & 1,2 \\
\hline (Z)- $\beta$-ocimene & 1040 & -- & --- & --- & 0.8 & 0.3 & 1,2 \\
\hline (E)- $\beta$-ocimene & 1051 & --- & --- & --- & 0.2 & 2.1 & 1,2 \\
\hline dihydrotagetone & 1056 & 0.4 & 0.4 & 1.3 & --- & --- & 1,2 \\
\hline$\gamma$-terpinene & 1062 & --- & --- & --- & 2.9 & 2.9 & 1,2 \\
\hline cis-sabinene hydrate & 1071 & --- & --- & --- & 0.1 & --- & 1,2 \\
\hline N.I. ${ }^{c}$ & 1088 & --- & 0.1 & --- & --- & --- & \\
\hline para-mentha- $2,4(8)$ diene & 1088 & --- & --- & --- & 0.2 & 0.2 & 1,2 \\
\hline N.I. ${ }^{c}$ & 1101 & 1.0 & 1.0 & --- & 0.4 & 0.8 & 1,2 \\
\hline N.I. ${ }^{c}$ & 1114 & --- & --- & 0.1 & --- & --- & \\
\hline trans-thujone & 1120 & --- & --- & --- & 0.1 & 0.3 & 1,2 \\
\hline N.I. ${ }^{c}$ & 1125 & --- & --- & --- & 0.1 & --- & 1,2 \\
\hline$\alpha$-campholenal & 1129 & --- & --- & -- & 0.1 & 0.1 & 1,2 \\
\hline N.I. ${ }^{c}$ & 1133 & --- & --- & 0.1 & --- & -- & \\
\hline trans-pinocarveol & 1142 & --- & --- & --- & 1.5 & 0.5 & 1,2 \\
\hline ipsdienol & 1147 & --- & --- & 1.0 & --- & --- & 1,2 \\
\hline myrcenone & 1153 & 45.2 & 64.2 & 35.0 & --- & --- & $1,2,3$ \\
\hline (Z)-tagetone & 1157 & 0.5 & 0.5 & --- & --- & --- & 1,2 \\
\hline N.I. ${ }^{c}$ & 1158 & --- & --- & 0.7 & -- & --- & \\
\hline N.I. ${ }^{c}$ & 1167 & 0.7 & 0.2 & --- & --- & --- & 1,2 \\
\hline trans-pinocamphone & 1164 & --- & --- & --- & 0.1 & --- & 1,2 \\
\hline pinocarvone & 1166 & --- & --- & --- & 3.0 & 0.1 & 1,2 \\
\hline borneol & 1169 & --- & --- & --- & 0.3 & 2.4 & 1,2 \\
\hline cis-pinocamphone & 1177 & --- & --- & --- & 4.5 & 3.1 & 1,2 \\
\hline terpinen-4-ol & 1180 & --- & --- & -- & 1.1 & 0.7 & 1,2 \\
\hline N.I. ${ }^{c}$ & 1189 & 0.1 & 0.1 & 0.6 & --- & -- & \\
\hline$\alpha$-terpineol & 1192 & 0.5 & 0.4 & 0.6 & 0.3 & 0.2 & 1,2 \\
\hline myrtenal & 1197 & --- & --- & --- & 22.3 & 16.7 & 1,2 \\
\hline N.I. ${ }^{c}$ & 1197 & 0.1 & 0.1 & 0.7 & --- & --- & \\
\hline N.I. ${ }^{c}$ & 1208 & 0.4 & 0.1 & --- & --- & --- & 1,2 \\
\hline N.I. ${ }^{c}$ & 1209 & --- & --- & 0.4 & --- & --- & \\
\hline (Z)-ocimenone & 1234 & 5.7 & 5.2 & 6.1 & --- & --- & 1,2 \\
\hline (E)-ocimenone & 1243 & 14.7 & 4.1 & 13.4 & --- & --- & 1,2 \\
\hline N.I. ${ }^{c}$ & 1248 & --- & 0.1 & 0.3 & --- & --- & \\
\hline N.I. ${ }^{c}$ & 1256 & --- & --- & --- & 0.2 & --- & 1,2 \\
\hline
\end{tabular}


Table 1. continuation

\begin{tabular}{|c|c|c|c|c|c|c|c|}
\hline \multirow{2}{*}{ Constituents } & \multirow{2}{*}{$\mathrm{RI}^{\mathrm{a}}$} & \multicolumn{3}{|c|}{ Lippia lacunosa } & \multicolumn{2}{|c|}{ Lippia rotundifolia } & \multirow{2}{*}{ Identification Method $^{b}$} \\
\hline & & Flowers & Leaves $^{\mathrm{d}}$ & Leaves $^{\mathrm{e}}$ & Flowers & Leaves & \\
\hline piperitone & 1258 & --- & --- & --- & 0.2 & --- & 1,2 \\
\hline N.I. ${ }^{c}$ & 1269 & --- & --- & 0.9 & --- & --- & \\
\hline thymol & 1293 & 0.5 & 0.2 & 0.1 & --- & --- & 1,2 \\
\hline trans-sabinyl acetate & 1294 & --- & --- & --- & $\mathrm{t}$ & 0.3 & 1,2 \\
\hline myrtenyl acetate & 1328 & --- & --- & --- & 1.2 & 2.1 & 1,2 \\
\hline$\delta$-elemene & 1340 & --- & --- & --- & --- & 0.3 & 1,2 \\
\hline neryl acetate & 1368 & --- & --- & 0.5 & --- & 0.2 & 1,2 \\
\hline$\alpha$-copaene & 1378 & --- & --- & --- & 0.1 & 0.7 & 1,2 \\
\hline geranyl acetate & 1386 & 0.5 & 0.5 & --- & --- & --- & 1,2 \\
\hline$\beta$-bourbonene & 1386 & --- & --- & --- & --- & 0.9 & 1,2 \\
\hline$\beta$-elemene & 1393 & --- & --- & --- & 0.3 & 10.9 & 1,2 \\
\hline (E)-caryophyllene & 1421 & --- & 0.7 & 2.7 & 0.9 & 7.9 & 1,2 \\
\hline$\alpha$-humulene & 1456 & 0.4 & 0.1 & 0.4 & 0.2 & 1.5 & 1,2 \\
\hline allo-aromadendrene & 1463 & --- & --- & --- & --- & 0.2 & 1,2 \\
\hline trans-cadina-1(6),4-diene & 1475 & --- & --- & --- & --- & 0.2 & 1,2 \\
\hline$\gamma$-gurjunene & 1478 & --- & --- & --- & --- & 0.1 & 1,2 \\
\hline germacrene D & 1480 & --- & --- & 0.8 & --- & --- & 1,2 \\
\hline$\gamma$-muurolene & 1482 & 0.3 & 0.1 & --- & 0.3 & 2.2 & 1,2 \\
\hline ar-curcumene & 1484 & --- & --- & --- & 0.2 & 1.0 & 1,2 \\
\hline$\beta$-selinene & 1487 & --- & --- & --- & --- & 0.3 & 1,2 \\
\hline muurola-4(14),5-diene & 1492 & --- & --- & --- & --- & 0.5 & 1,2 \\
\hline$\alpha$-muurolene & 1501 & --- & --- & --- & --- & 0.2 & 1,2 \\
\hline germacrene $\mathrm{A}$ & 1506 & --- & --- & --- & --- & 1.9 & 1,2 \\
\hline$\gamma$-cadinene & 1516 & --- & --- & --- & --- & 0.7 & 1,2 \\
\hline$\delta$-cadinene & 1525 & --- & 0.8 & --- & --- & 0.9 & 1,2 \\
\hline germacrene B & 1559 & --- & --- & --- & --- & 0.3 & 1,2 \\
\hline caryophyllene oxide & 1584 & 0.4 & 1.1 & 0.7 & --- & 2.5 & 1,2 \\
\hline $\begin{array}{l}\text { epi- } \alpha \text {-cadinol and/or } \\
\text { epi- } \alpha \text {-muurolol }\end{array}$ & 1643 & --- & 0.2 & --- & --- & 0.6 & 1,2 \\
\hline$\alpha$-muurulol & 1649 & --- & --- & --- & --- & 0.7 & 1,2 \\
\hline Monoterpenes & & 84.5 & 88.3 & 74.5 & 95.6 & 52.5 & \\
\hline Total Identified Compounds & & 85.9 & 91.3 & 79.7 & 97.3 & 87.0 & \\
\hline
\end{tabular}

${ }^{a} \mathrm{RI}$ - retention index obtained using an HP-5 column, $\mathrm{t}=$ trace (below $0.05 \%$ ). ${ }^{\mathrm{b}}$ Identification Methods: 1-Retention indices; 2 -Wiley library; $3-{ }^{1} \mathrm{H}$ and ${ }^{13} \mathrm{C}$ NMR. ${ }^{\mathrm{c} N}$.I.-not identified. ${ }^{\mathrm{d}}$ Essential oil extracted in August 2005. ${ }^{\mathrm{e}}$ Essential oil extracted in May 2007.

The aroma of the essential oils from $L$. rotundifolia (flowers and leaves) is somewhat different from those of L. lacunosa. The essential oil from the flowers has a strong and pleasant floral scent, less pronounced in the essential oil from the leaves. Myrtenal, the second major constituent of the flowers oil, and the major one on the leaves oil, is also found in eucalyptus, mint, pepper and cumin seeds essential oils. It is used in perfumery, its odour being described as spicy, with the following odour descriptions: sweet cinnamon, tonka, terpene, camphor and jam, ${ }^{22}$ as well as an insecticide ${ }^{23}$ (from Myrtus communis L.). This substance is also used by the European grapevine moth (Lobesia botrana) in its chemical communication system. ${ }^{24}$

\section{Conclusions}

Although L. lacunosa and L. rotundifolia are considered as synonyms in many herbarium samples, there are marked differences in the composition of their essential oils. The olfactive description of the volatile constituents of both the investigated oils could be included in the herbarium tags of the species, as "floral" for L. rotundifolia, and "mango aroma", for L. lacunosa, being of great help for the differentiation of the species and further botanical classification. 


\section{Acknowledgments}

The authors wish to thank CNPq (Edital Universal, 477060/2004-8) and FAPEMIG for financial support. One of us (D.R.O.) wishes to thank CNPq for a fellowship. We are also indebted to Dr. Renato Salvi, from MANE do Brasil for performing olfactive analyses.

\section{Supplementary Information}

Supplementary data are available free of charge at http:// jbcs.sbq.org.br, as PDF file.

\section{References}

1. Pascual, M.; Slowing, K.; Carretero, E.; Sánchez Mata, D.; Villar, A.; J. Ethnopharmacol. 2001, 76, 201.

2. Salimena, F. R. G.; PhD Thesis, Universidade de São Paulo, Brazil, 2000.

3. Moldenke, H. N.; Phytologia 1978, 38, 230.

4. Viccini, L. F.; Souza da Costa, D. C.; Machado, M. A.; Campos, A. L.; Plant Syst. Evol. 2004, 246, 1.

5. Salimena, F. R. G.; Darwiniana 2002, 40,121.

6. Salimena, F. R. G.; unpublished results.

7. van Den Dool, H.; Kratz, P. D.; J. Chromatogr., A 1963, 11, 463.

8. Adams, R. P.; Identification of Essential Oil Components by Gas Chromatography/Mass Spectrometry, Allured Publishing Corp.: Carol Stream, USA, 1995; Adams, R. P; Identification of Essential Oil Components by Gas Chromatography/Quadrupole Mass Spectrometry, Allured Publishing Corp.: Carol Stream, USA, 2001.

9. Baeckström, P.; Stridh, K.; Li, L.; Norin, T.; Acta Chem. Scand. B Org. Chem. Biochem. 1987, B41, 442; Weyerstahl, P.; Zombik, W.; Gansau, C.; Liebigs Ann. Chem. 1986, 3, 422.
10. Abegaz, B.; Asfaw, N.; Lwande, W.; J. Essent. Oil Res. 1993, $5,487$.

11. Fischer, U.; Lopez, R.; Poell, E.; Vetter, S.; Novak, J.; Franz, C. M.; Flavour Fragr. J. 2004, 19, 333.

12. Agnaniet, H.; Makani, T.; Akagah, A.; Menut, C.; Bessiere, J. M. ; Flavour Fragr. J. 2005, 20, 34.

13. Zygadlo, J. A.; Lamarque, A. L.; Guzman, C. A.; Grosso, N. R.; J. Essent. Oil Res. 1995, 7, 593.

14. Mwangi, J. W.; Addae-Mensah, I.; Munavu, R. M.; Lwande, W.; Flavour Fragr. J. 1991, 6, 221.

15. Naves, Y. R.; Helv. Chim. Acta 1948, 31, 29.

16. Zygadlo, J. A.; Lamarque, A. L.; Maestri, D. M.; Guzman, C. A.; Lucini, E. I.; Grosso, N. R.; Ariza-Espinar, L.; J. Essent. Oil Res. 1994, 6, 407.

17. Velasco-Negueruela, A.; Perez-Alonso, M. J.; Esteban, J. L.; Guzman, C. A.; Zygadlo, J. A.; Espinar, L. A.; J. Essent. Oil Res. 1995, 7, 81.

18. Andrade, E. H. A.; Maia, J. G. S.; Zoghbi, M. G. B.; J. Food Comp. Anal. 2000, 13, 27.

19. MacLeod, A. J.; Pieris, N. M.; Phytochemistry 1984, 23, 361.

20. Lopes, D. C.; Fraga, S. R.; Rezende, C. M.; Quim. Nova 1999, 22,31 .

21. Bauer, K.; Garbe, D. Surburg, H.; Common Fragrance and Flavour Materials; Wiley-VCH: Wienheim, 1997, p.213.

22. The Good Scents Company, available in http://www. thegoodscentscompany.com/data/rw1008861.html, accessed in March 2006.

23. Duke, James A.; Handbook of Phytochemical Constituents of GRAS Herbs and other Economic Plants, CRC Press: Boca Raton, Florida, 1992.

24. Witzgall, P.; Tasin, M.; Buser, H. R.; Wegner-Kiss, G.; Mancebon, V. S. M.; Ioriatti, C.; Bäckman, A. C.; Bengtsson, M.; Lehmann, L.; Francke, W.; J. Chem. Ecol. 2005, 31, 2923. 


\section{Analysis of the Chemical Composition of the Essential Oils Extracted from Lippia lacunosa Mart. \& Schauer and Lippia rotundifolia Cham. (Verbenaceae) by Gas Chromatography and Gas Chromatography-Mass Spectrometry}

Suzana G. Leitão, ${ }^{*, a}$ Danilo R. de Oliveira, ${ }^{b}$ Valeria Sülsen,${ }^{c}$ Virginia Martino, ${ }^{c}$ Ymira Galico Barbosa, ${ }^{a}$ Humberto R. Bizzo, ${ }^{d}$ Daíse Lopes, ${ }^{d}$ Lyderson F. Viccini, ${ }^{e}$ Fatima R. G. Salimena, ${ }^{e}$ Paulo H. P. Peixoto ${ }^{e}$ and Gilda G. Leitão ${ }^{b}$

${ }^{a}$ Faculdade de Farmácia, Universidade Federal do Rio de Janeiro, Bloco A, Ilha do Fundão, 21941-590 Rio de Janeiro-RJ, Brazil

${ }^{b}$ Núcleo de Pesquisas de Produtos Naturais, Universidade Federal do Rio de Janeiro, Bloco H, Rio de Janeiro-RJ, Brazil

${ }^{c}$ Facultad de Farmacia y Bioquímica, Universidad de Buenos Aires, Junín 956 (1113) Buenos Aires, Argentina

${ }^{d}$ Embrapa Agroindústria de Alimentos, Avenida das Américas 29501, 23020-470 Rio de Janeiro-RJ, Brazil

eInstituto de Ciências Biológicas, Universidade Federal de Juiz de Fora, Juiz de Fora-MG, Brazil

Abundance

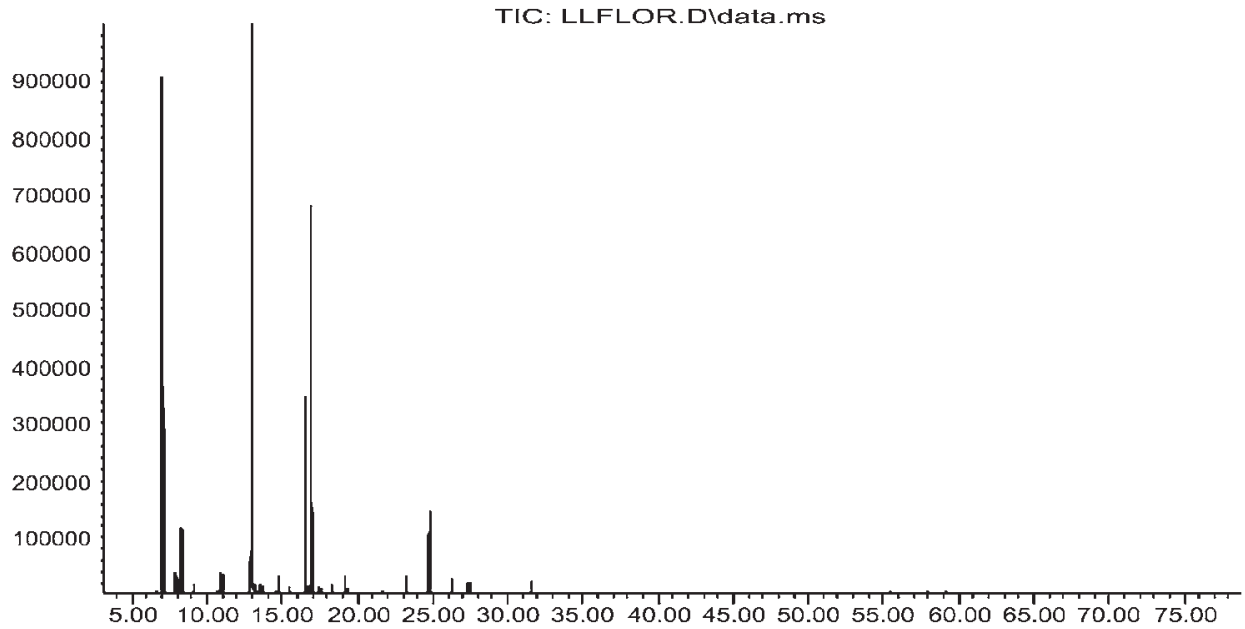

Time-->

Figure S1. Gas Chromatogram (GC-MS) of the essential oil of Lippia lacunosa flowers.

*e-mail: sgleitao@pharma.ufrj.br 


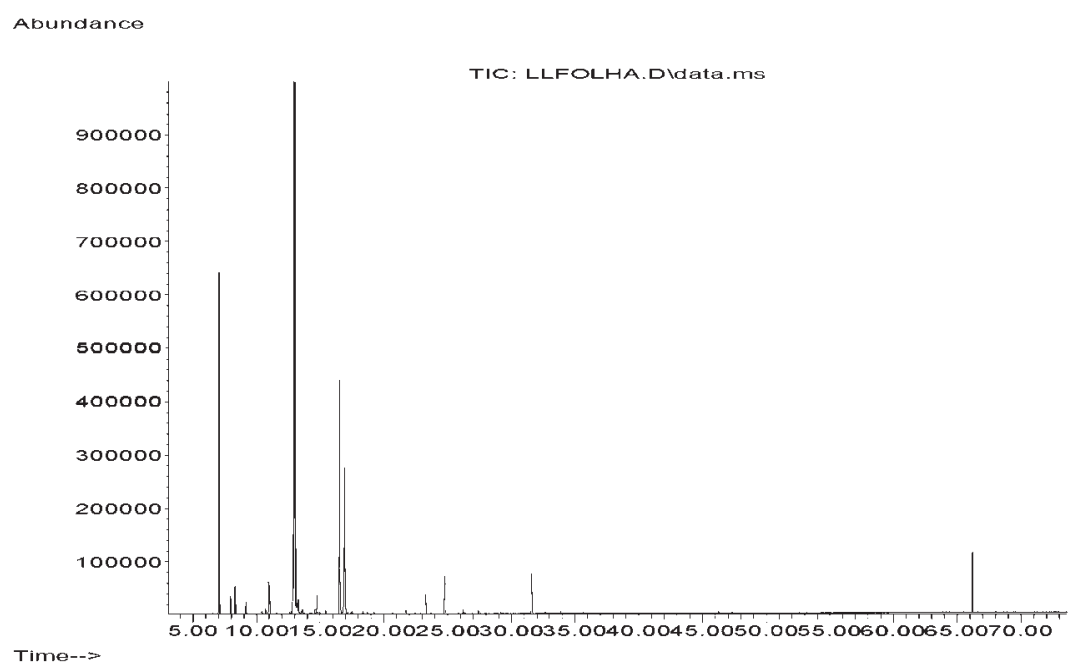

Figure S2. Gas Chromatogram (GC-MS) of the essential oil of Lippia lacunosa leaves.

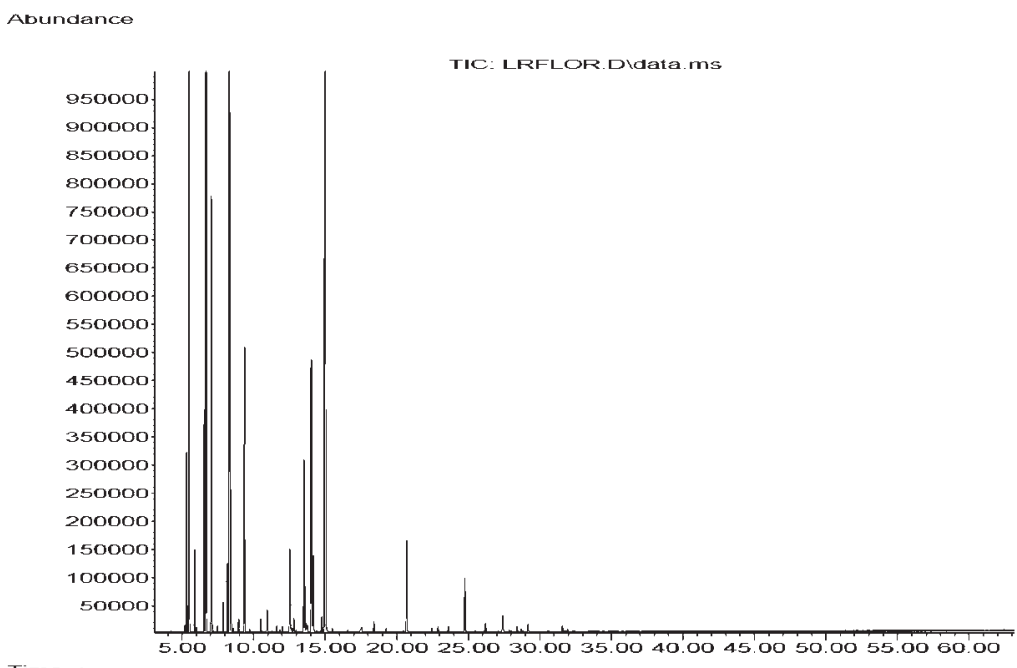

Figure S3. Gas Chromatogram (GC-MS) of the essential oil of Lippia rotundifolia flowers.

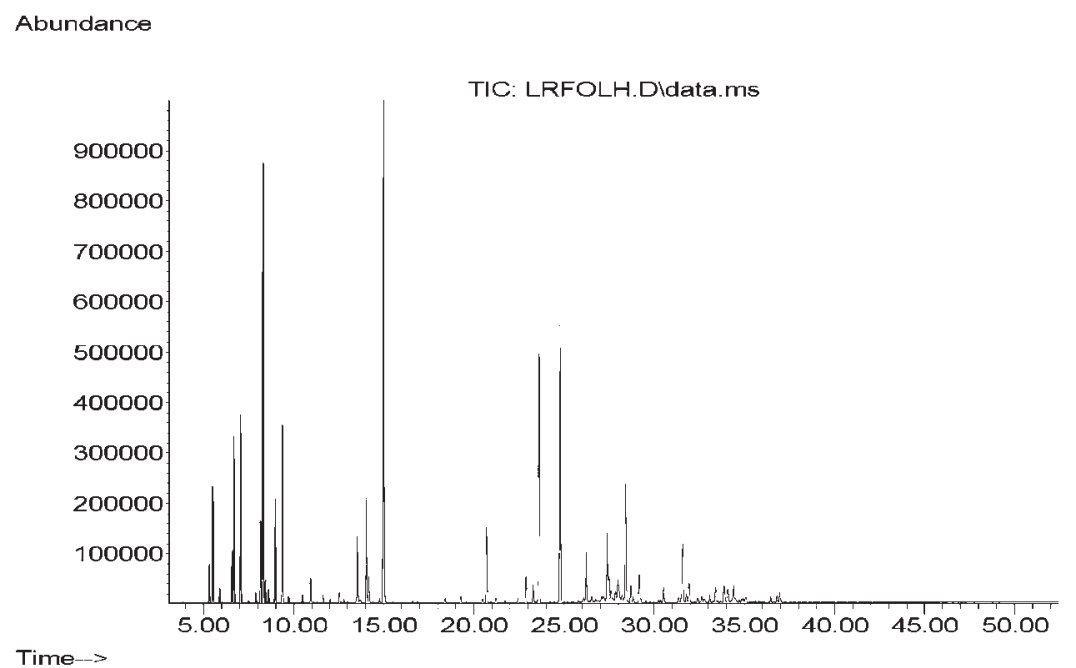

Figure S4. Gas Chromatogram (GC-MS) of the essential oil of Lippia rotundifolia leaves. 
Mass Spectra of Compounds in Lippia lacunosa and Lippia rotundifolia Essential Oils

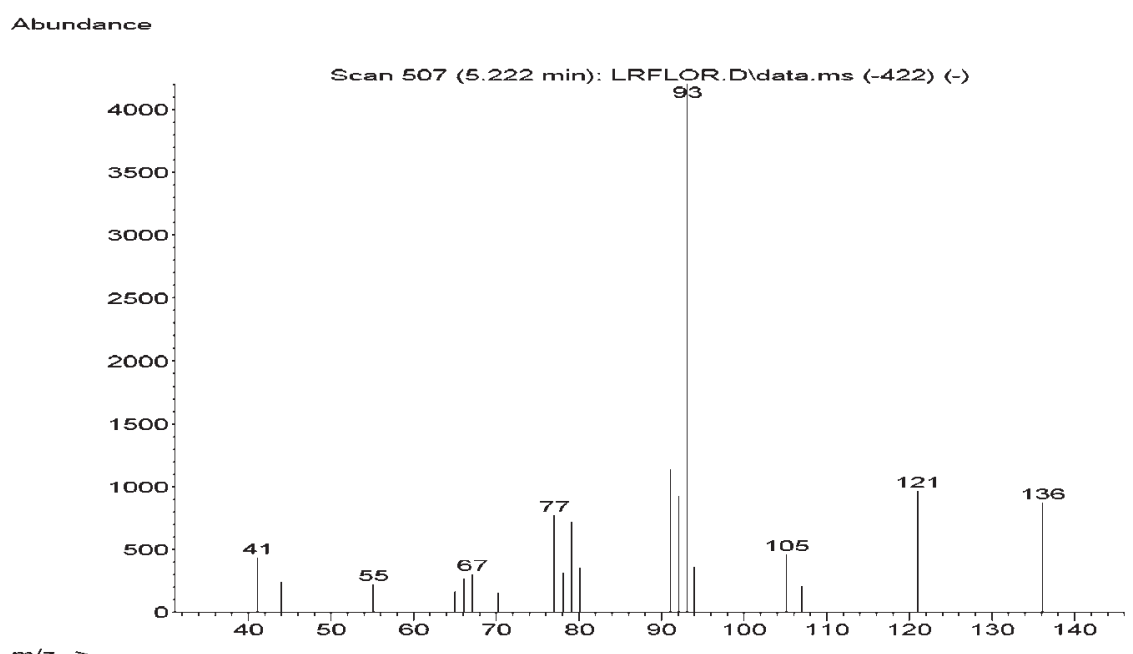

Figure S5. Mass spectra of tricyclene in Lippia lacunosa and Lippia rotundifolia essential oils.

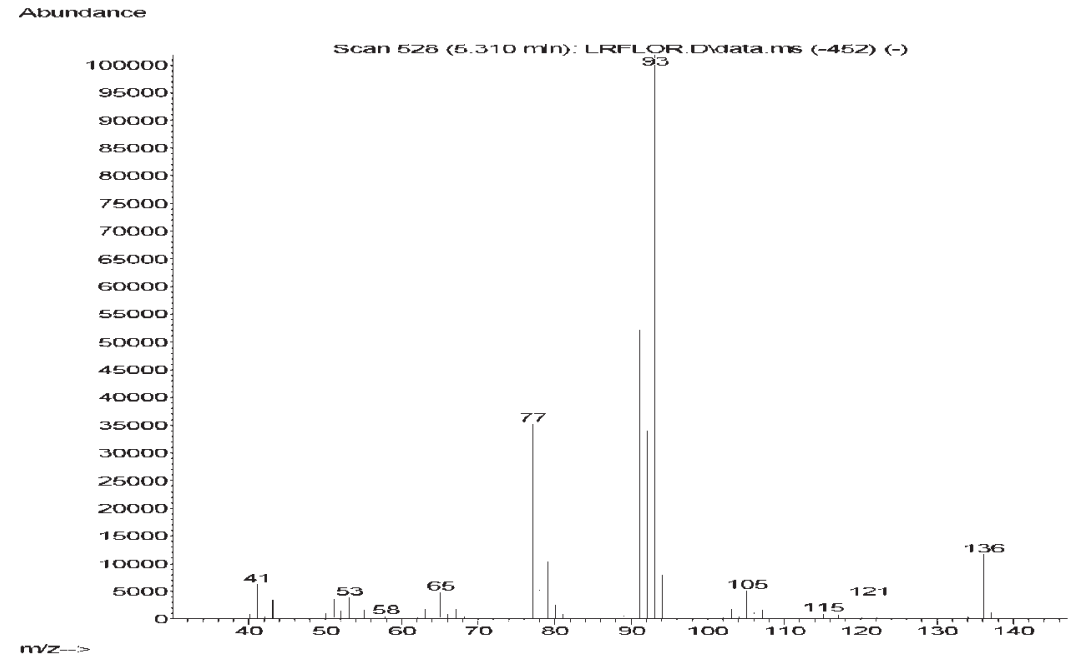

Figure S6. Mass spectra of alpha-thujene in Lippia lacunosa and Lippia rotundifolia essential oils.

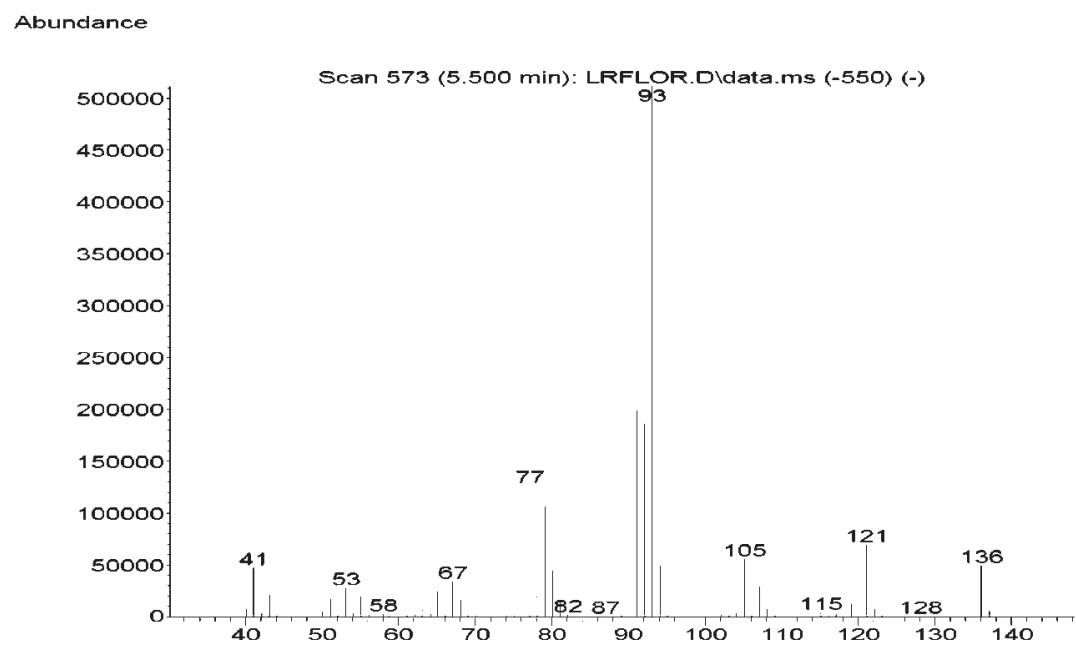

Figure S7. Mass spectra of alpha-pinene in Lippia lacunosa and Lippia rotundifolia essential oils. 


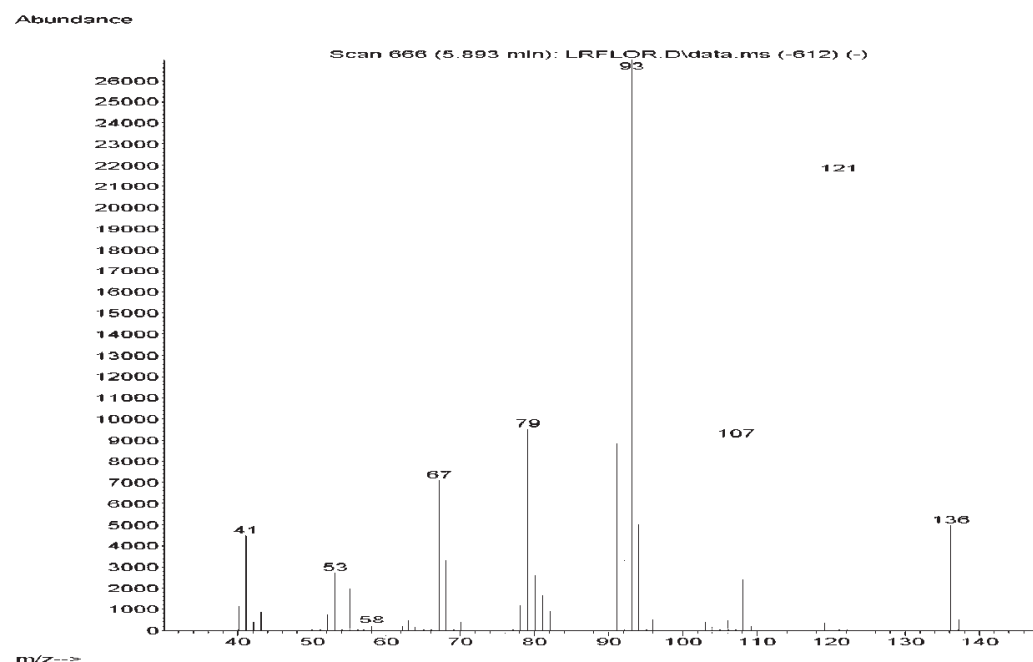

Figure S8. Mass spectra of camphene in Lippia lacunosa and Lippia rotundifolia essential oils.

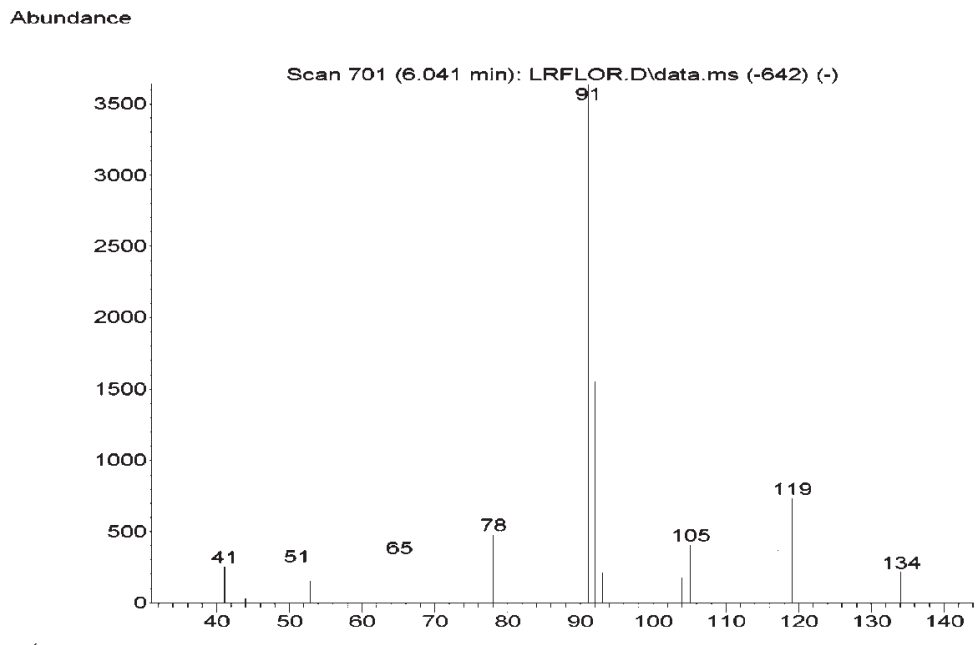

$m / z-->$

Figure S9. Mass spectra of thuja-2,4-(10)-diene in Lippia lacunosa and Lippia rotundifolia essential oils.

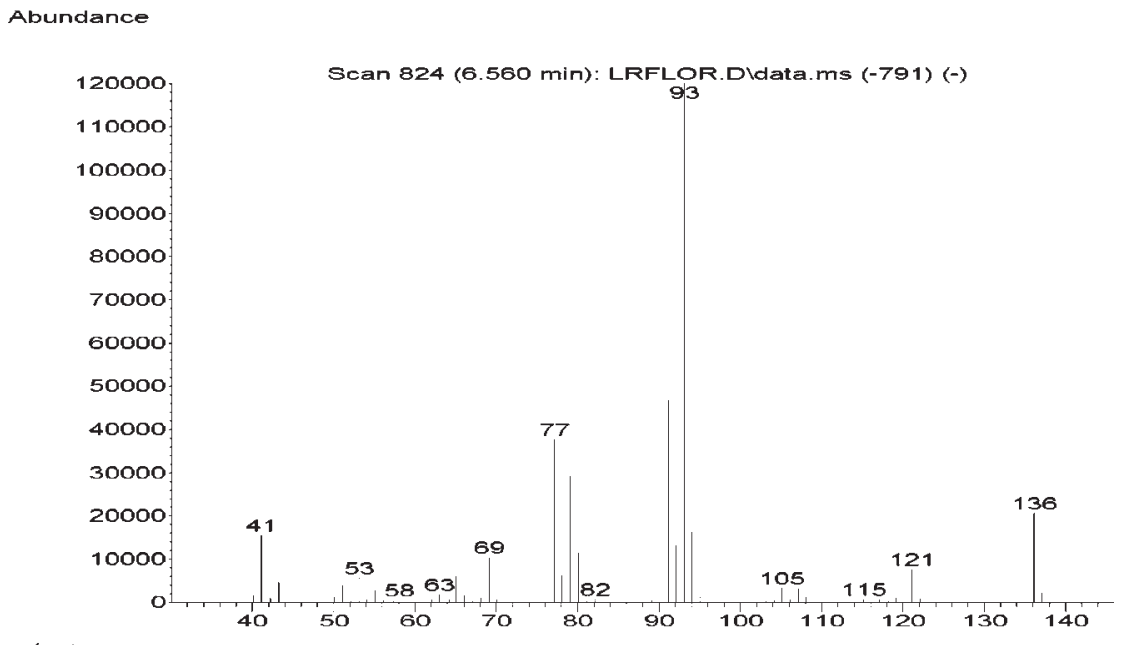

Figure S10. Mass spectra of sabinene in Lippia lacunosa and Lippia rotundifolia essential oils. 


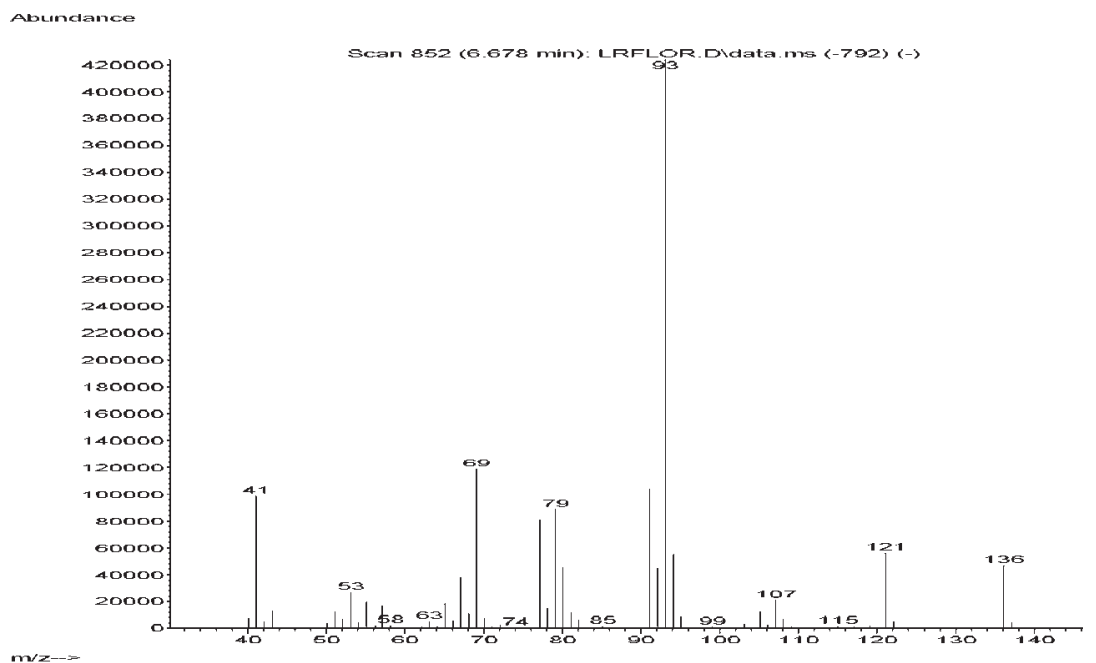

Figure S11. Mass spectra of beta-pinene in Lippia lacunosa and Lippia rotundifolia essential oils.

Abundance

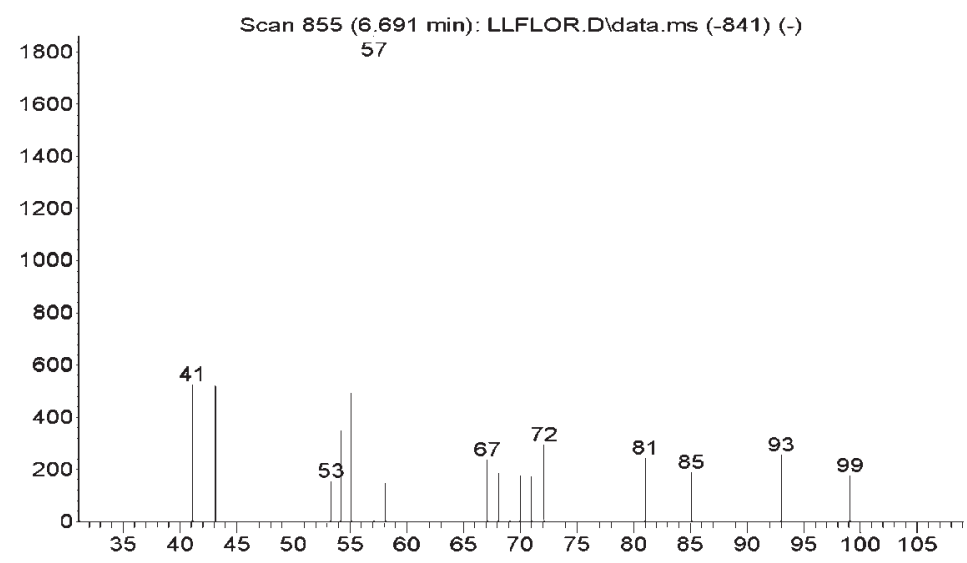

$m / z-->$

Figure S12. Mass spectra of 1-octen-3-ol in Lippia lacunosa and Lippia rotundifolia essential oils.

Abundance

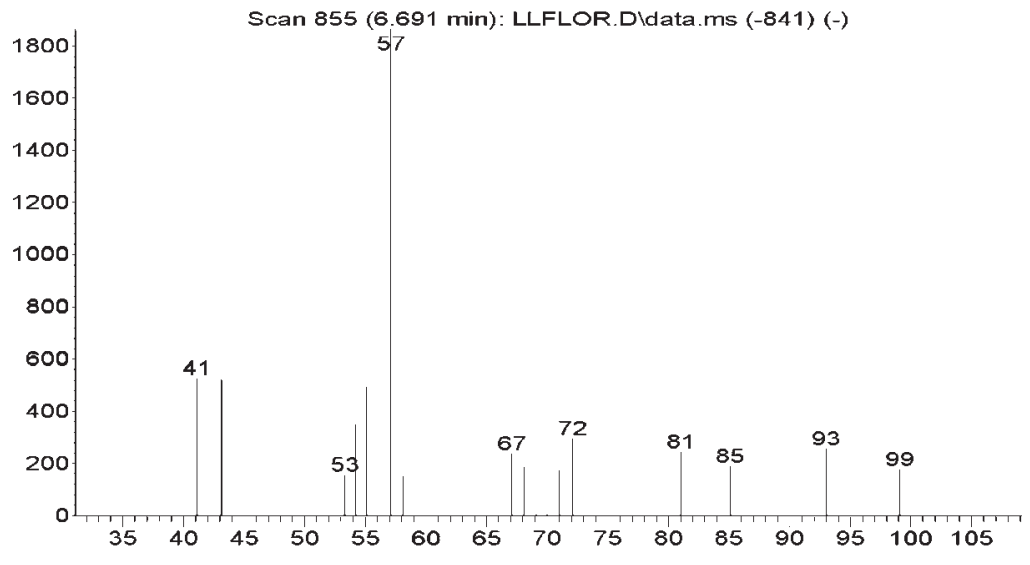

$m / z->$

Figure S13. Mass spectra of myrcene in Lippia lacunosa and Lippia rotundifolia essential oils. 


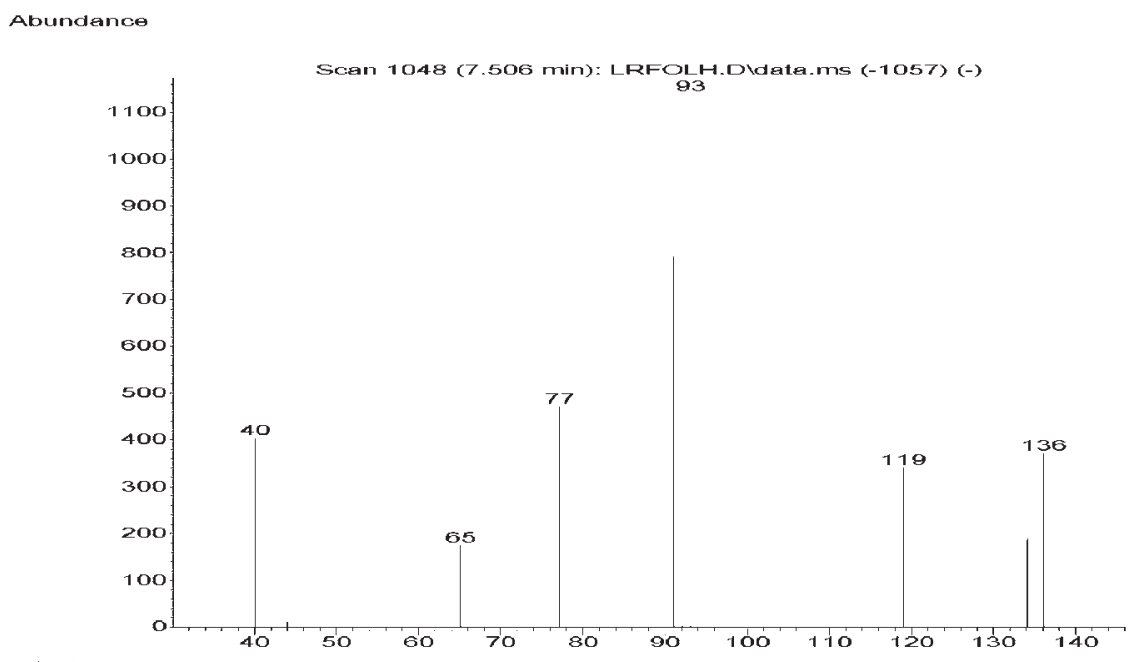

Figure S14. Mass spectra of alpha-phelandrene in Lippia lacunosa and Lippia rotundifolia essential oils.

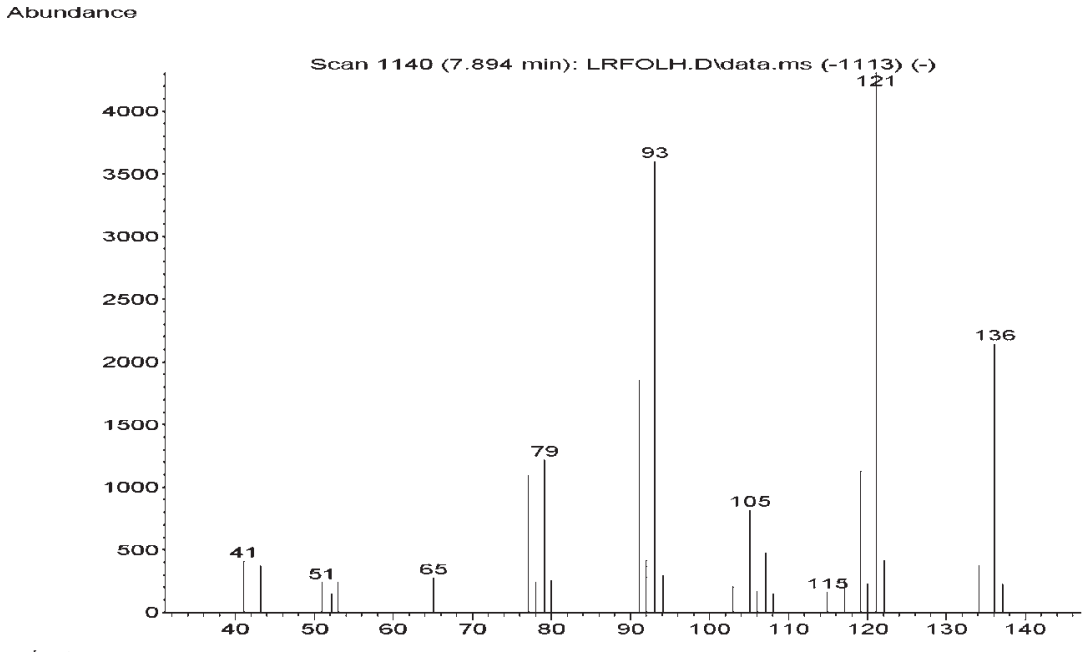

Figure S15. Mass spectra of alpha-terpinene in Lippia lacunosa and Lippia rotundifolia essential oils.

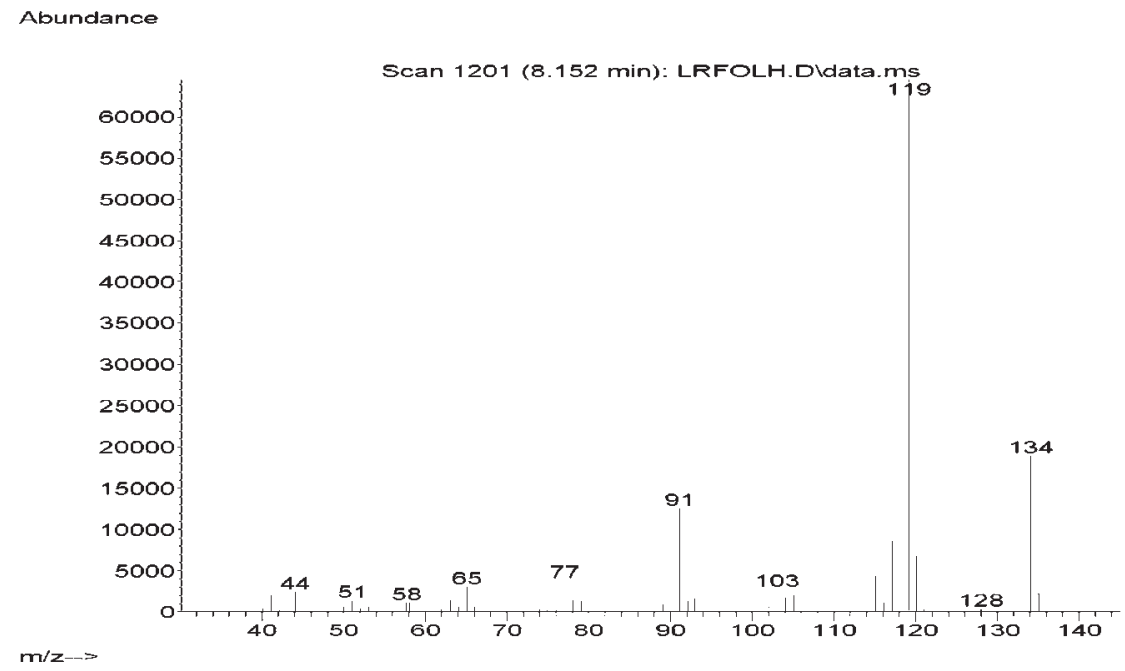

Figure S16. Mass spectra of para-cymene in Lippia lacunosa and Lippia rotundifolia essential oils. 


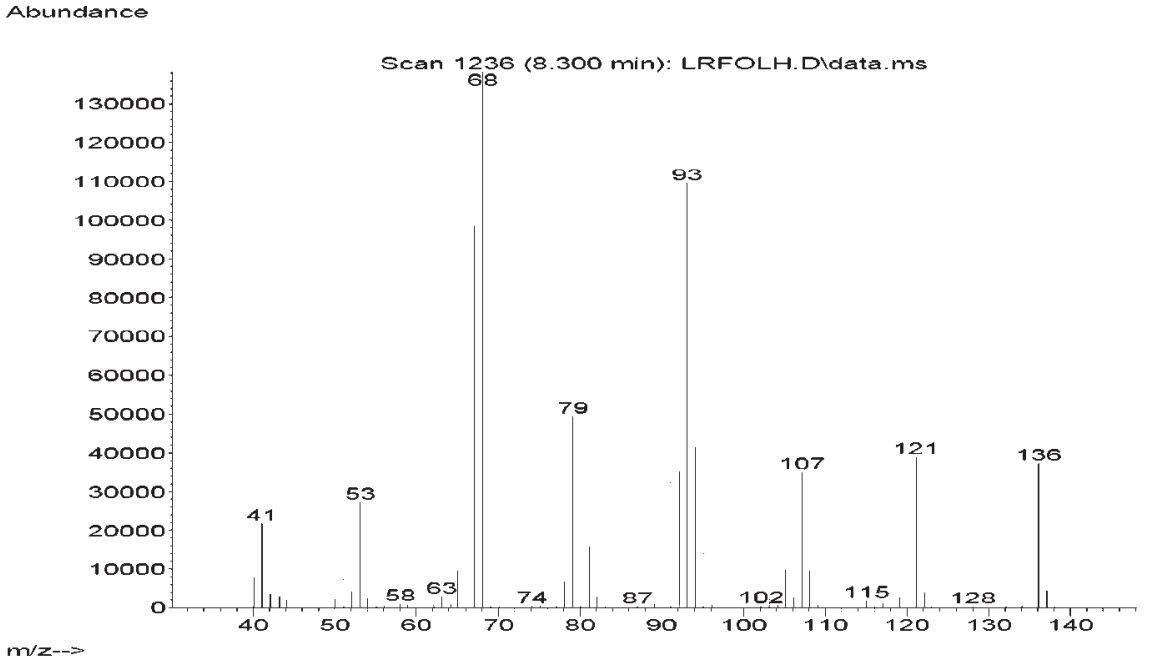

Figure S17. Mass spectra of limonene in Lippia lacunosa and Lippia rotundifolia essential oils.

Abundance

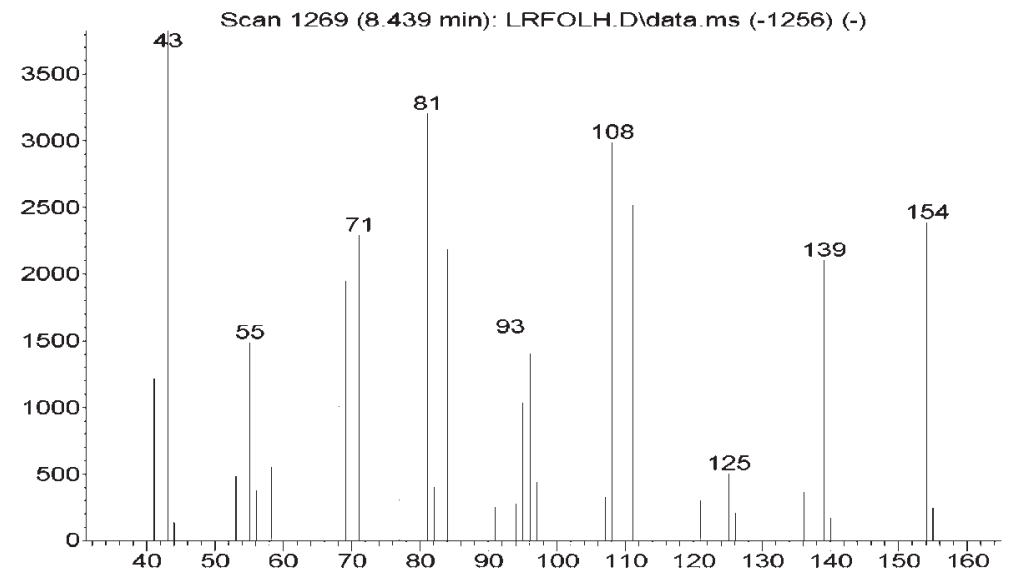

$m / z-->$

Figure S18. Mass spectra of 1,8-cineole in Lippia lacunosa and Lippia rotundifolia essential oils.

Abundance

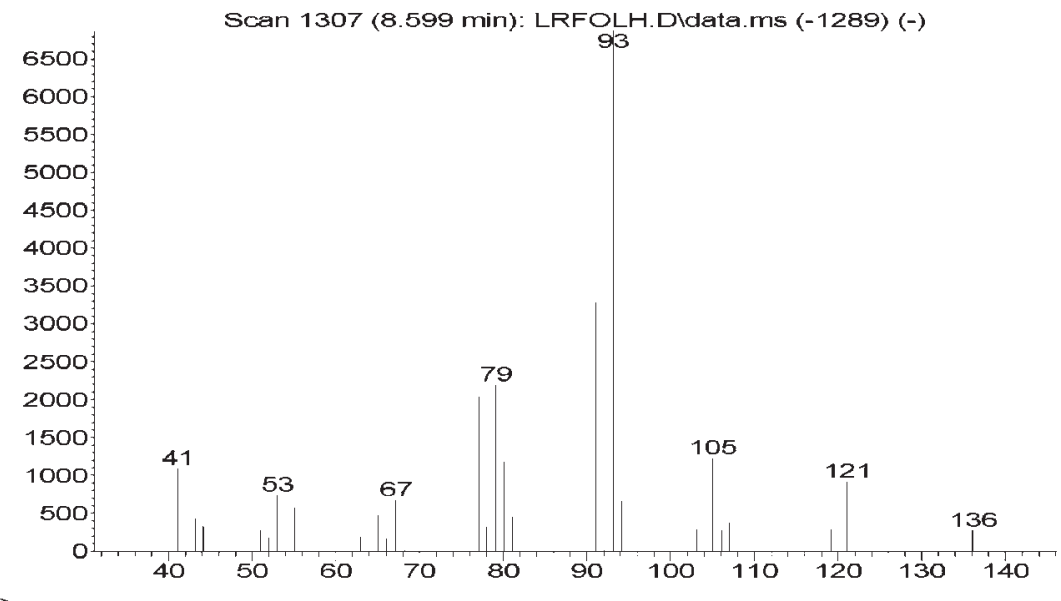

$m / z-->$

Figure S19. Mass spectra of (z)-beta-ocimene in Lippia lacunosa and Lippia rotundifolia essential oils. 


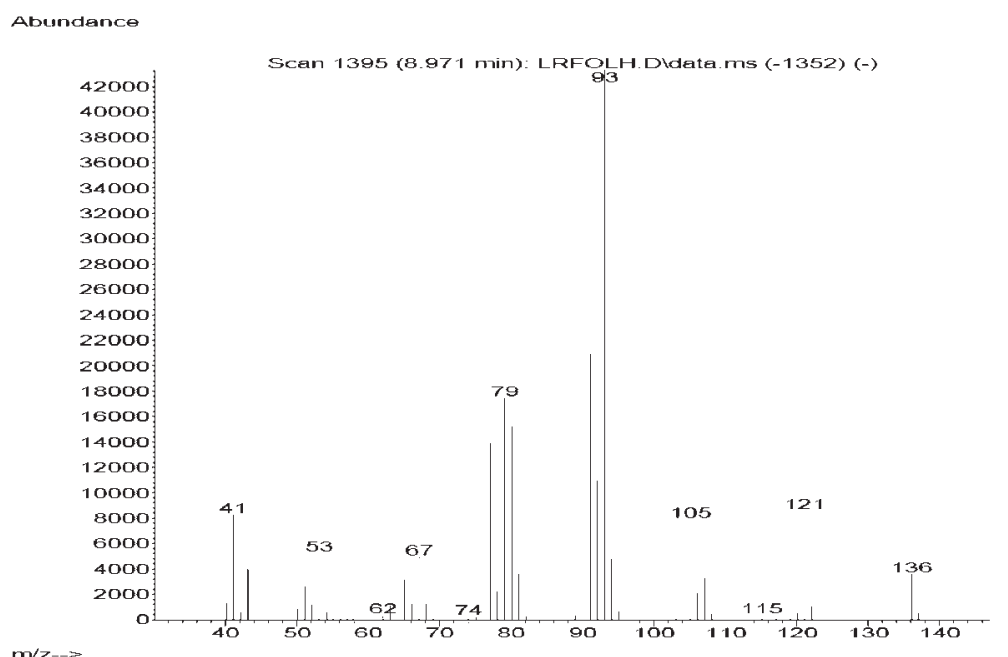

Figure S20. Mass spectra of (e)-beta-ocimene in Lippia lacunosa and Lippia rotundifolia essential oils.

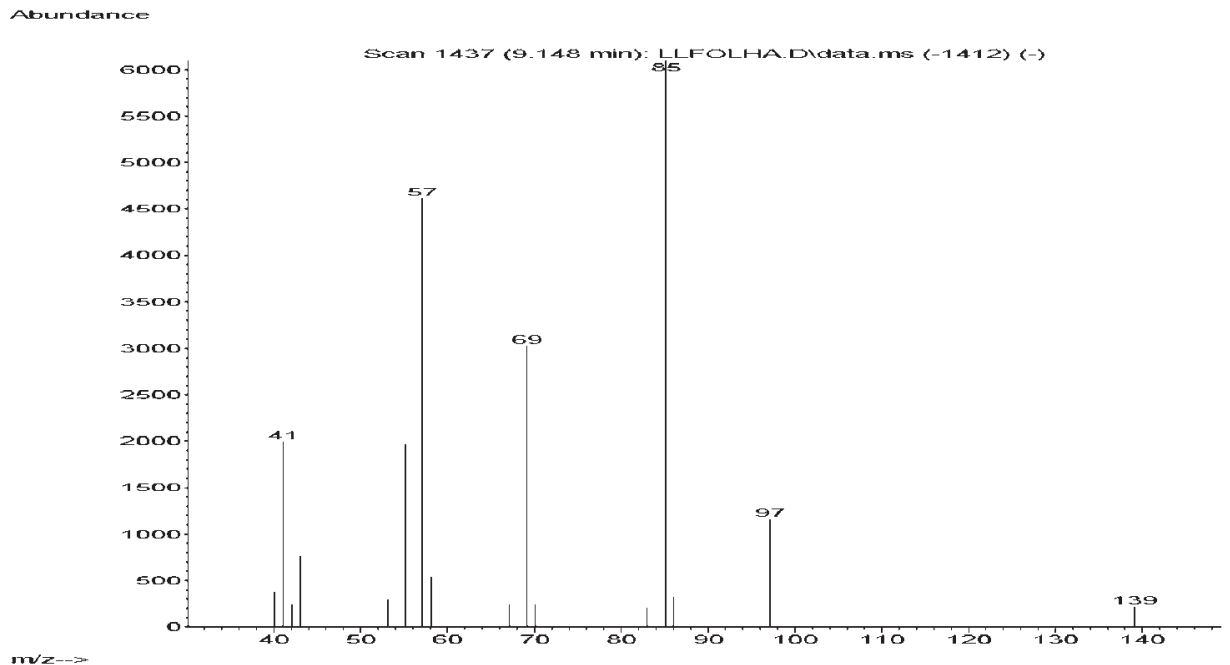

Figure S21. Mass spectra of dihydrotagetone in Lippia lacunosa and Lippia rotundifolia essential oils.

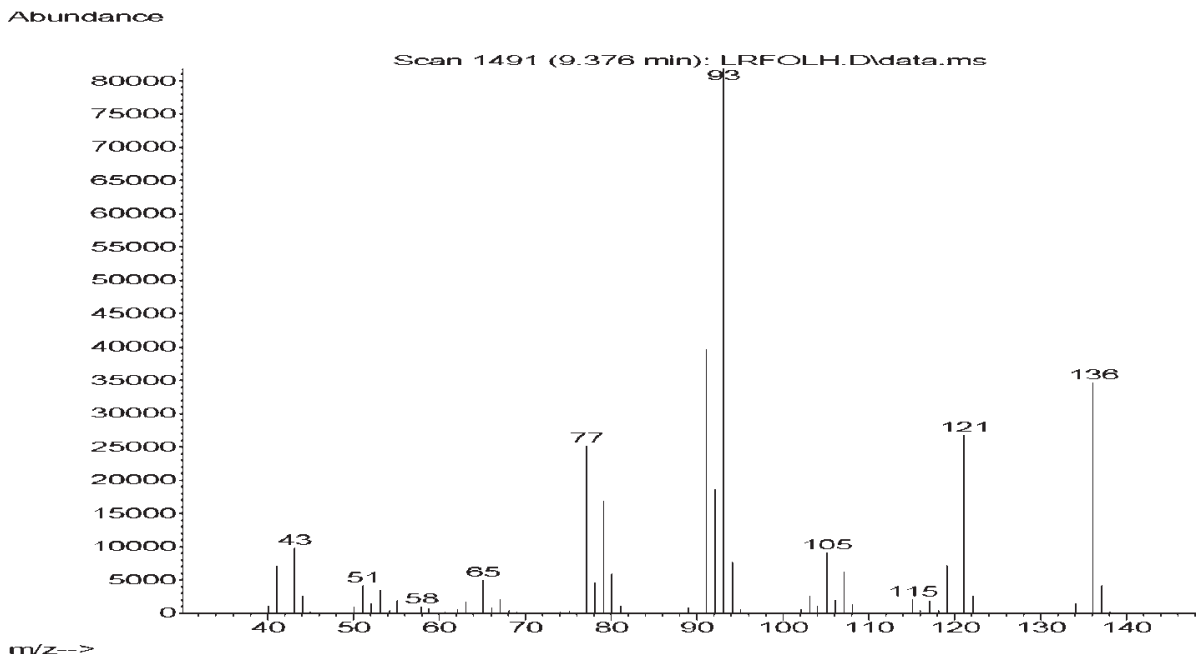

Figure S22. Mass spectra of gamma-terpinene in Lippia lacunosa and Lippia rotundifolia essential oils. 


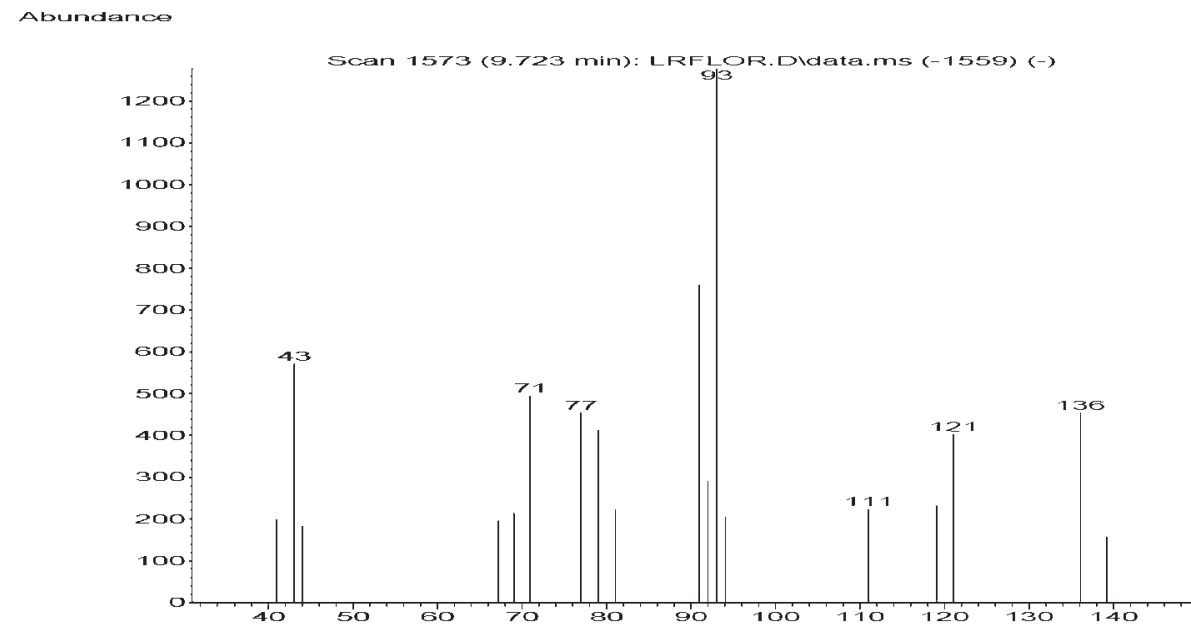

Figure S23. Mass spectra of cis-sabinene-hydrate in Lippia lacunosa and Lippia rotundifolia essential oils.

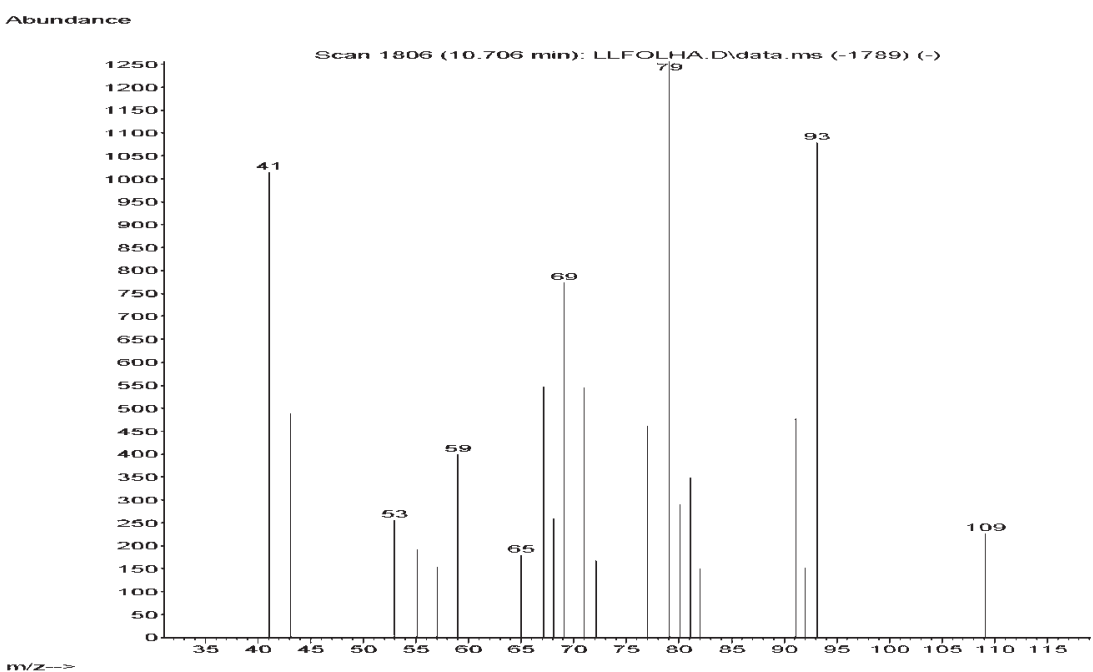

Figure S24. Mass spectra of not identified compound (IR=1088) in Lippia lacunosa and Lippia rotundifolia essential oils.

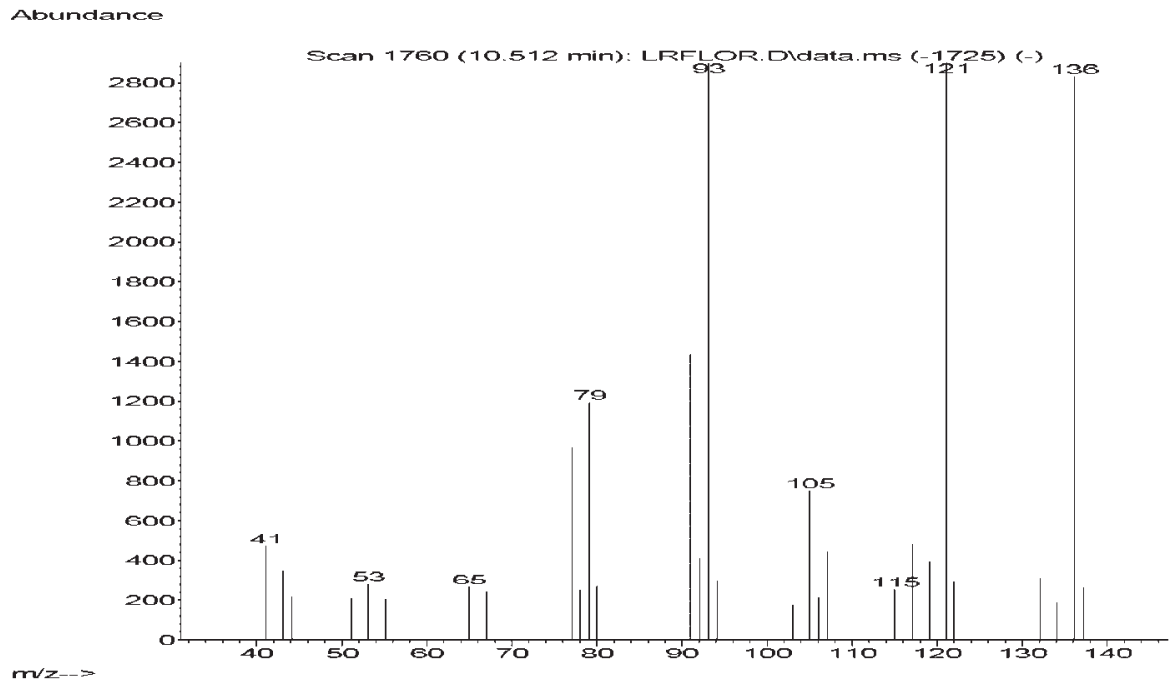

Figure S25. Mass spectra of terpinolene in Lippia lacunosa and Lippia rotundifolia essential oils. 
Abundance

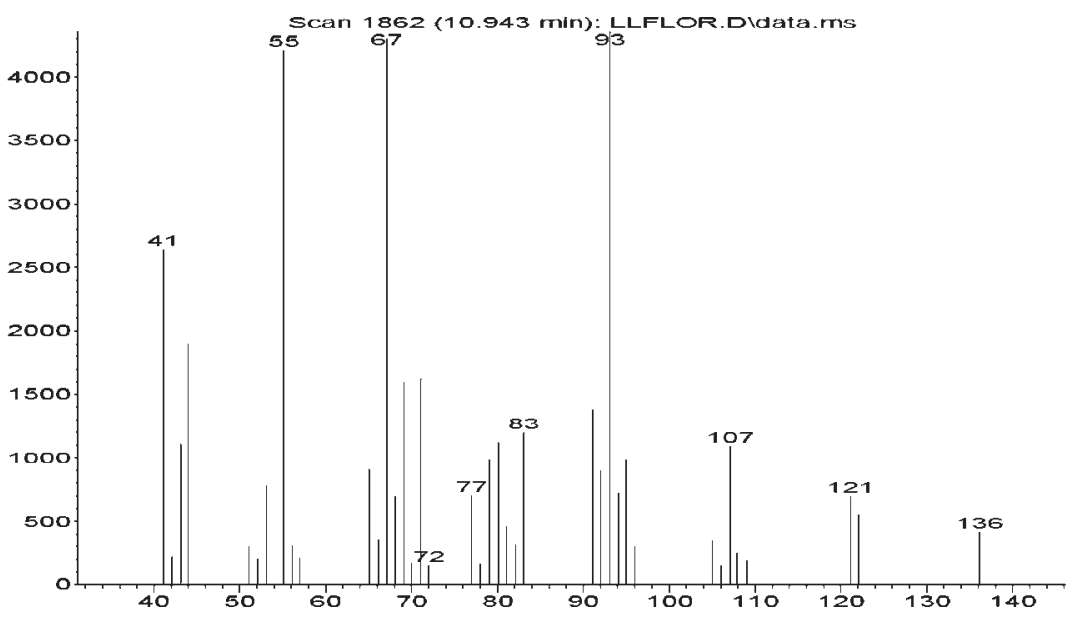

Figure S26. Mass spectra of not identified compound (IR=1101) in Lippia lacunosa and Lippia rotundifolia essential oils.

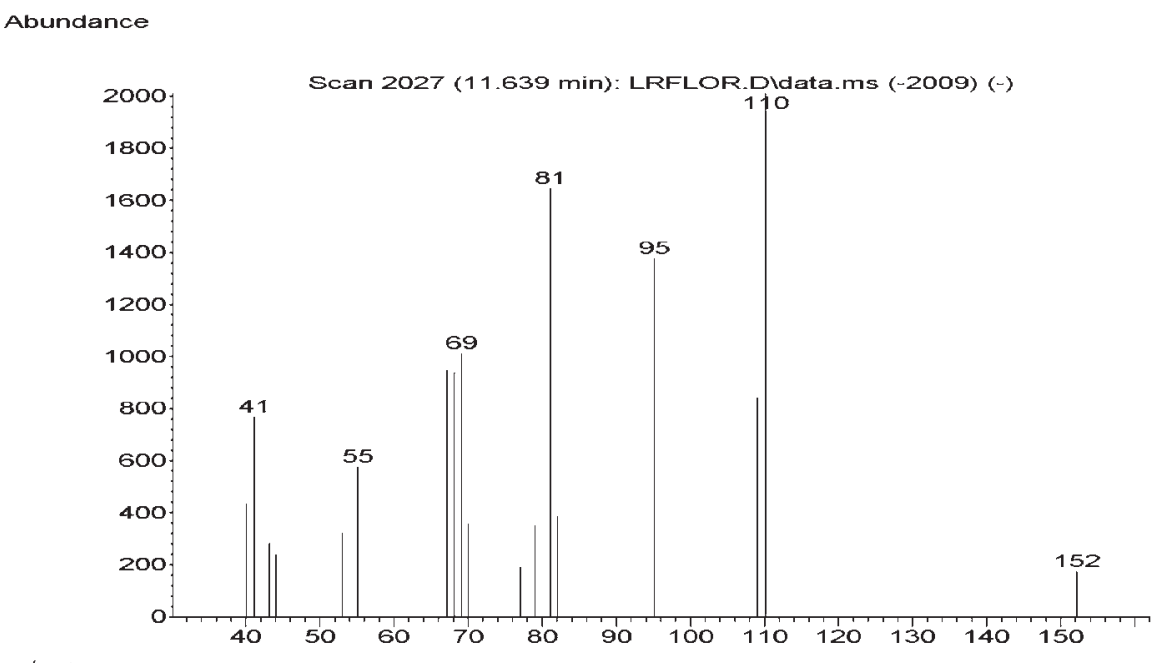

Figure S27. Mass spectra of trans-thujone in Lippia lacunosa and Lippia rotundifolia essential oils.

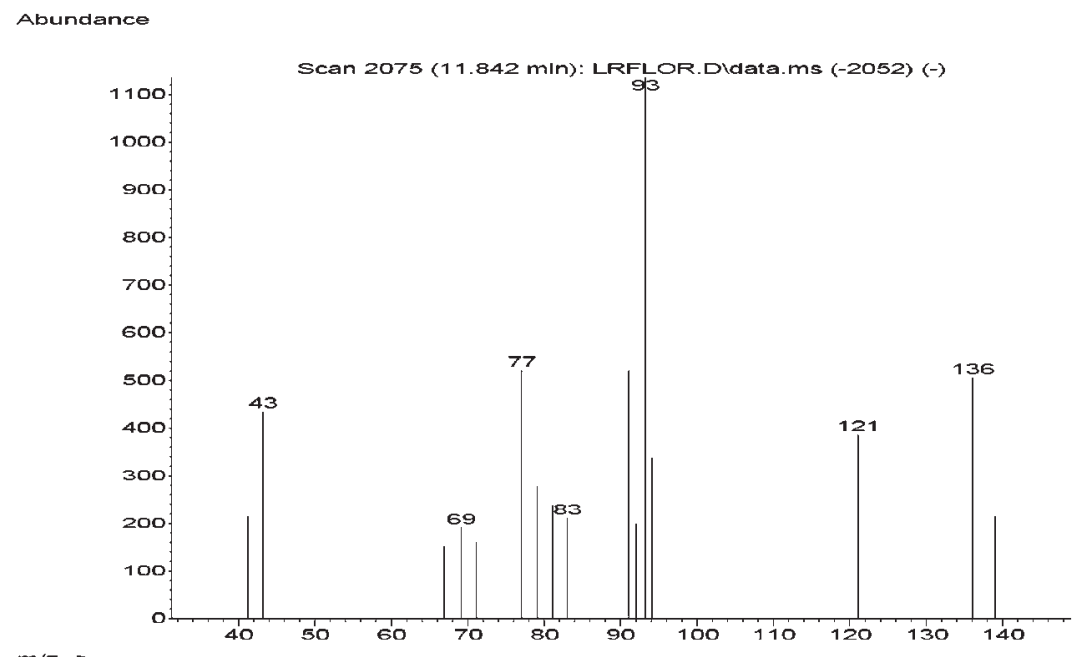

Figure S28. Mass spectra of not identified compound (IR=1125) in Lippia lacunosa and Lippia rotundifolia essential oils. 


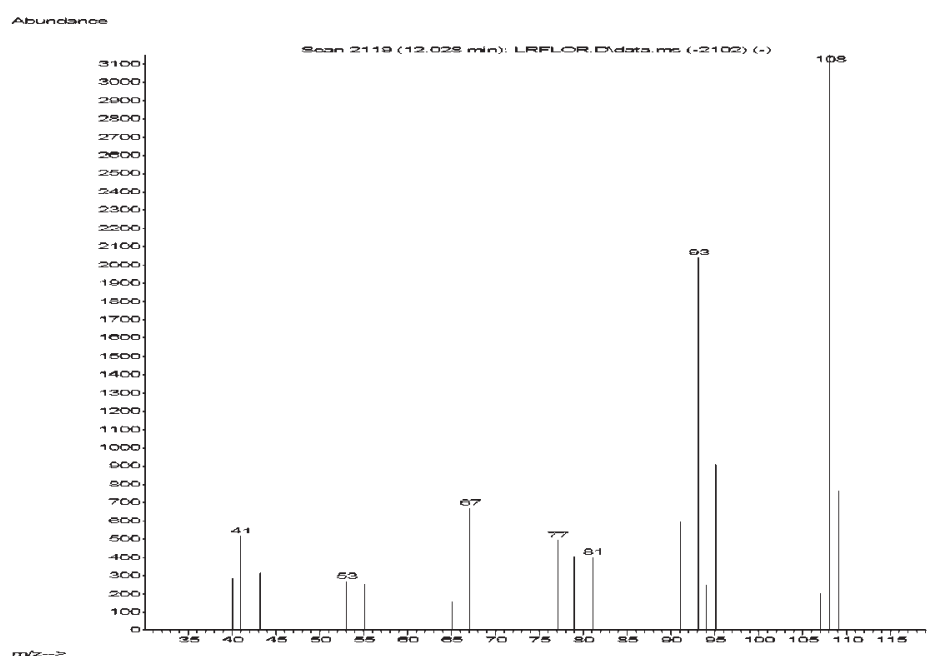

Figure S29. Mass spectra of alpha-campholenal in Lippia lacunosa and Lippia rotundifolia essential oils.

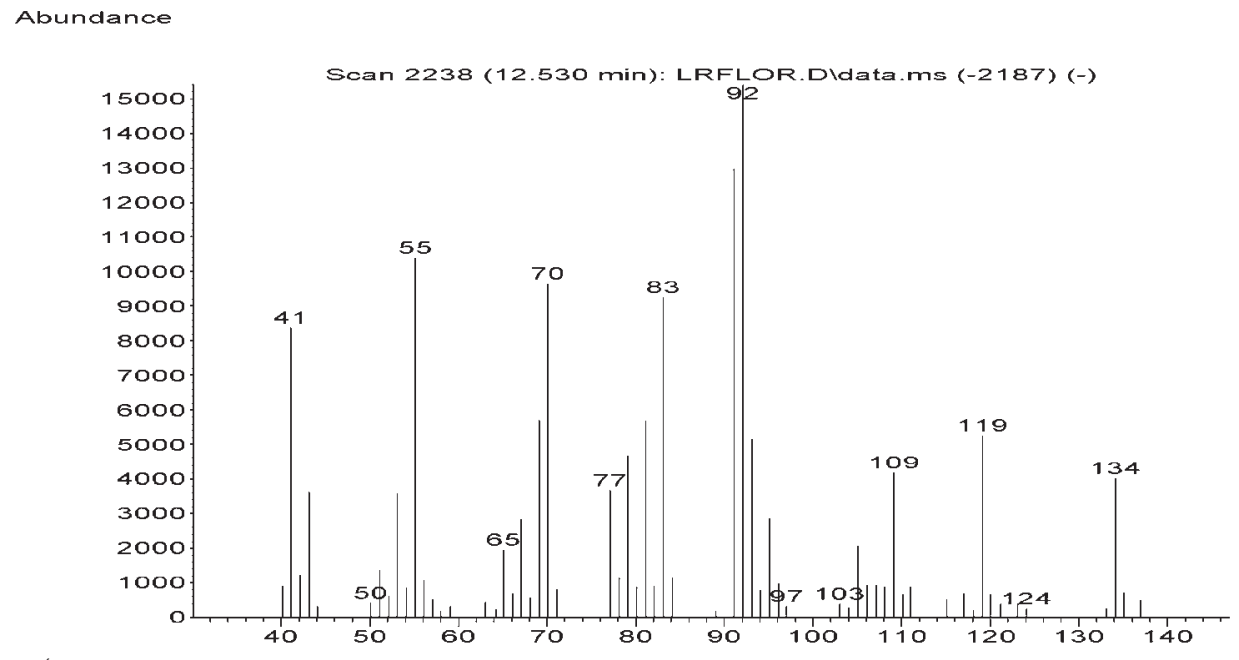

Figure S30. Mass spectra of trans-pinocarveol in Lippia lacunosa and Lippia rotundifolia essential oils.

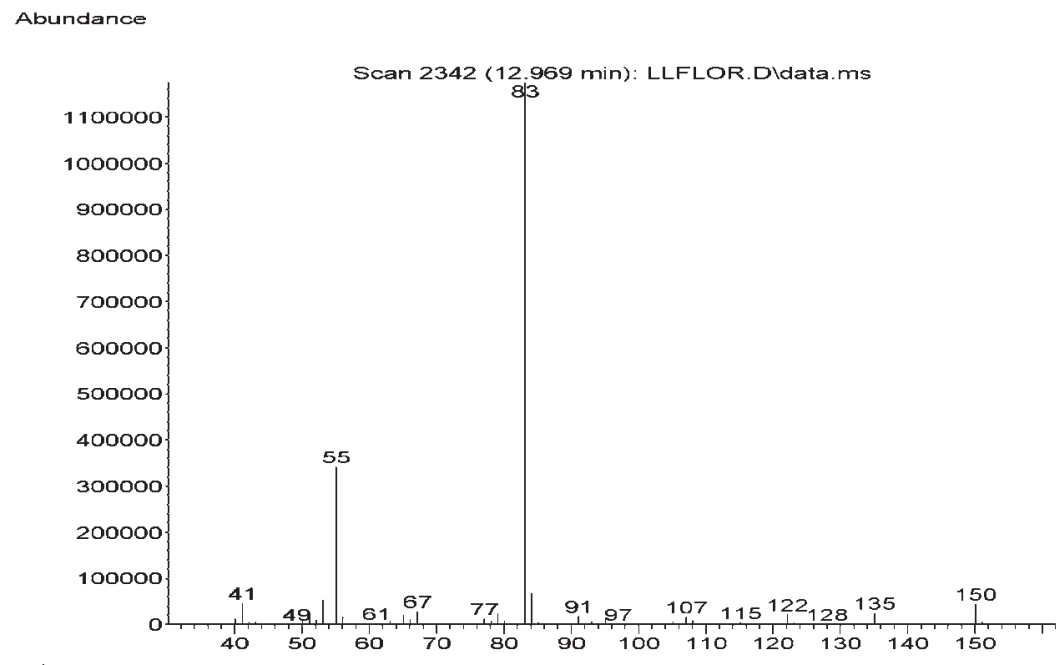

Figure S31. Mass spectra of myrcenone in Lippia lacunosa and Lippia rotundifolia essential oils. 
Abundance

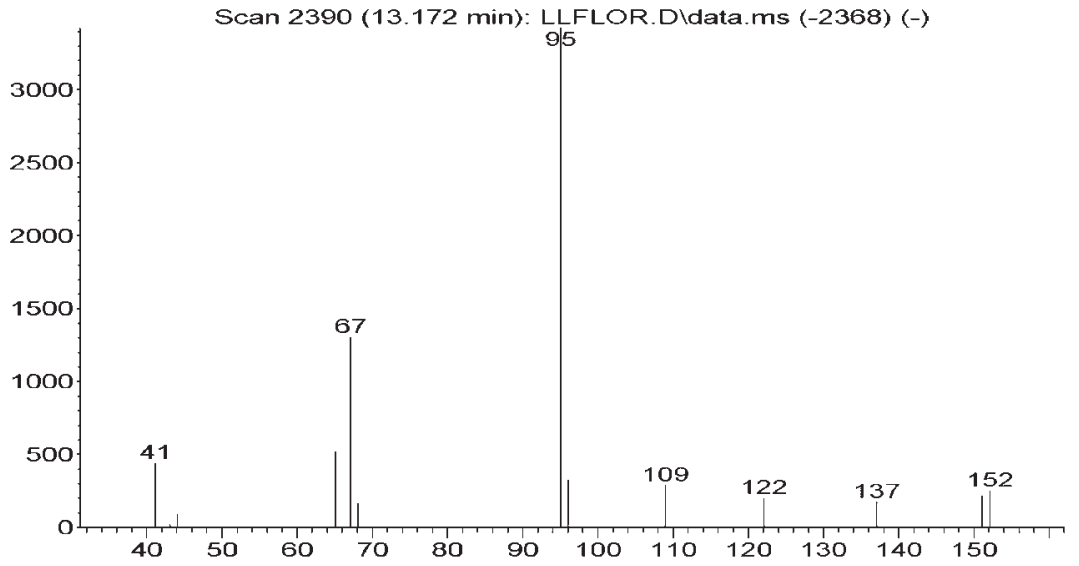

$m / z-->$

Figure S32. Mass spectra of cis-tagetone in Lippia lacunosa and Lippia rotundifolia essential oils.

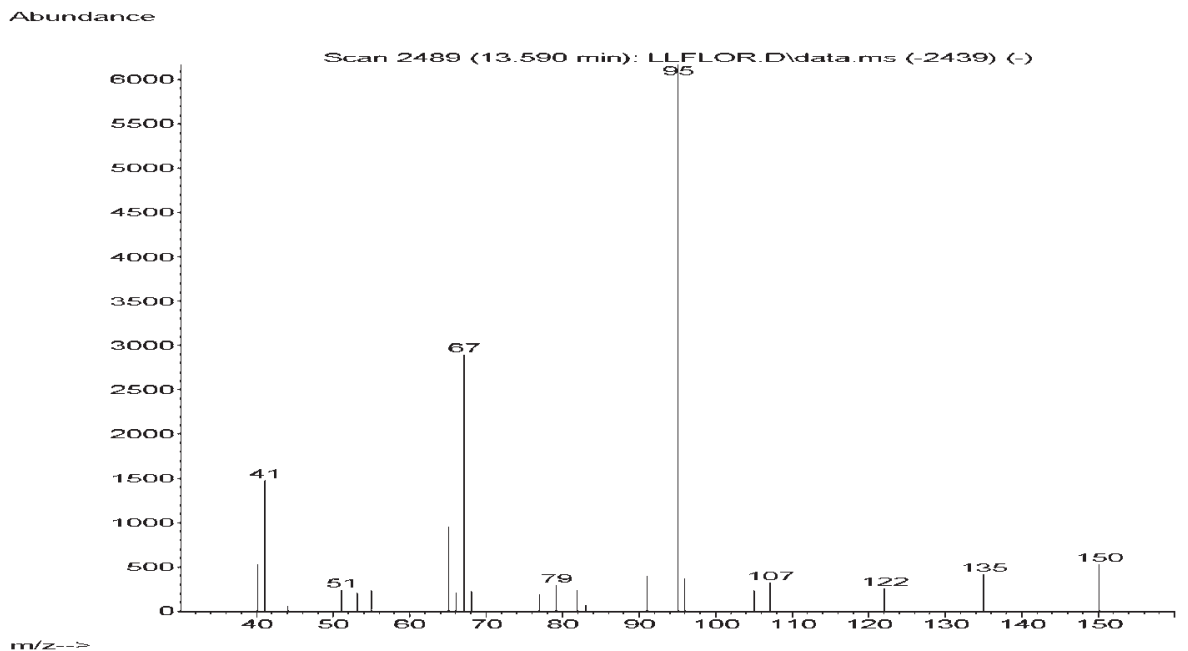

Figure S33. Mass spectra of not identified compound (IR=1167)in Lippia lacunosa and Lippia rotundifolia essential oils.

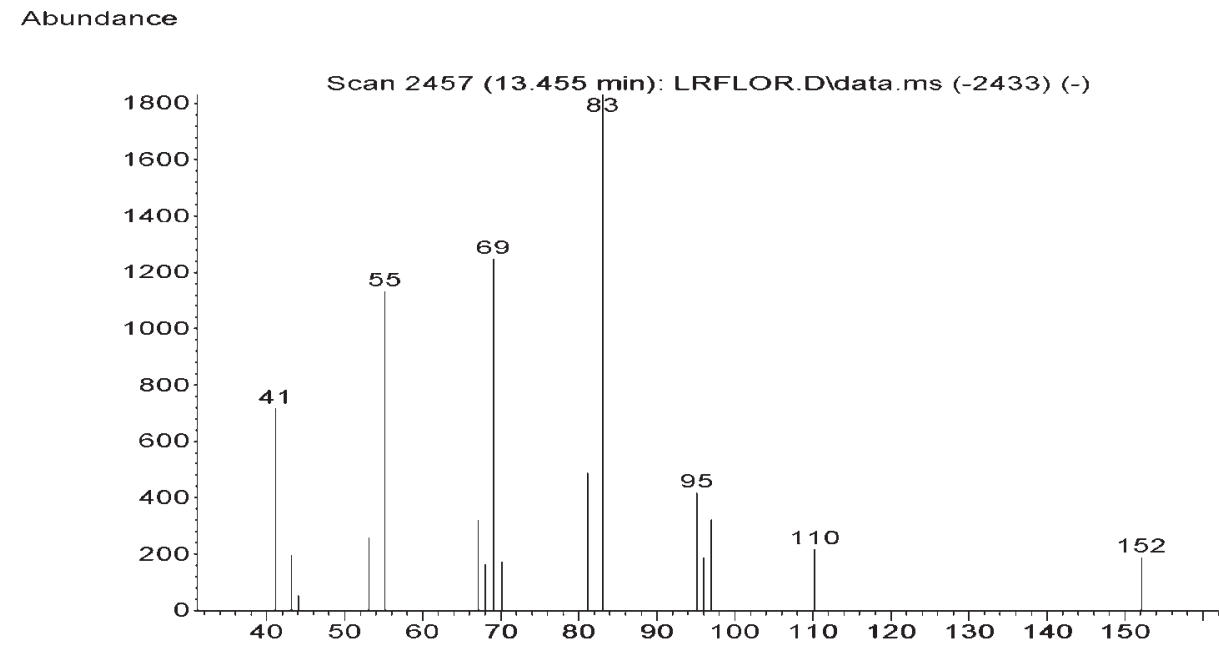

$m / z-->$

Figure S34. Mass spectra of trans-pinocamphone in Lippia lacunosa and Lippia rotundifolia essential oils. 
Abundance

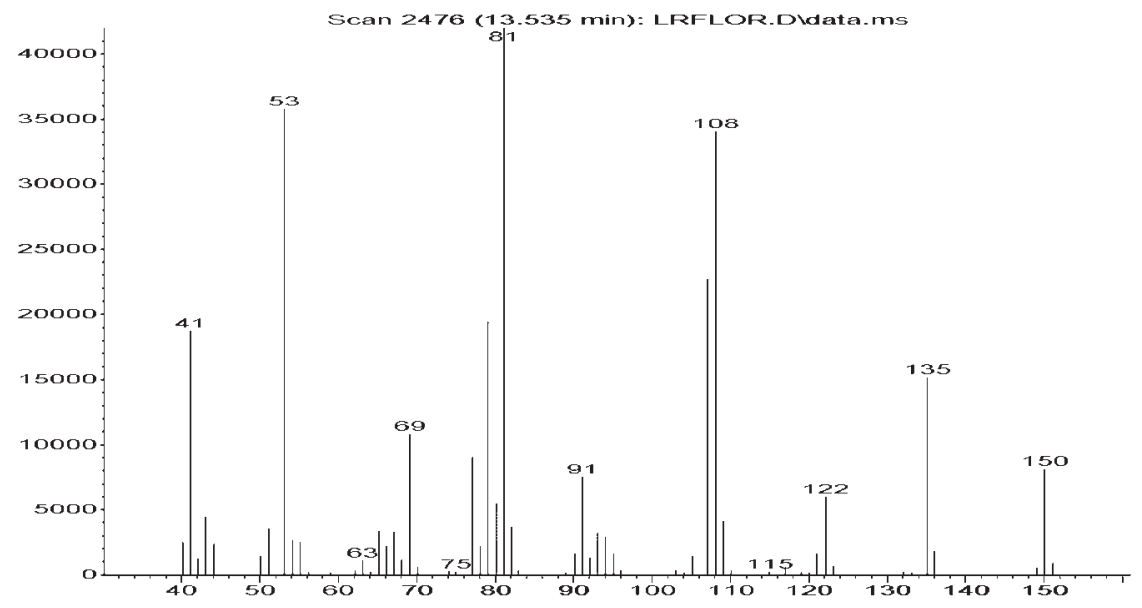

Figure S35. Mass spectra of pinocarvone in Lippia lacunosa and Lippia rotundifolia essential oils.

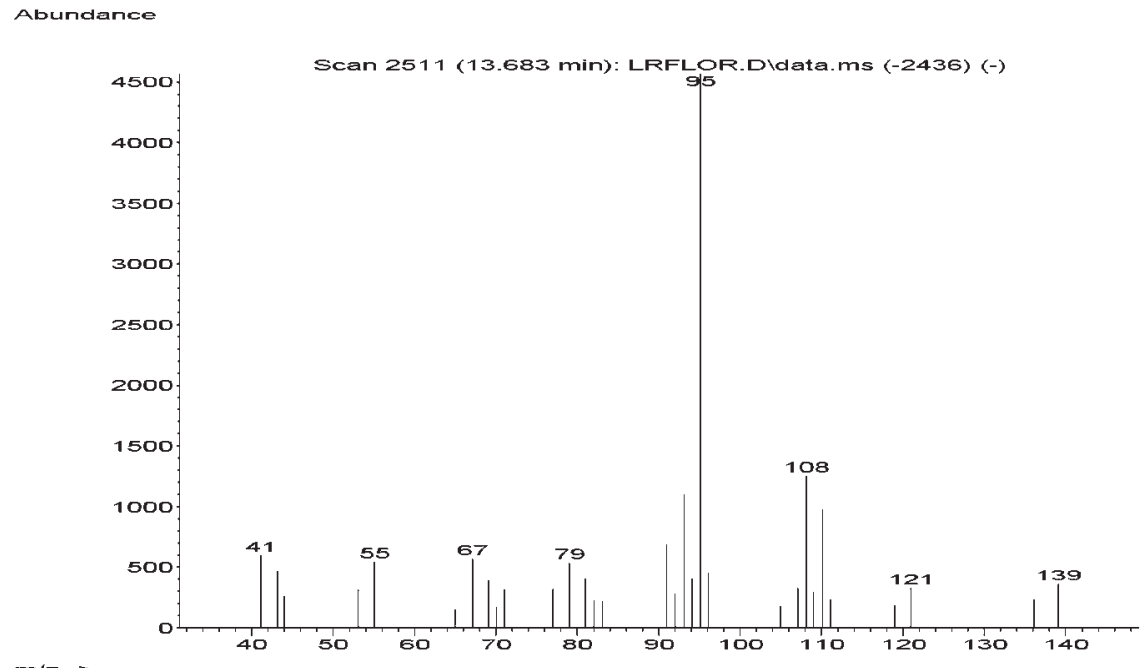

Figure S36. Mass spectra of borneol in Lippia lacunosa and Lippia rotundifolia essential oils.

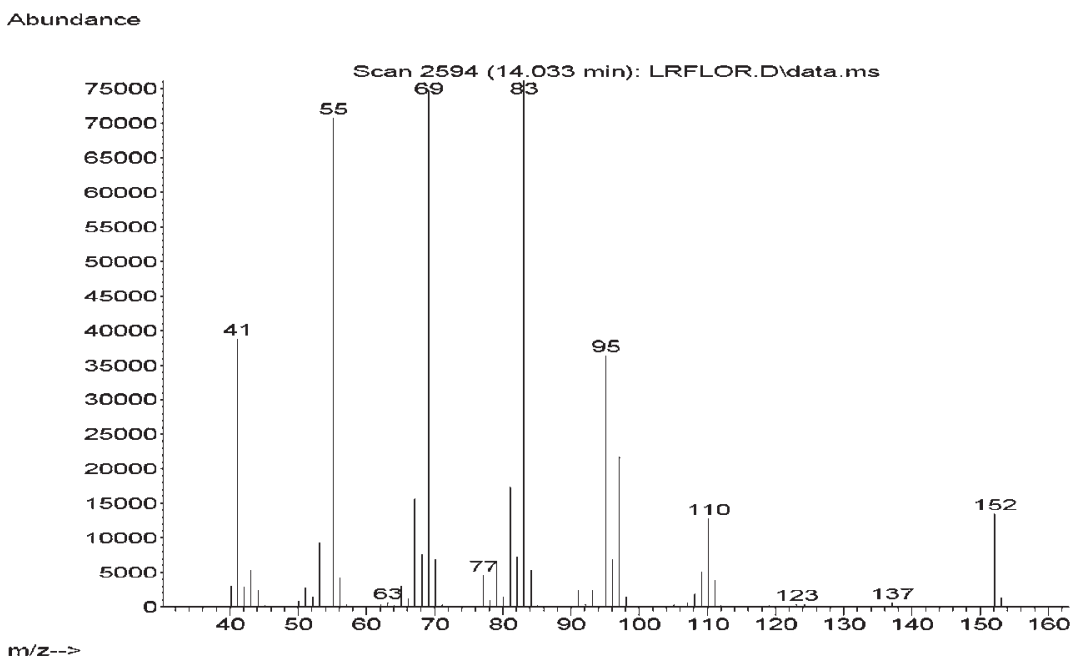

Figure S37. Mass spectra of cis-pinocamphone in Lippia lacunosa and Lippia rotundifolia essential oils. 


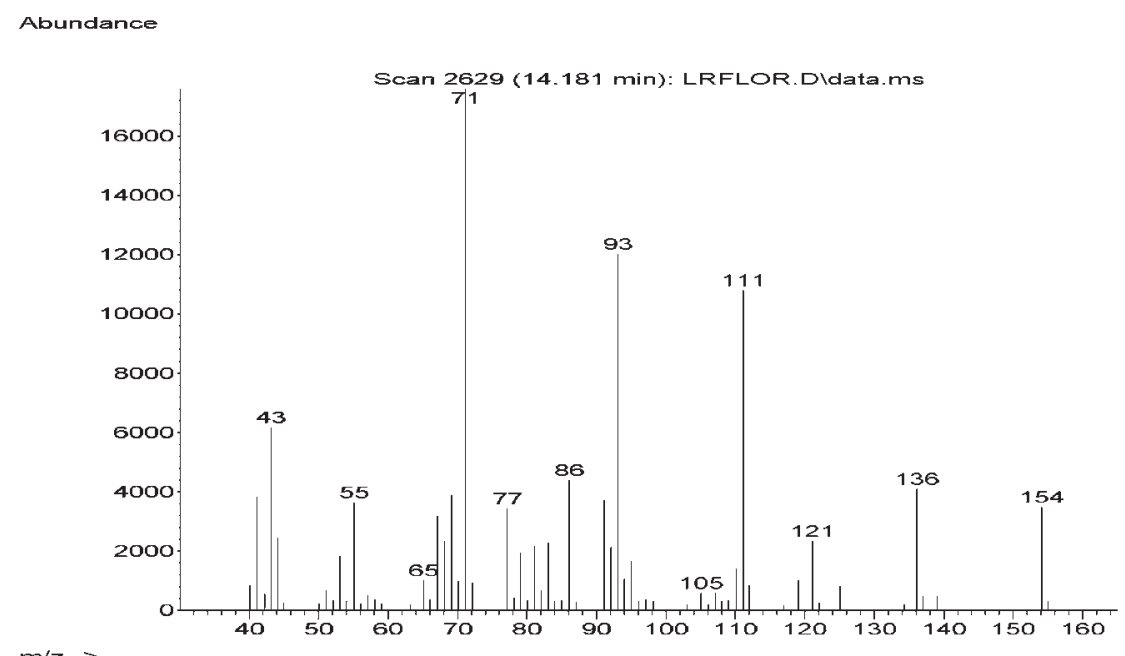

Figure S38. Mass spectra of terpinen-4-ol in Lippia lacunosa and Lippia rotundifolia essential oils.

Abundance

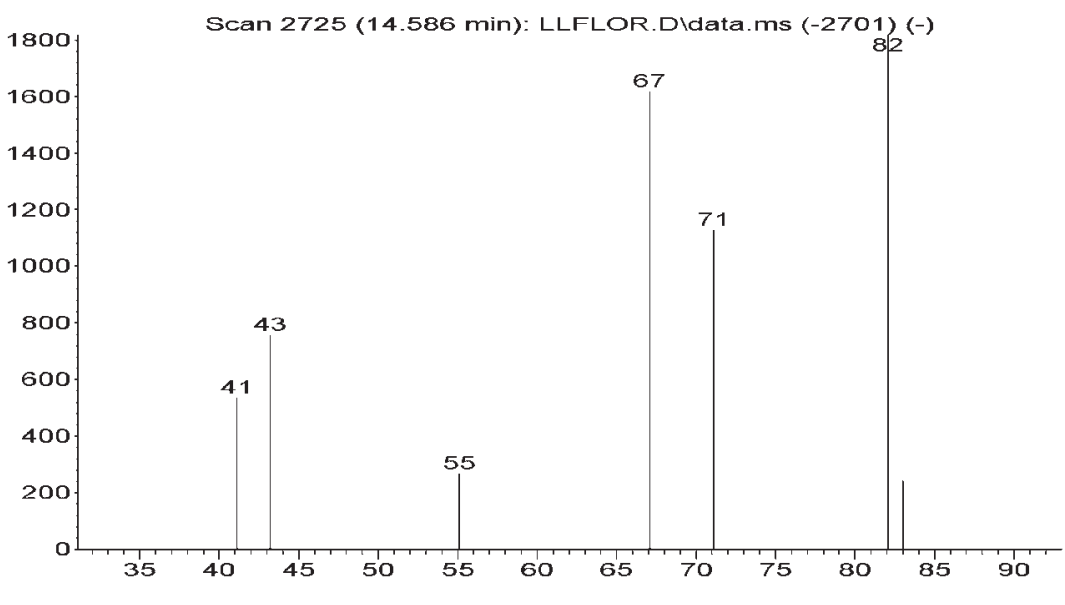

$m / z--=$

Figure S39. Mass spectra of not identified compound (IR=1189) in Lippia lacunosa and Lippia rotundifolia essential oils.

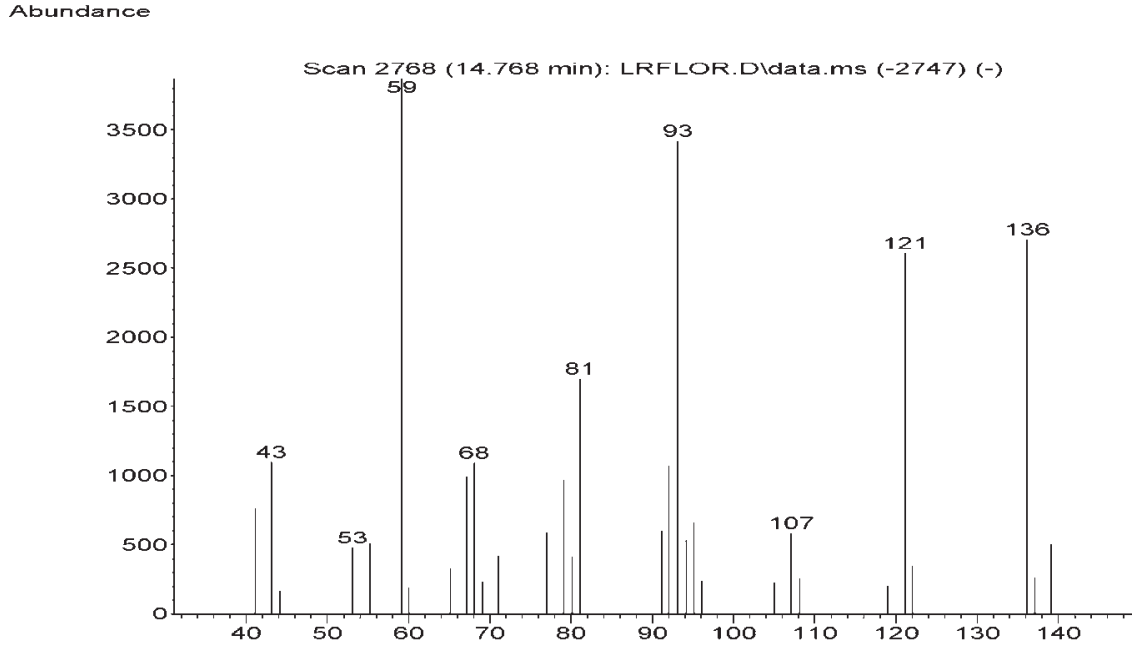

Figure S40. Mass spectra of alpha-terpineol in Lippia lacunosa and Lippia rotundifolia essential oils. 


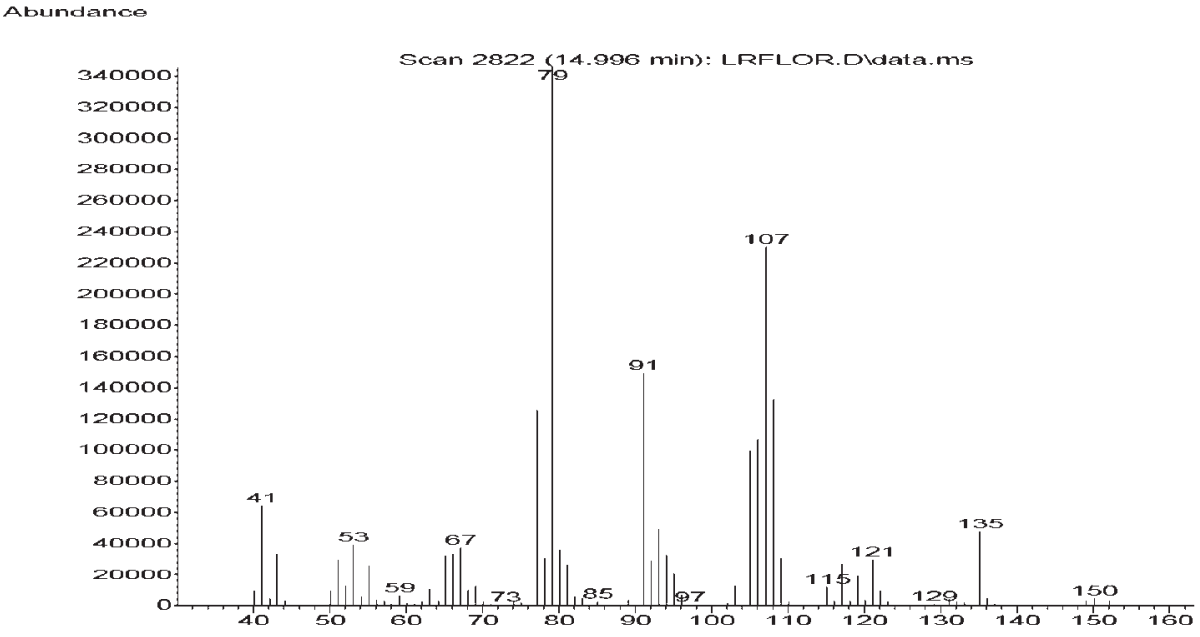

Figure S41. Mass spectra of myrtenal in Lippia lacunosa and Lippia rotundifolia essential oils.

Abundance

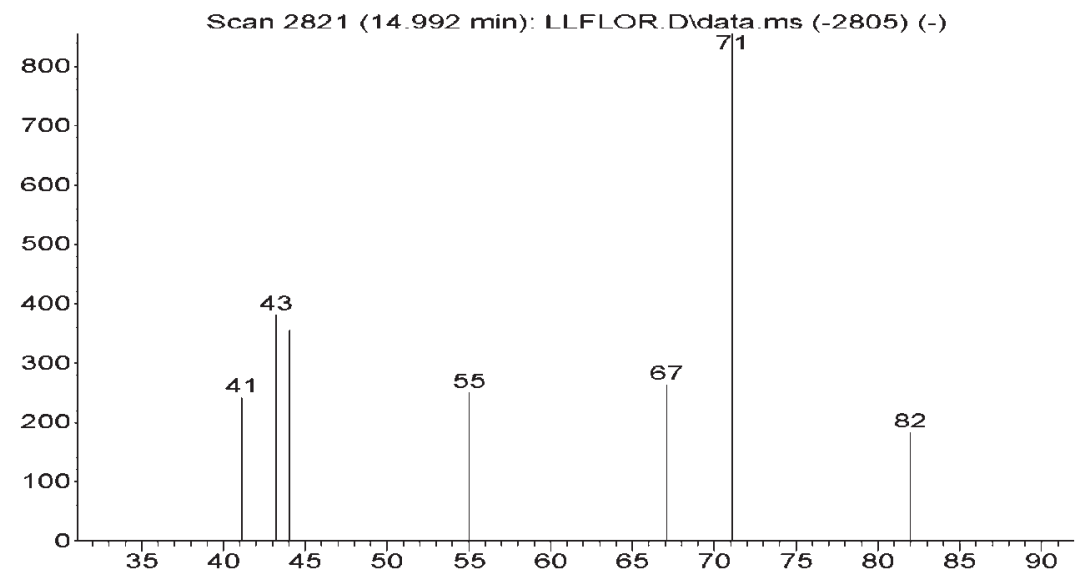

$m / z-->$

Figure S42. Mass spectra of not identified compound (IR=1197) in Lippia lacunosa and Lippia rotundifolia essential oils.

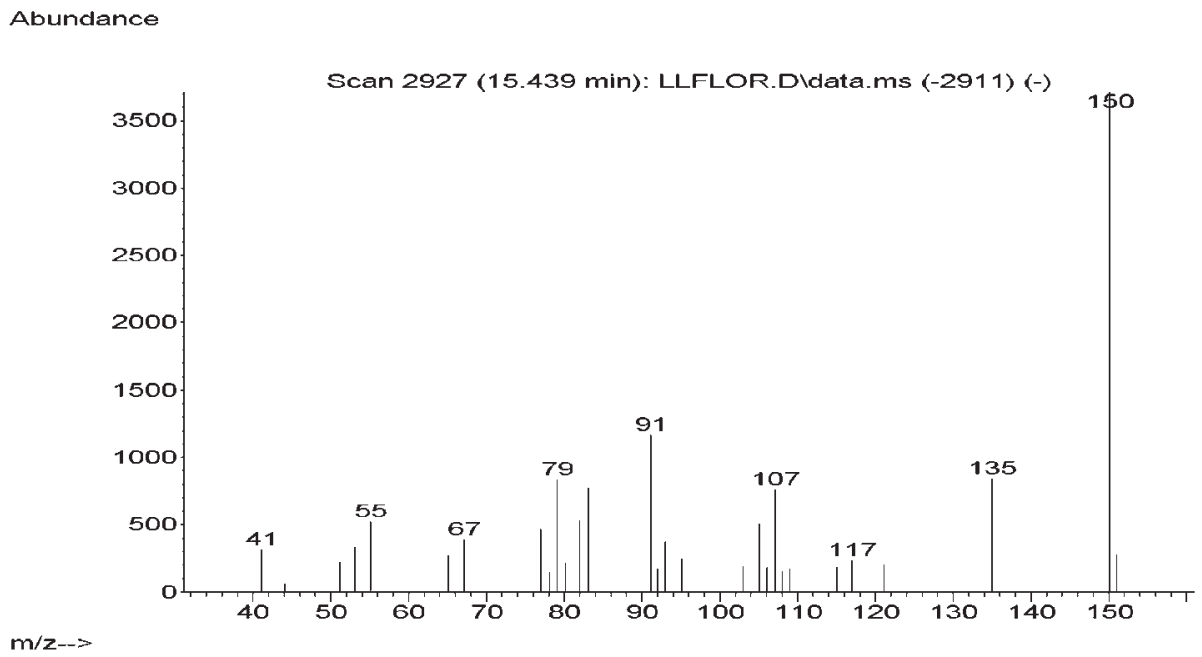

Figure S43. Mass spectra of not identified compound (IR=1208) in Lippia lacunosa and Lippia rotundifolia essential oils. 
Abundance

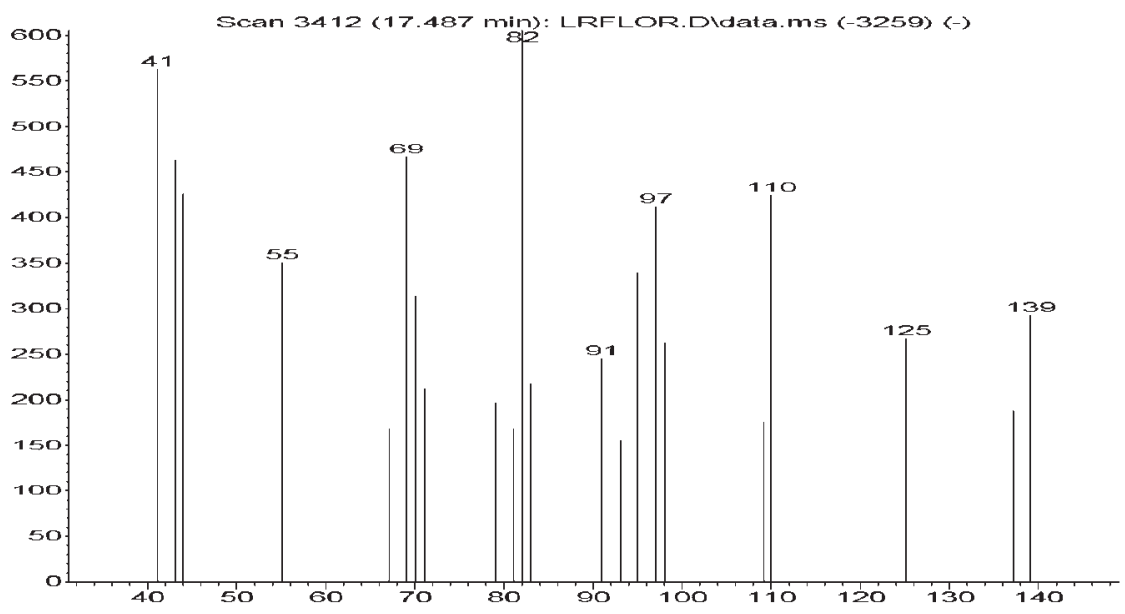

$m / z_{--}>$

Figure S44. Mass spectra of not identified compound (IR=1256) in Lippia lacunosa and Lippia rotundifolia essential oils.

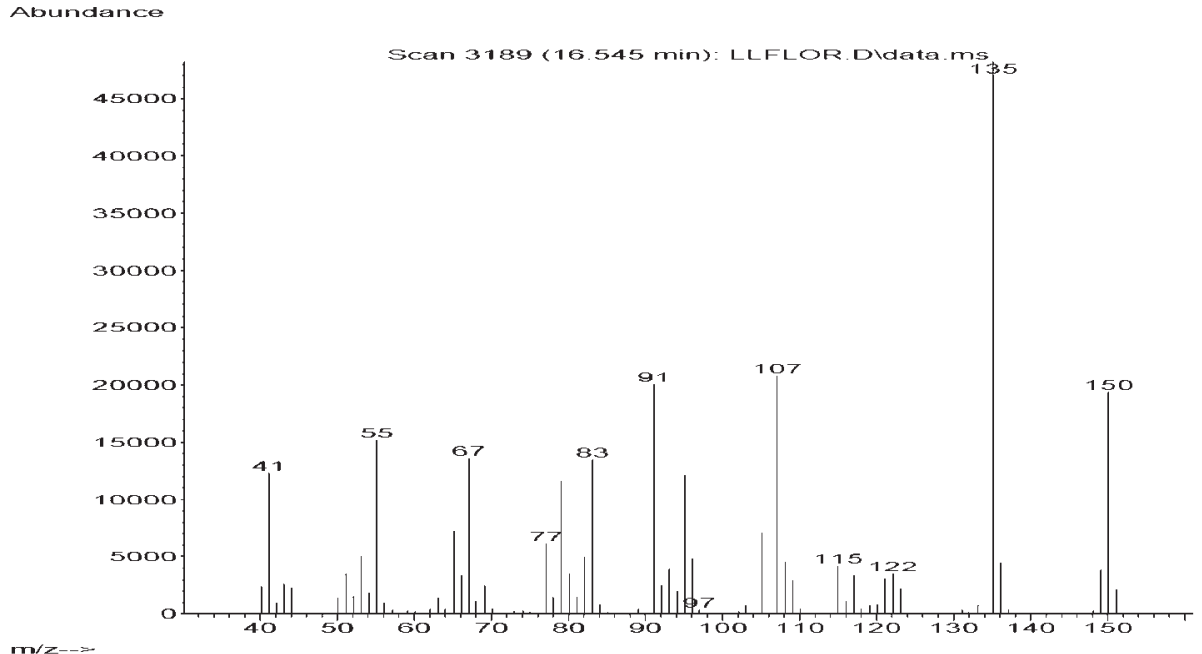

Figure S45. Mass spectra of (z)-ocimenone in Lippia lacunosa and Lippia rotundifolia essential oils.

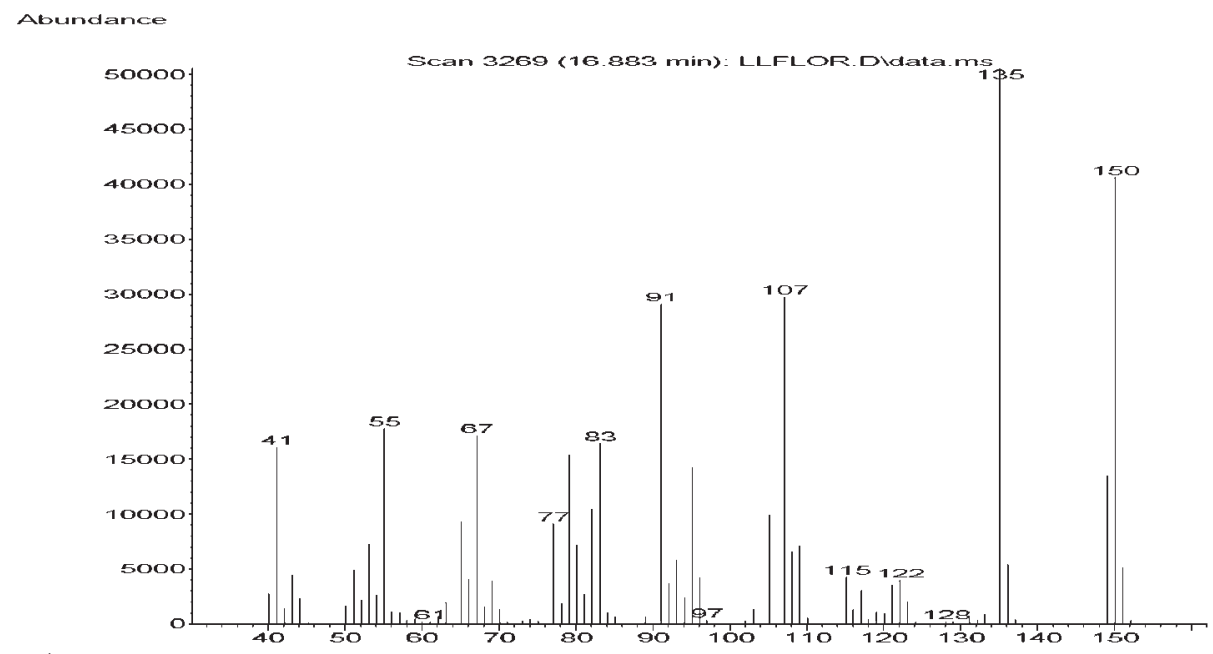

Figure S46. Mass spectra of (E)-ocimenone in Lippia lacunosa and Lippia rotundifolia essential oils. 


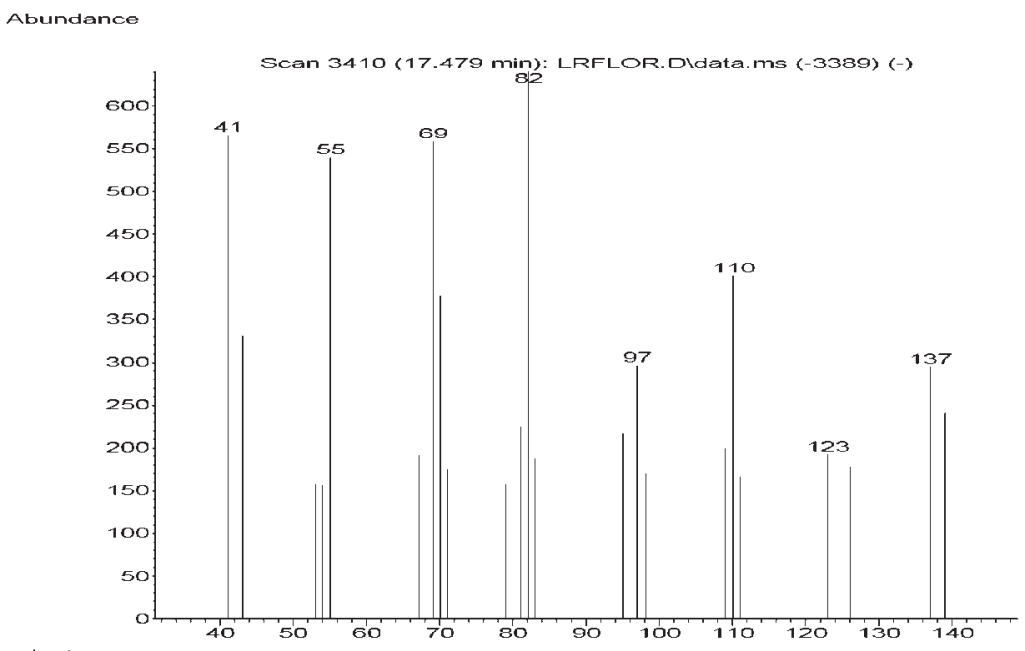

Figure S47. Mass spectra of not identified compound (IR=1256) in Lippia lacunosa and Lippia rotundifolia essential oils.

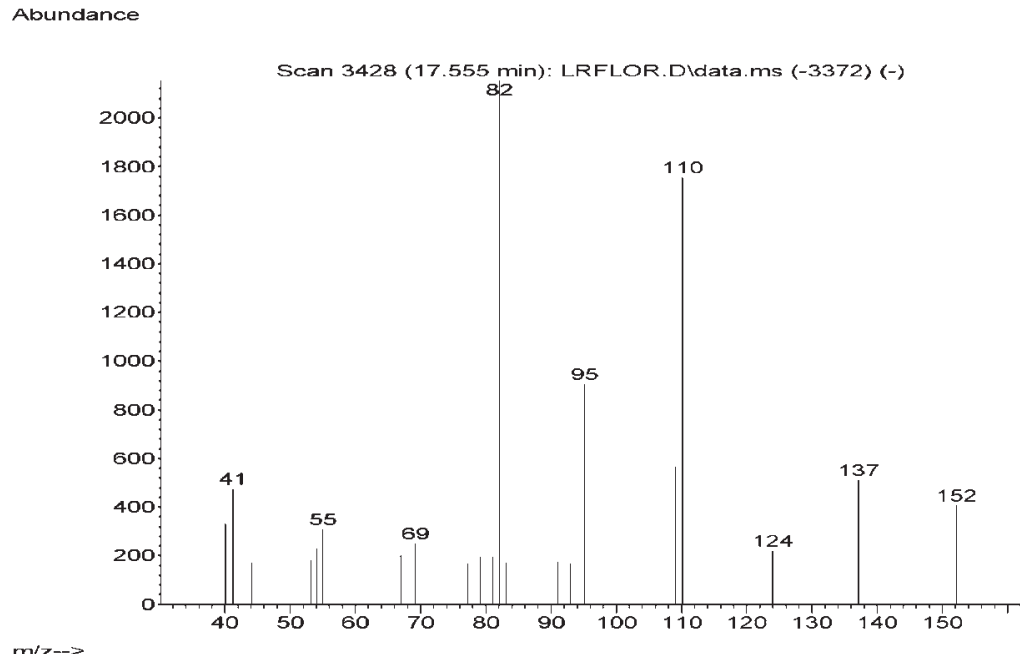

Figure S48. Mass spectra of piperitone in Lippia lacunosa and Lippia rotundifolia essential oils.

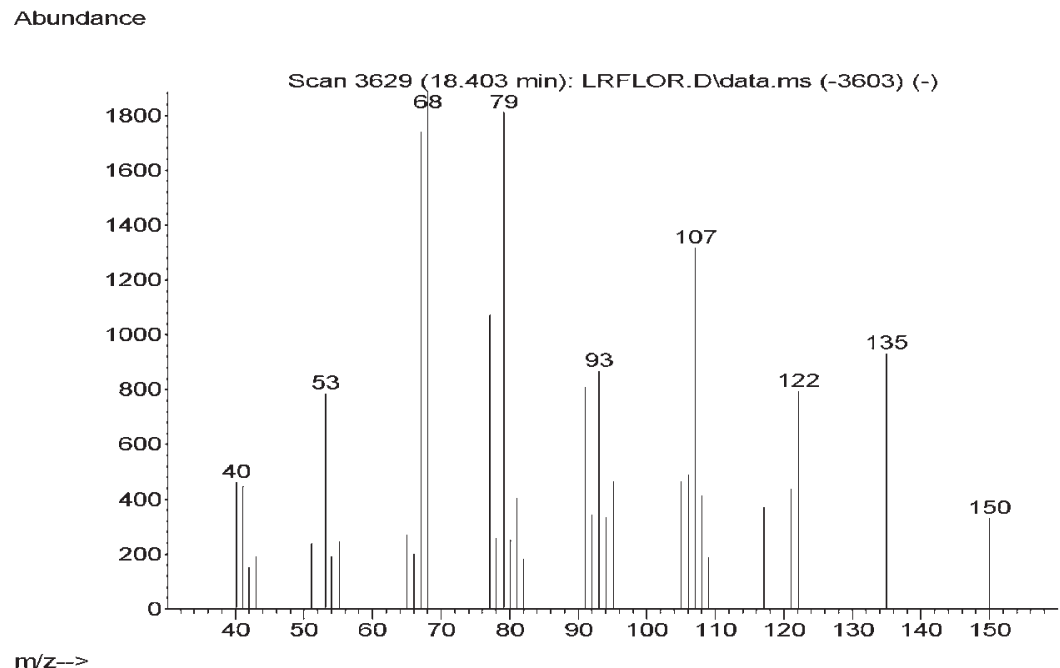

Figure S49. Mass spectra of perilla aldehyde in Lippia lacunosa and Lippia rotundifolia essential oils. 


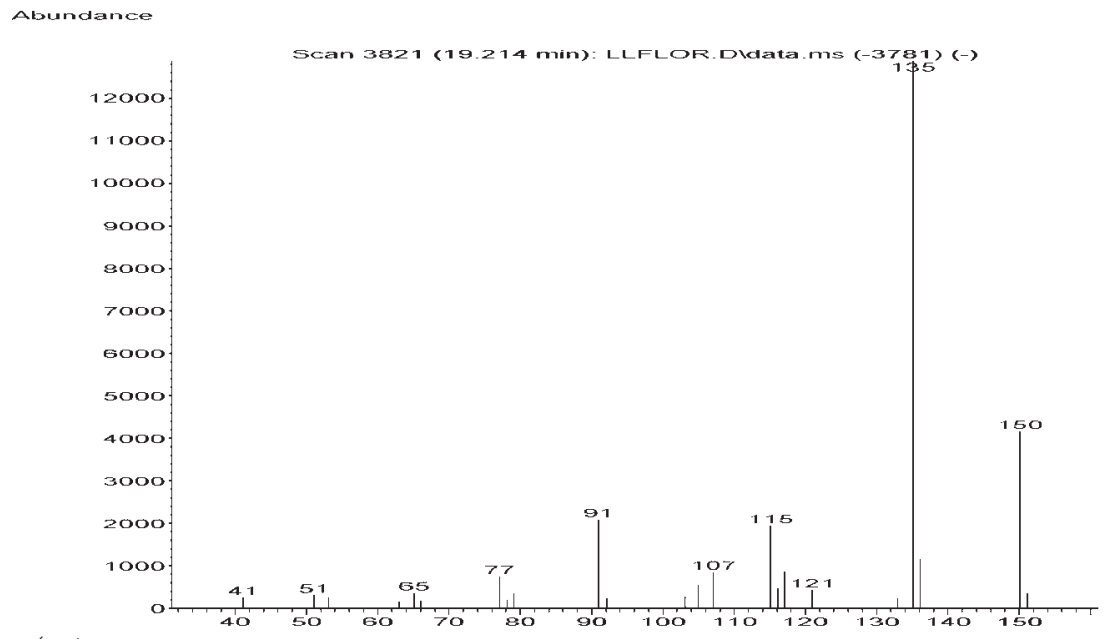

Figure S50. Mass spectra of thymol in Lippia lacunosa and Lippia rotundifolia essential oils.

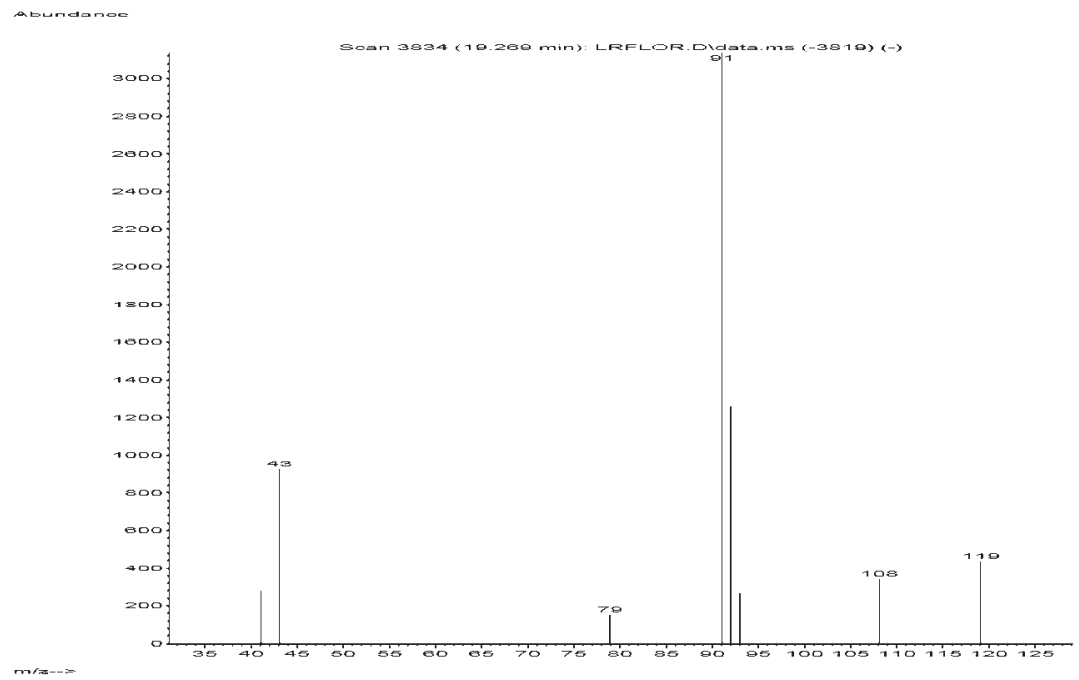

Figure S51. Mass spectra of trans-sabinyl acetate in Lippia lacunosa and Lippia rotundifolia essential oils.

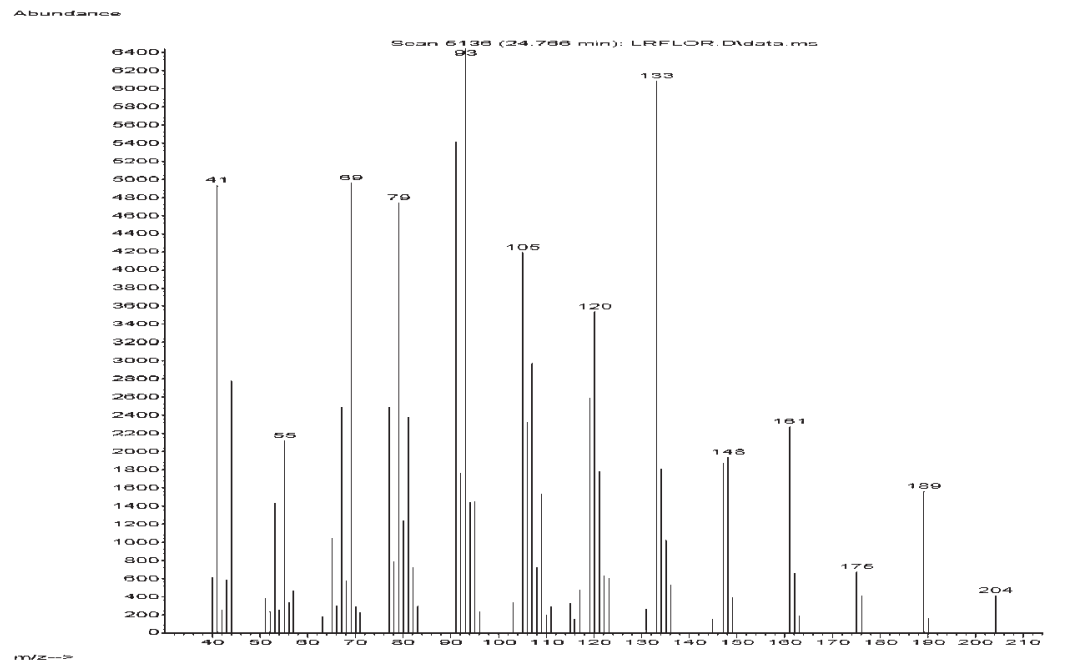

Figure S52. Mass spectra of myrtenyl acetate in Lippia lacunosa and Lippia rotundifolia essential oils. 
Abundance

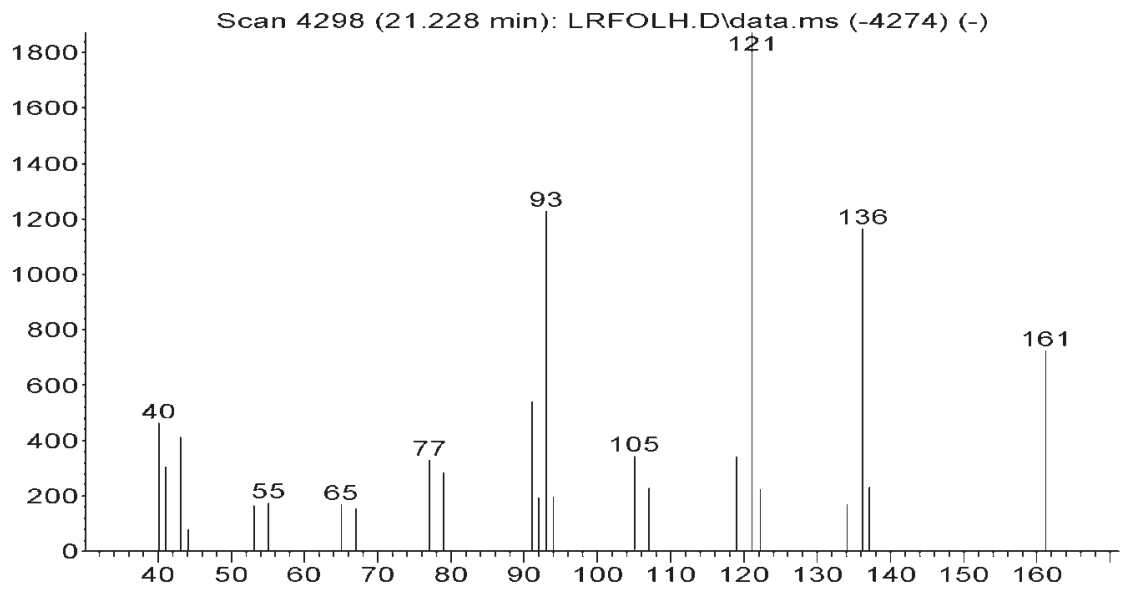

$m / z-->$

Figure S53. Mass spectra of delta-elemene in Lippia lacunosa and Lippia rotundifolia essential oils.

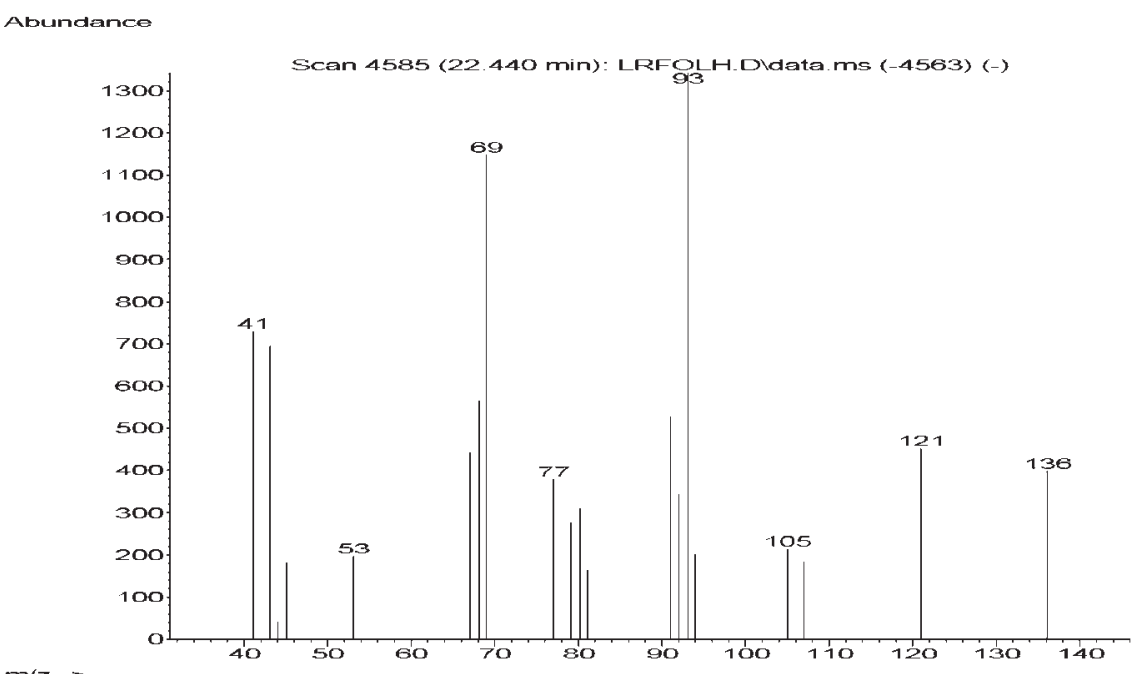

Figure S54. Mass spectra of neryl acetate in Lippia lacunosa and Lippia rotundifolia essential oils.

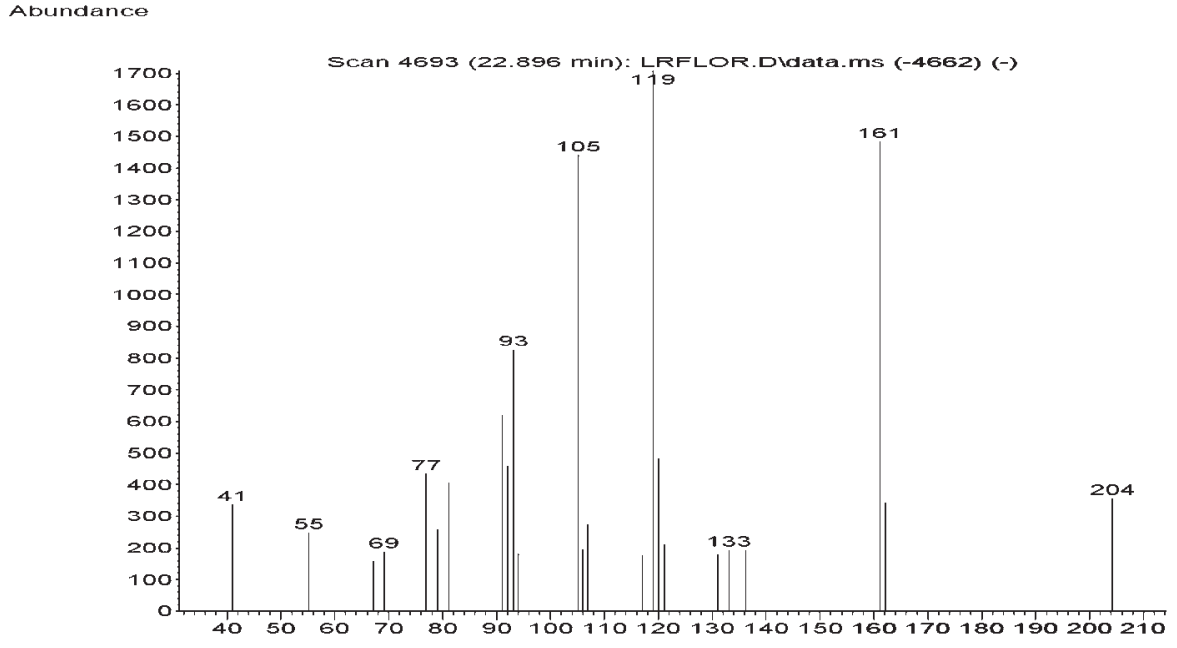

$m / z-->$

Figure S55. Mass spectra of alpha-copaene in Lippia lacunosa and Lippia rotundifolia essential oils. 


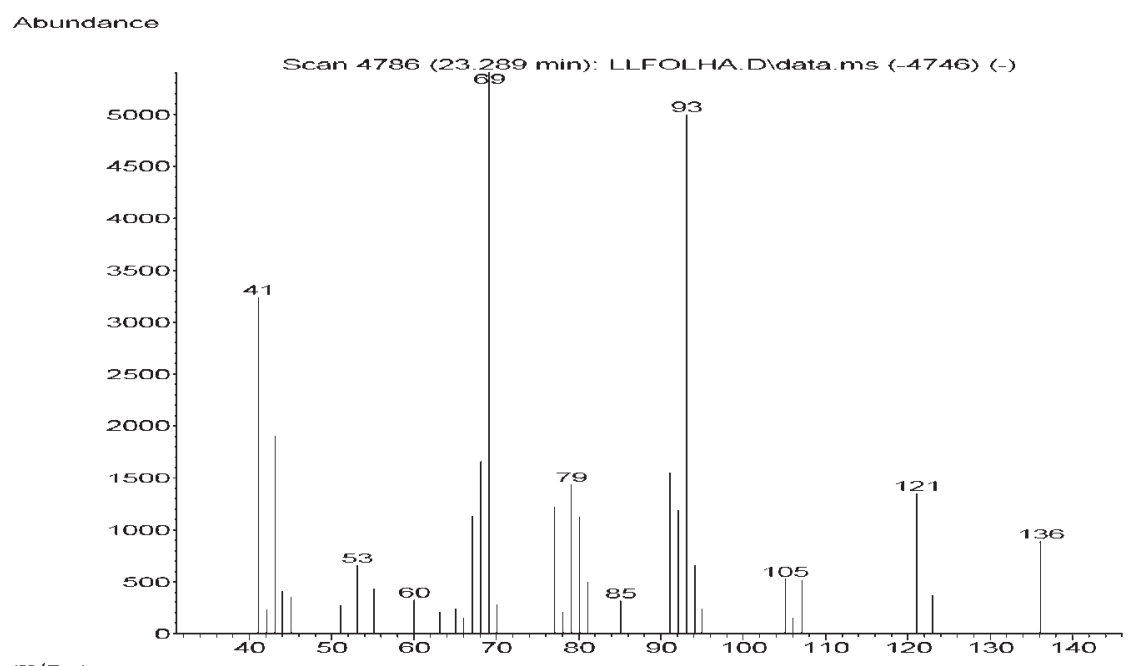

Figure S56. Mass spectra of geranyl acetate in Lippia lacunosa and Lippia rotundifolia essential oils.

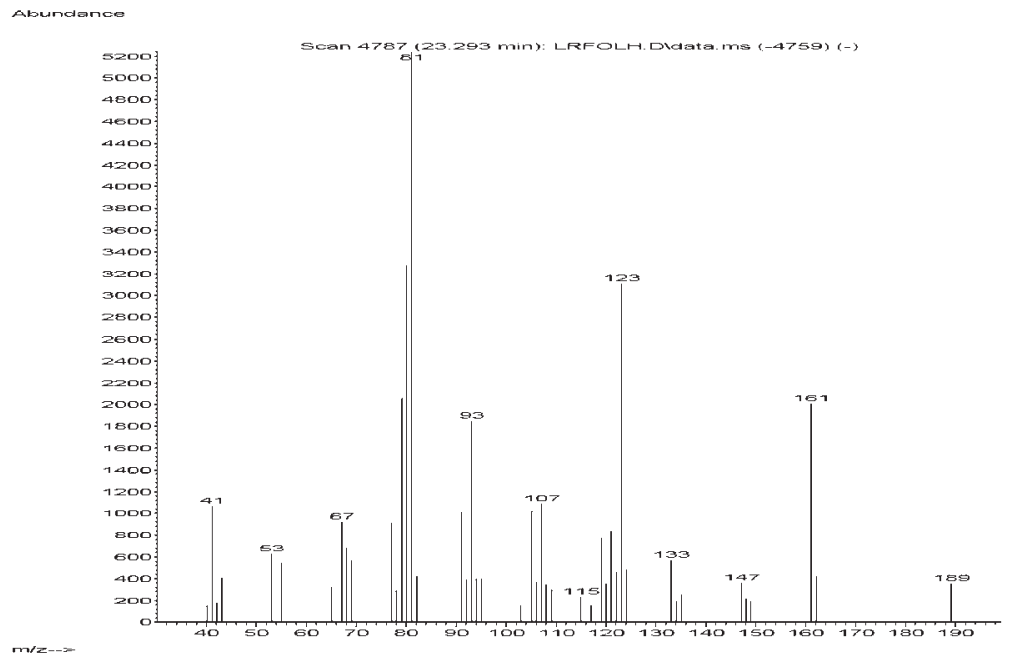

Figure S57. Mass spectra of beta-bourbonene in Lippia lacunosa and Lippia rotundifolia essential oils.

\section{Abundance}

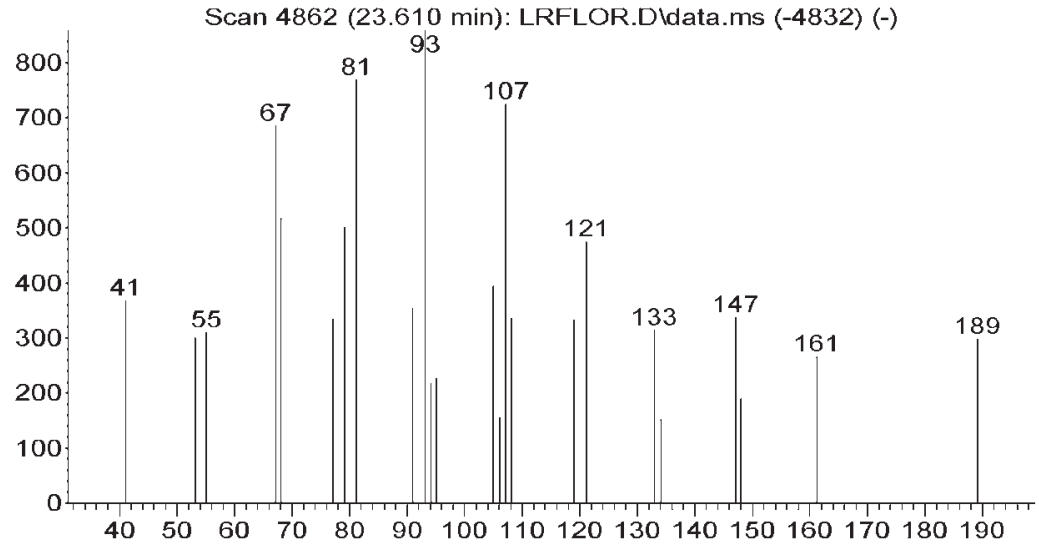

$\mathrm{m} / \mathrm{z}-\mathrm{-}>$

Figure S58. Mass spectra of beta-elemene in Lippia lacunosa and Lippia rotundifolia essential oils. 


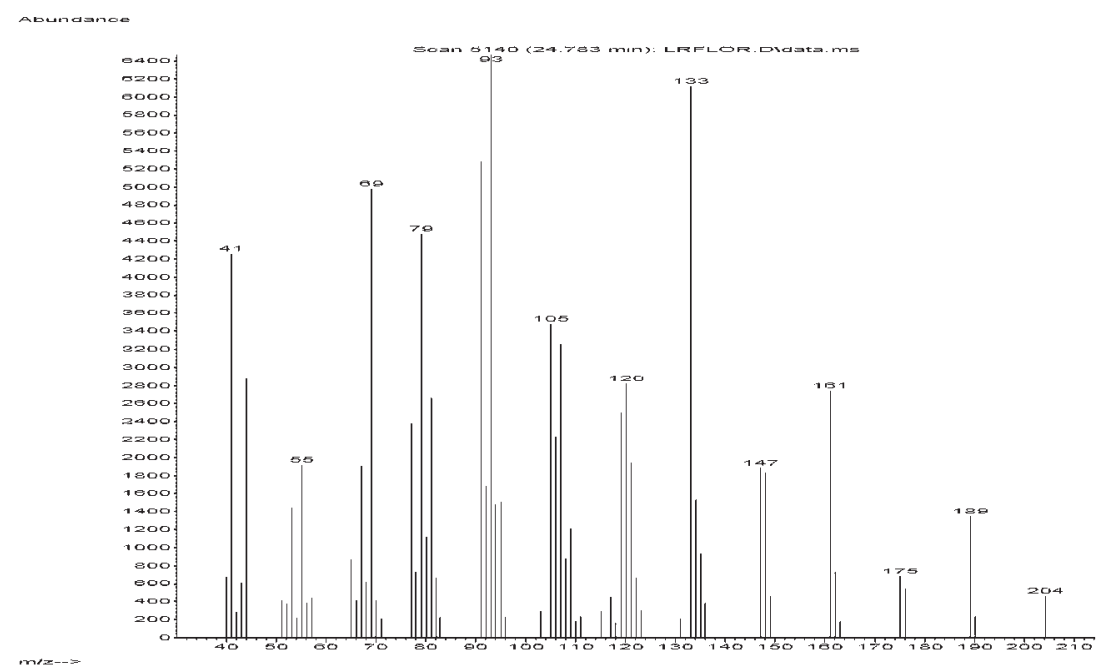

Figure S59. Mass spectra of trans-caryophyllene in Lippia lacunosa and Lippia rotundifolia essential oils.

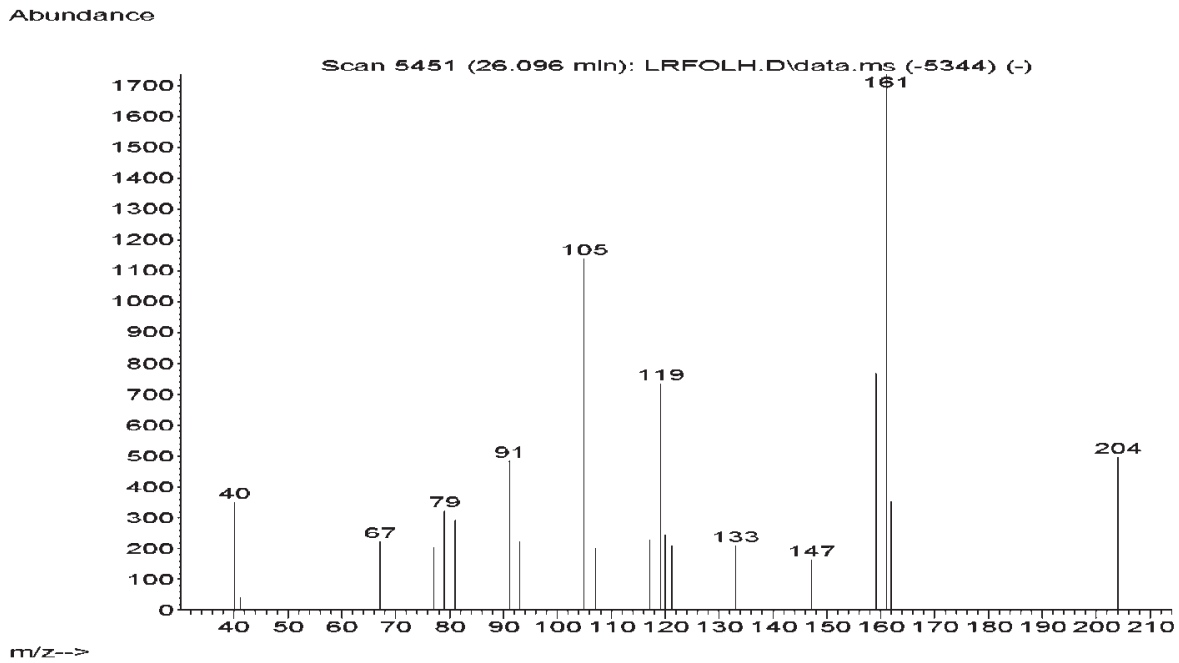

Figure S60. Mass spectra of muurola-3,5-diene in Lippia lacunosa and Lippia rotundifolia essential oils.

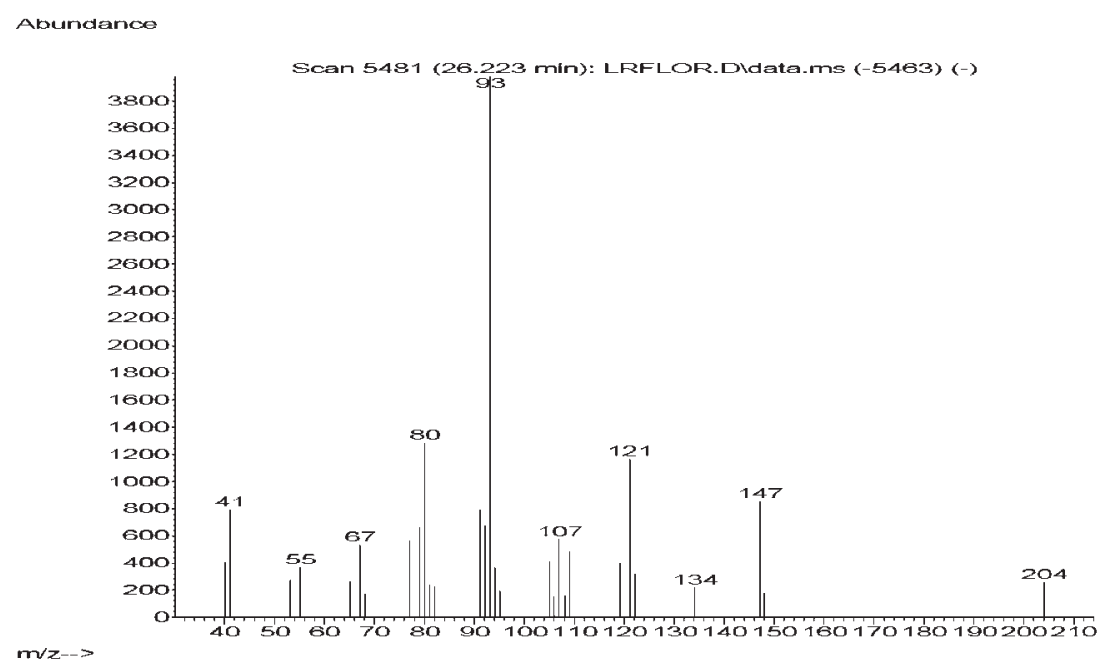

Figure S61. Mass spectra of alpha-humulene in Lippia lacunosa and Lippia rotundifolia essential oils. 


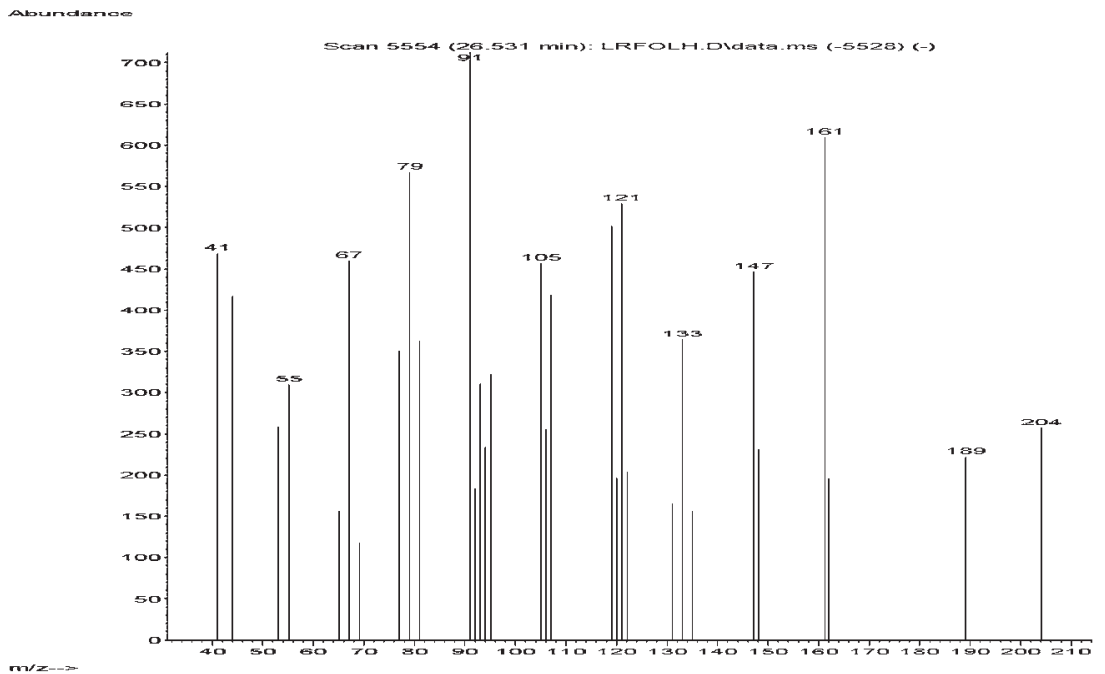

Figure S62. Mass spectra of allo-aromadendrene in Lippia lacunosa and Lippia rotundifolia essential oils.

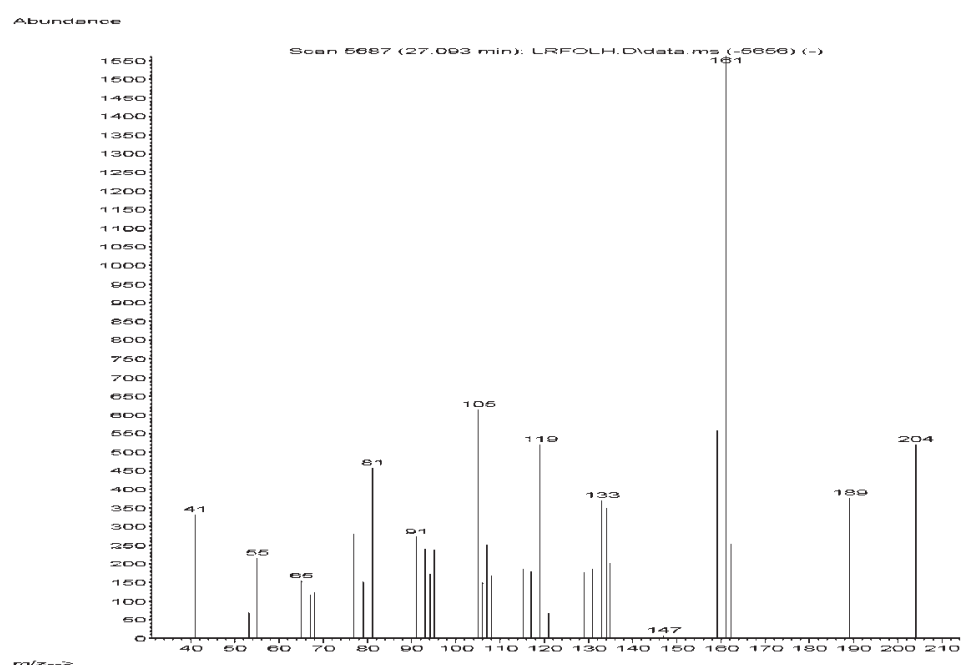

Figure S63. Mass spectra of cadina-1(6),4-diene in Lippia lacunosa and Lippia rotundifolia essential oils.

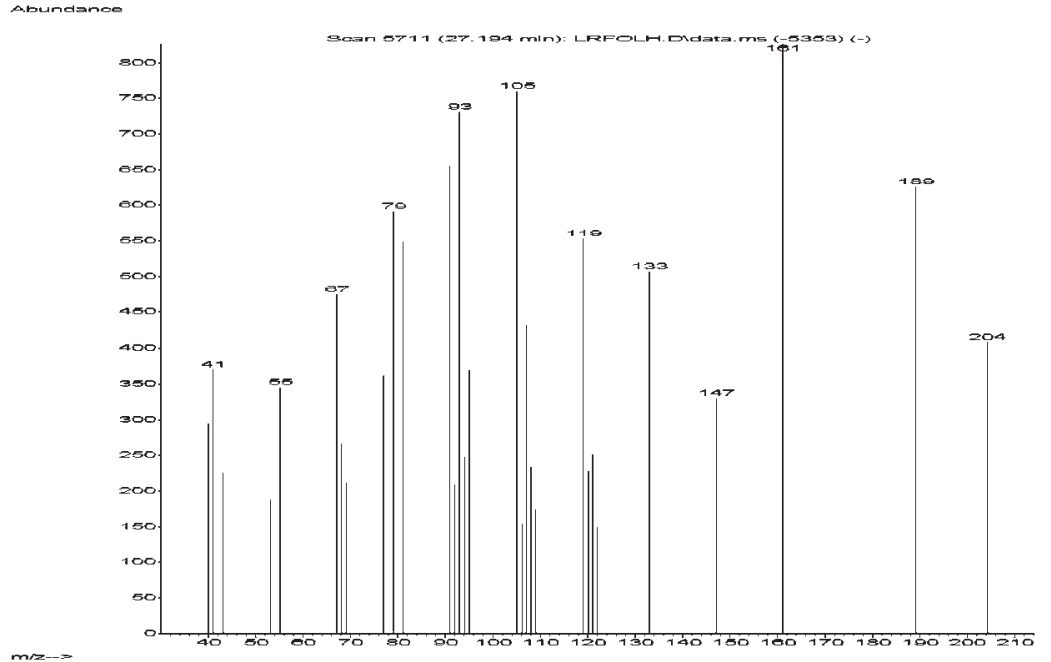

Figure S64. Mass spectra of gamma-gurjunene in Lippia lacunosa and Lippia rotundifolia essential oils. 


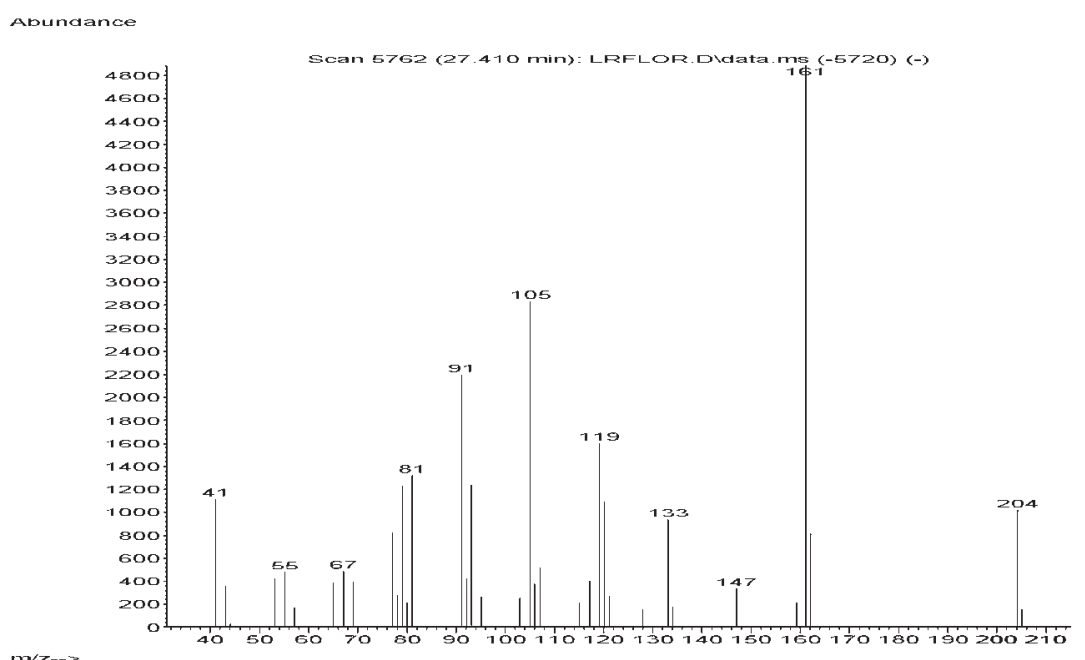

Figure S65. Mass spectra of gamma-muurolene in Lippia lacunosa and Lippia rotundifolia essential oils.

\section{ARYL-CURCUMENE}

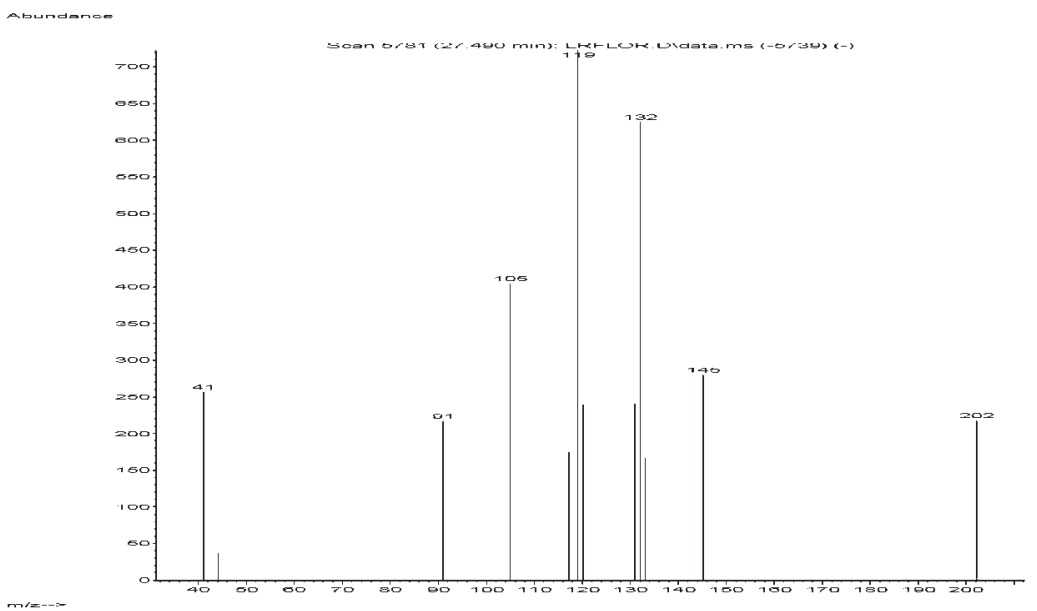

Figure S66. Mass spectra of neryl acetate in Lippia lacunosa and Lippia rotundifolia essential oils.

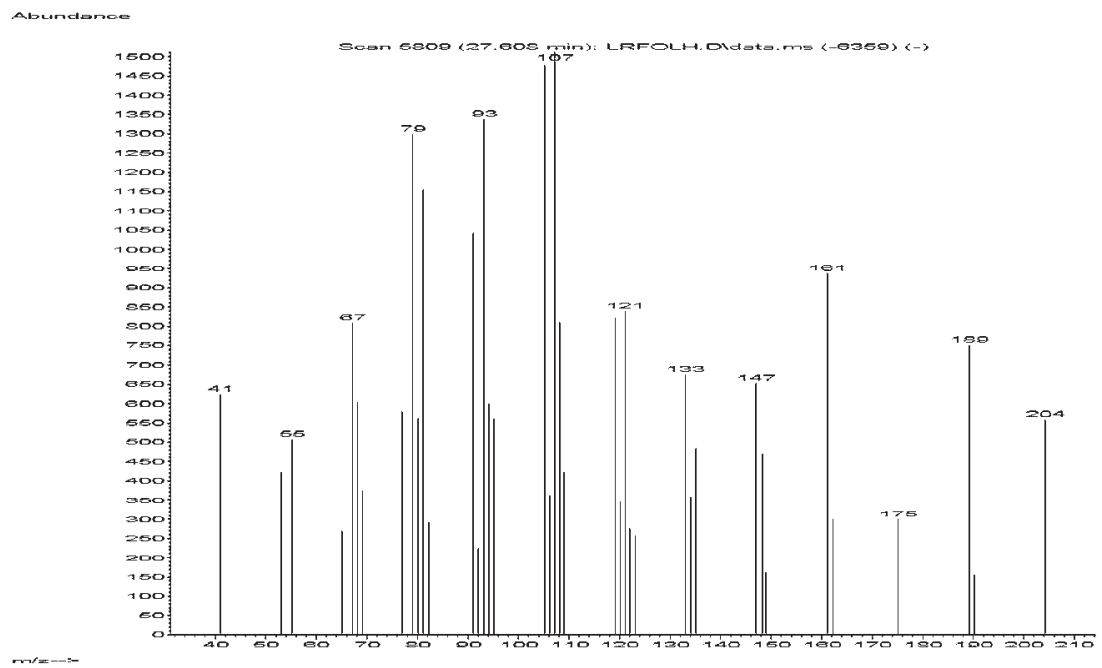

Figure S67. Mass spectra of beta-selinene in Lippia lacunosa and Lippia rotundifolia essential oils. 


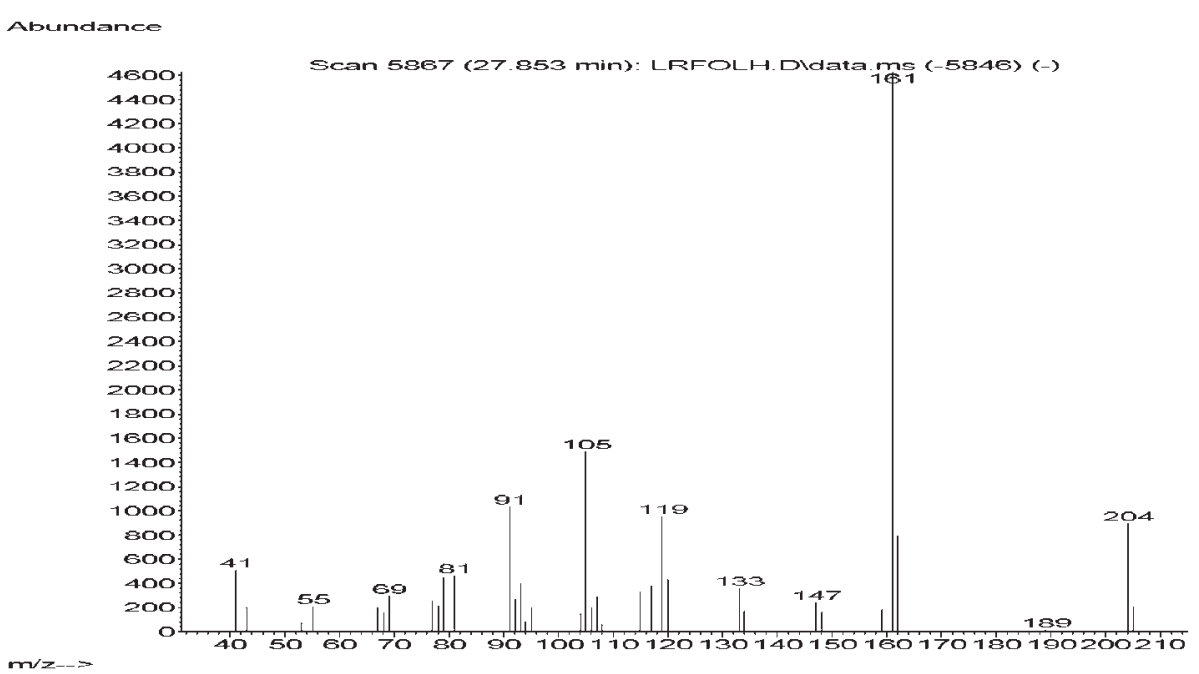

Figure S68. Mass spectra of muurola-4(14),5-diene in Lippia lacunosa and Lippia rotundifolia essential oils.

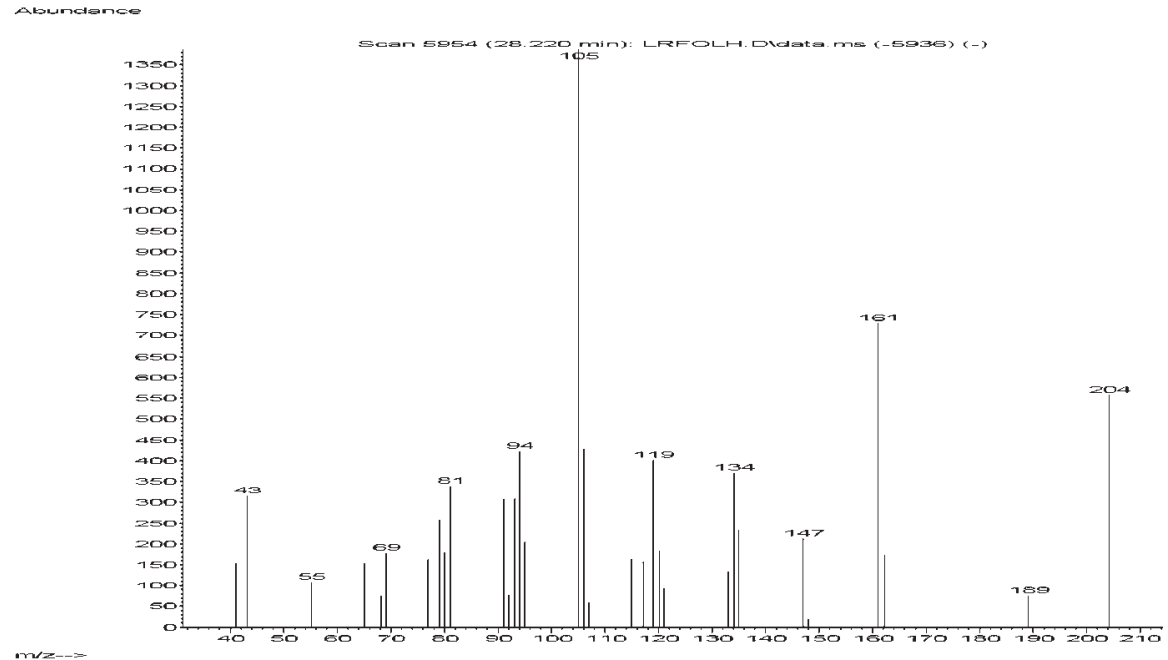

Figure S69. Mass spectra of alpha-muurolene in Lippia lacunosa and Lippia rotundifolia essential oils.

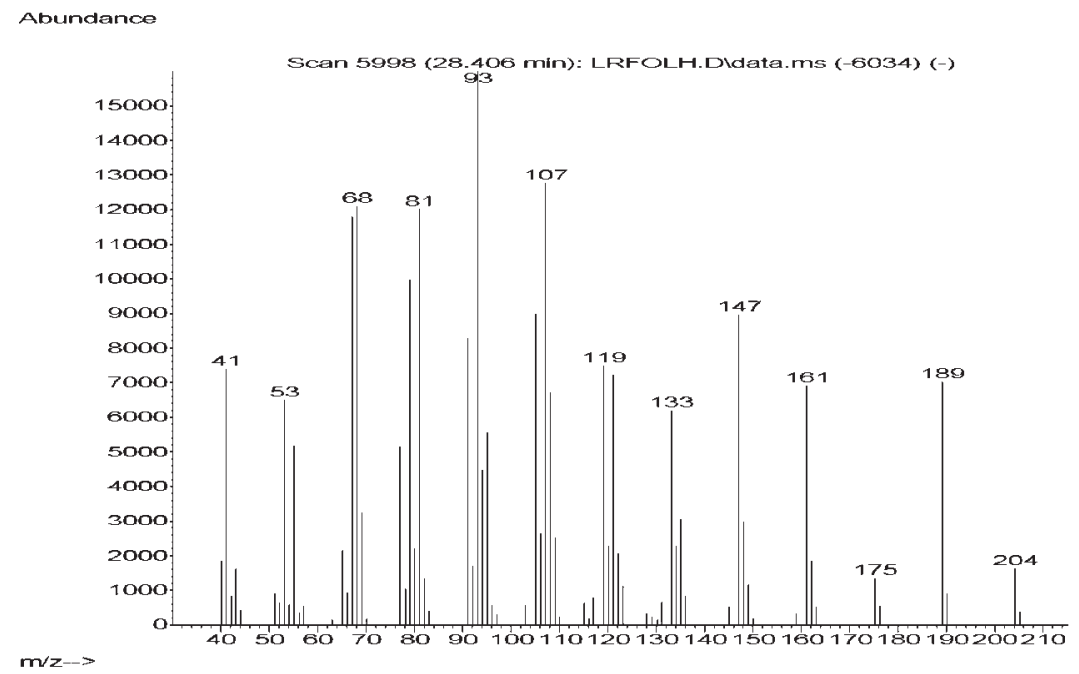

Figure S70. Mass spectra of germacrene A in Lippia lacunosa and Lippia rotundifolia essential oils. 


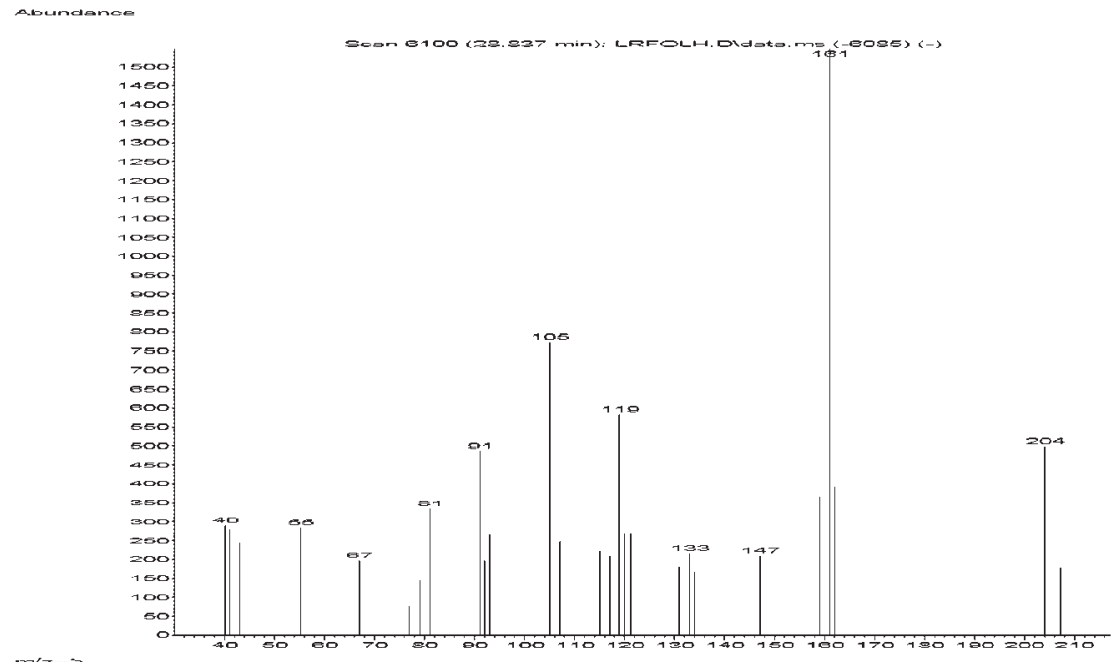

Figure S71. Mass spectra of gamma-cadinene in Lippia lacunosa and Lippia rotundifolia essential oils.

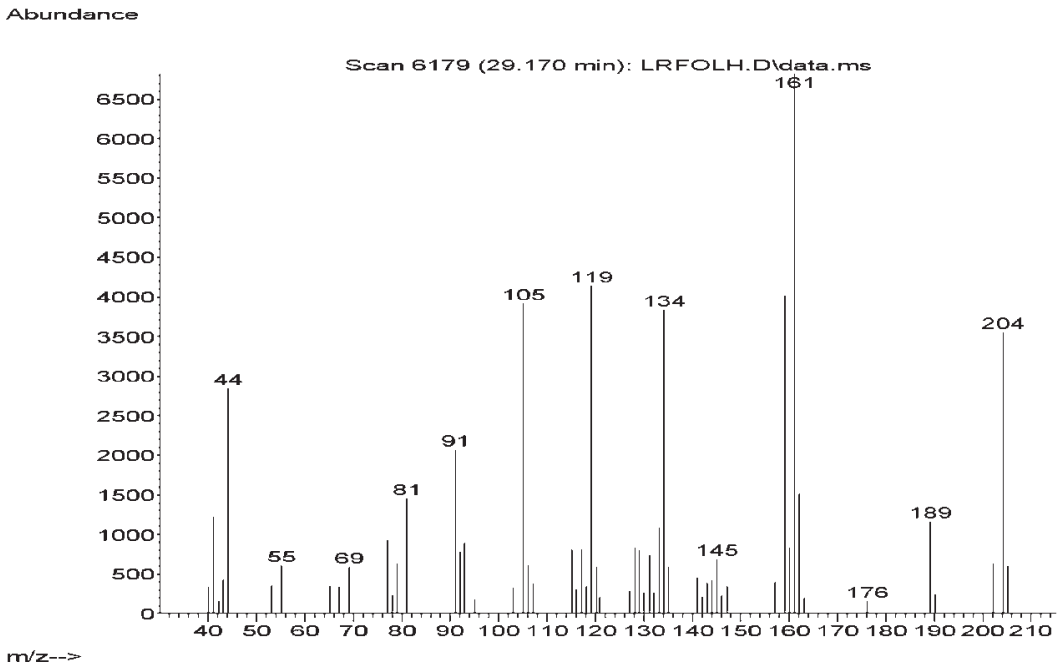

Figure S72. Mass spectra of delta-cadinene in Lippia lacunosa and Lippia rotundifolia essential oils.

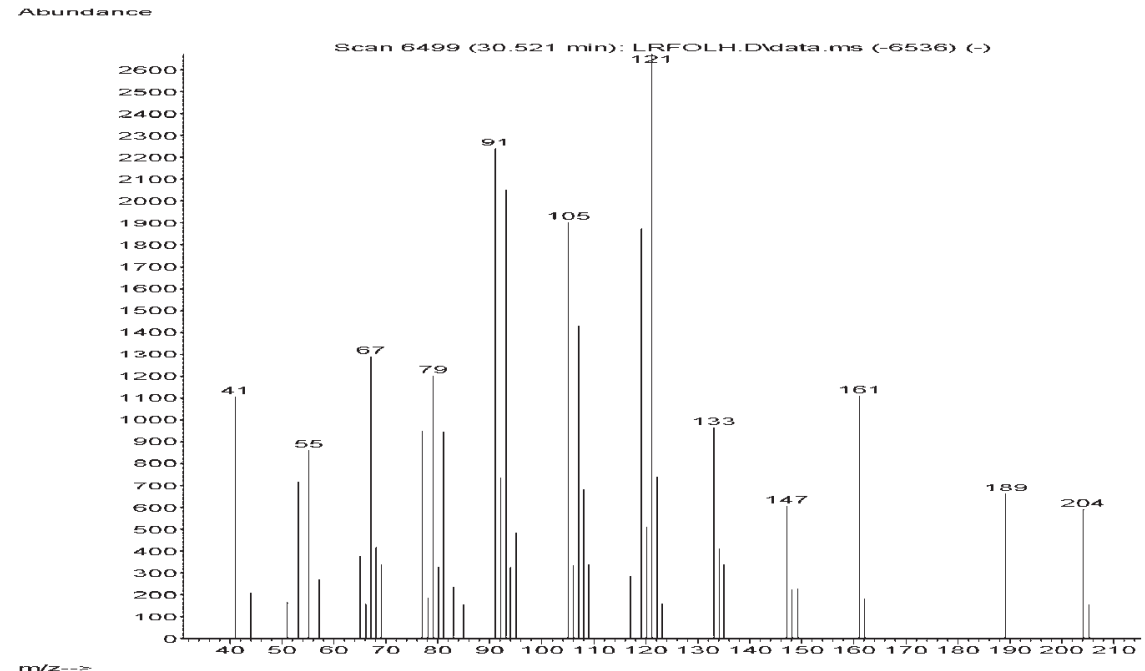

Figure S73. Mass spectra of germacrene B in Lippia lacunosa and Lippia rotundifolia essential oils. 


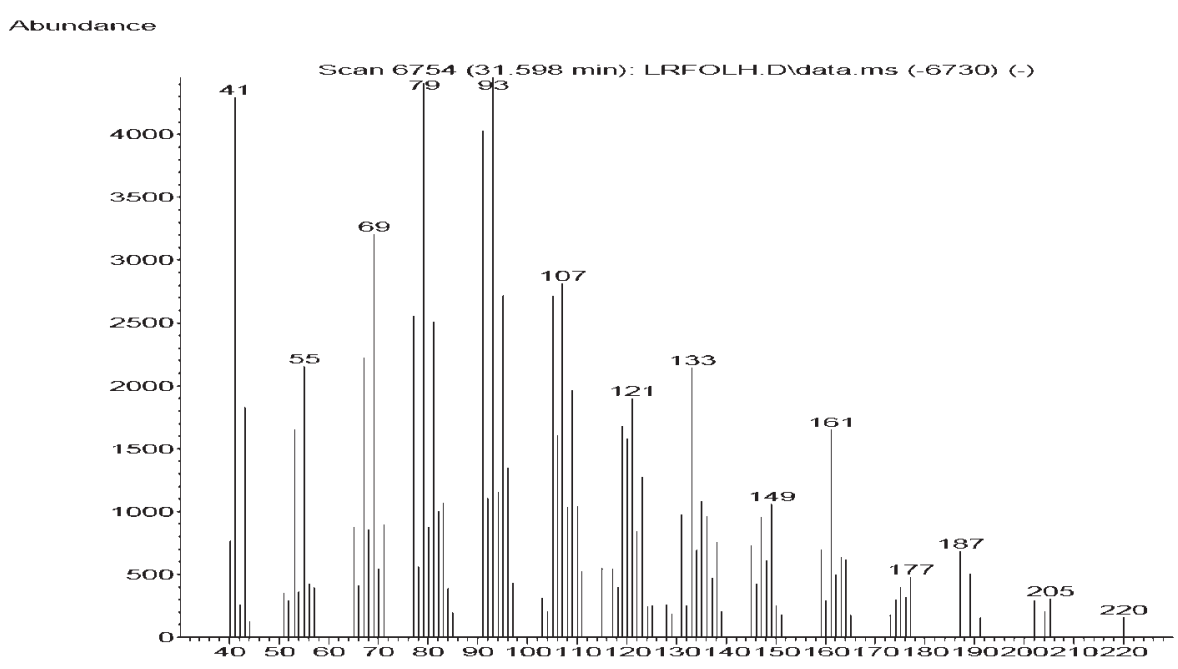

Figure S74. Mass spectra of caryophyllene oxide in Lippia lacunosa and Lippia rotundifolia essential oils.

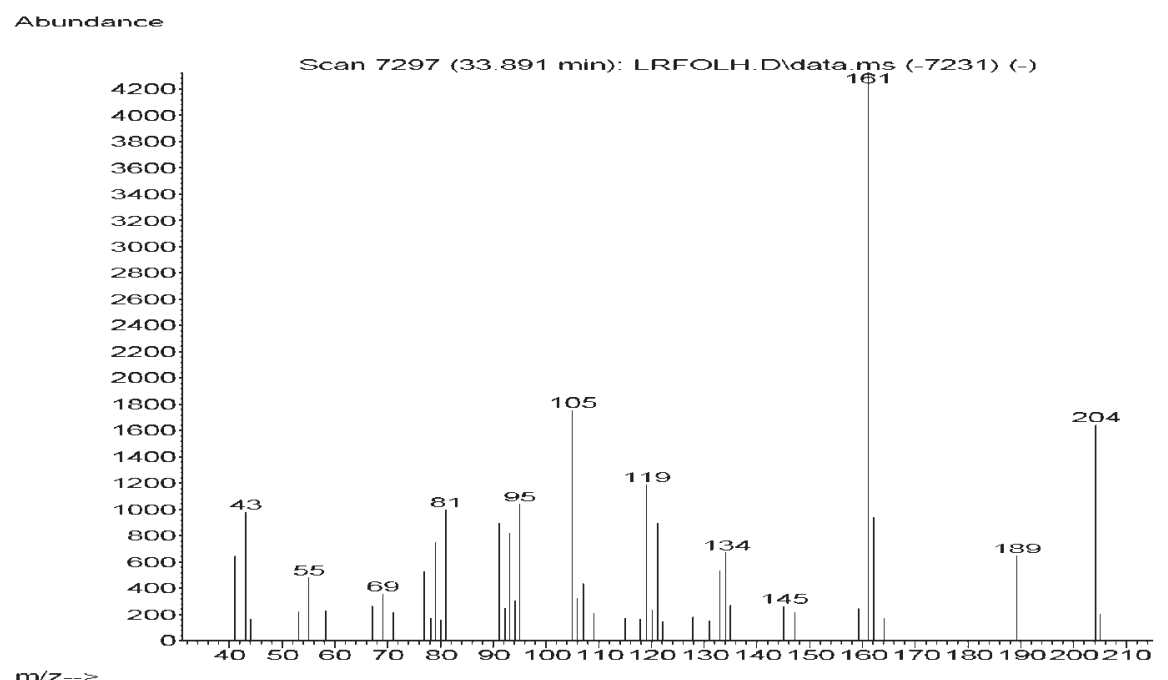

Figure S75. Mass spectra of epi-alpha-cadinol or epi-alpha-muurolol in Lippia lacunosa and Lippia rotundifolia essential oils.

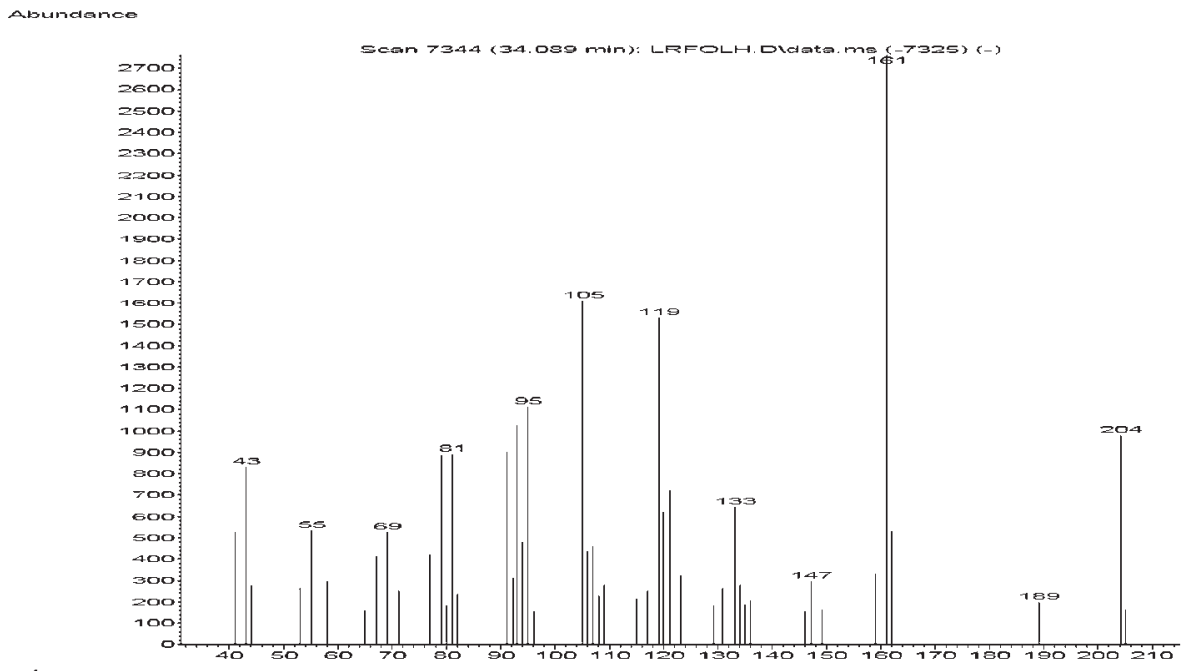

Figure S76. Mass spectra of alpha-muurolol in Lippia lacunosa and Lippia rotundifolia essential oils. 

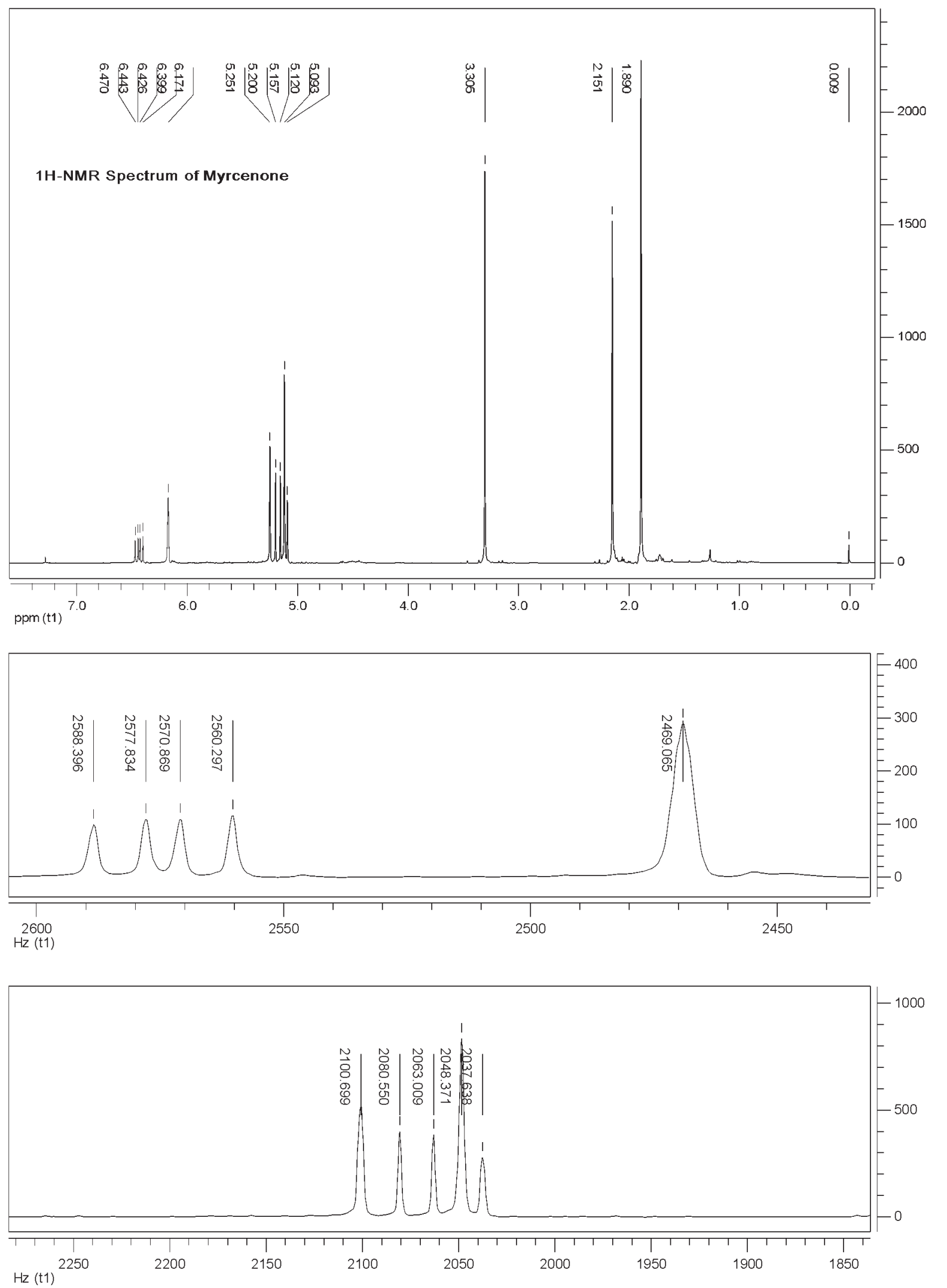

1 H-NMR Spectrum of Myrcenone

Figure S77. ${ }^{1} \mathrm{H}-\mathrm{NMR}$ spectrum of Myrcenone. 


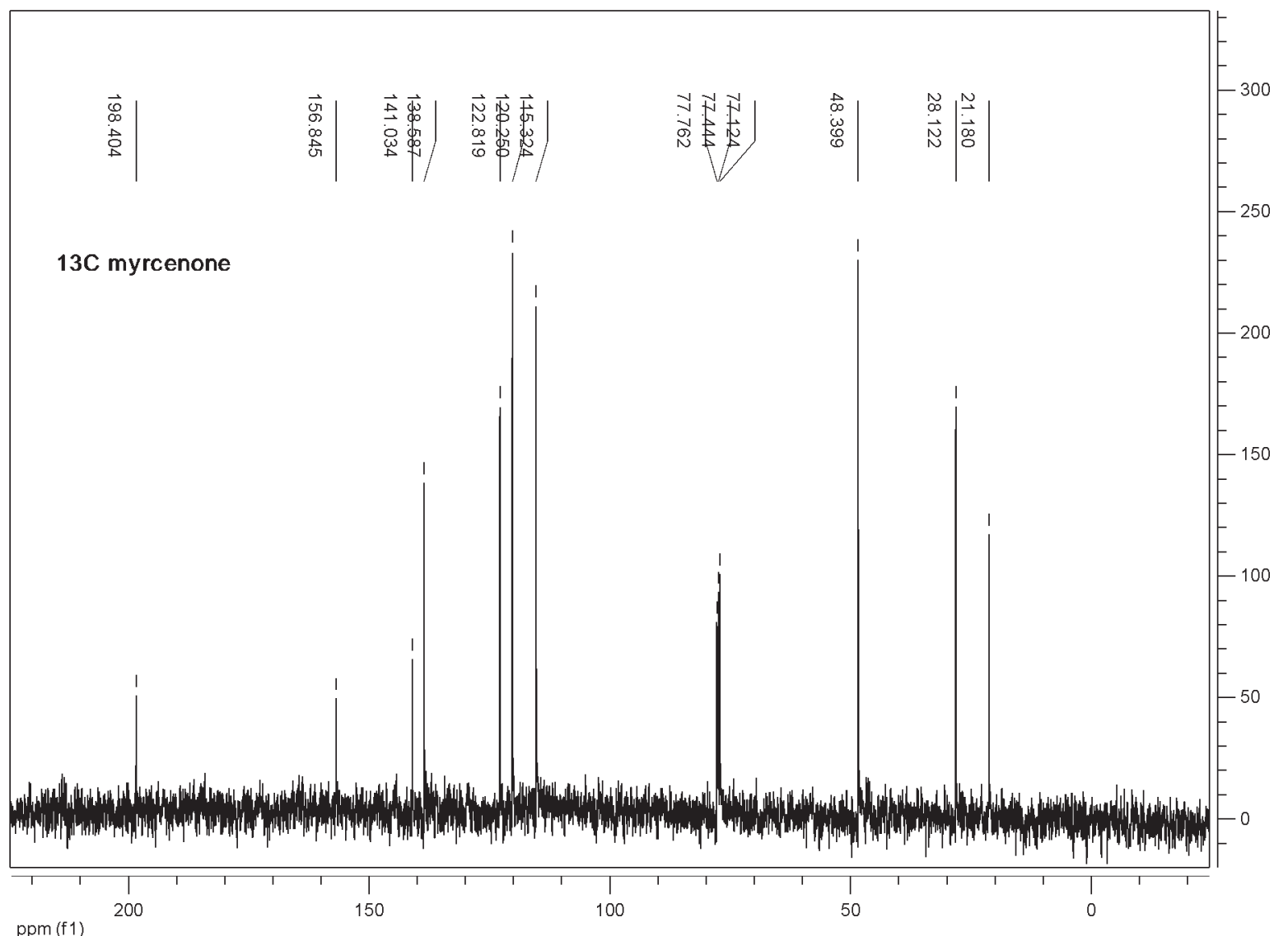

Figure S78. ${ }^{13} \mathrm{C}$-NMR spectrum of myrcenone. 